\title{
URBAN ENVIRONMENTAL MANAGEMENT APPROACHES BY TOURISM ORGANISATIONS \\ IN WELLINGTON, NEW ZEALAND
}

by

\section{Raymond John Mullan}

\author{
A thesis \\ submitted to the Victoria University of Wellington \\ in fulfilment of the requirements for the degree of \\ Master of Tourism Management
}

Victoria University of Wellington 2009 


\section{ABSTRACT}

Tourism in New Zealand depends heavily on the quality of the environment yet at the same time holds the potential of destroying the very environment on which it relies upon if not managed properly. Therefore, concerted actions must be taken to ensure New Zealand's ' $100 \%$ Pure' image is maintained. According to the New Zealand Tourism Strategy 2015, the tourism sector's ability to take a leading role in protecting and enhancing the environment is a key priority.

While most tourism studies on environmental management tend to focus on rural or protected areas there is a need to investigate environmental management within urban settings. This research takes a qualitative approach based on semi-structured interviews to investigate and examine the nature of environmental management approaches taken by tourism organisations in the urban setting of Wellington. It also aims to identify the factors influencing the adoption of environmentally-friendly practices, barriers which may hinder the adoption of such practices, and the role of public and private sector agencies in environmental management for tourism businesses.

The research found that tourism organisations in Wellington mainly took an informal approach towards environmental management. However, a qualitative method of enquiry revealed that tourism businesses were slowly moving towards change. This was evident from the number of businesses that indicated they were adopting environmental practices related to supply chain management, employee awareness and training, and interpretation. The main factors influencing adoption have also provided reasons for this change. Though, the barriers and difficulties faced by tourism businesses continue to affect the pace of change.

As with businesses, public and private sector organisations have an important role to play in urban environmental management. The responses of interviewees indicate that these 'bigger' organisations such as the RTO need to take on a much more proactive role. The need for greater cooperation and communication between key stakeholders of tourism is essential to the success of urban environmental sustainability. 


\section{ACKNOWLEDGEMENTS}

I would like to formally acknowledge the assistance of a number of people who have played an influential part in ensuring the completion of this study. Firstly, thank you very much to the Tourism Department at Victoria University of Wellington who have provided constant encouragement and advice throughout this academic challenge; in particular, Dr. Bob Garnham who solely supervised this Masters thesis. Bob - I am very grateful for your enthusiasm, continuous support and constructive feedback in the development of this research project. Without it, this thesis would not have been possible. Your sense of humour, patience and sympathy during the difficult times was much appreciated. I would also like to extend my sincerest thanks to the rest of the Victoria Management School staff and administration for their additional support.

As a Ministry of Tourism Research Scholarship recipient I must sincerely thank the Ministry for financially supporting this research and providing me with this amazing opportunity. Also, from within the industry I would like to thank Michael Grace and Esme Gibbins at Positively Wellington Tourism for taking an interest in my research and acknowledging the relevance of my study at the industry level. Your knowledge and time have been invaluable. To all of the respondents who offered their time and participation - it has been very much appreciated.

To my fellow Masters students: Diana, Vi, Rudy and Michael it has been an absolute pleasure being able to share this experience alongside you all. I am very thankful for your sincere friendship, humour, and continuous support over the last few years especially during the hard times. This has been an amazing achievement for us all.

Additional thanks must go to Maria for her transcription service and Lyn for teaching NVivo. Your support, knowledge, and assistance have been greatly noted.

Lastly, but certainly not the least - thank you to my family, friends and to all those who have offered constant kindness, support and been there throughout it all. Mum and Dad, thank you for always supporting me in everything that I do. I am very fortunate to be able to share this challenging yet rewarding experience with all of you. 


\section{TABLE OF CONTENTS}

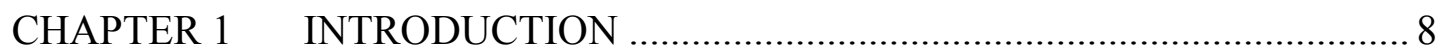

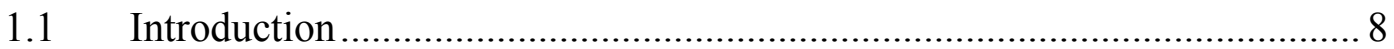

1.2 The Importance of Environmental Sustainability ................................... 9

1.3 Tourism and Environmental Sustainability......................................... 10

1.4 Sustainable Tourism Development and the Global-Local Nexus .............. 12

1.4.1 The Global Significance of Environmental Sustainability................ 14

1.4.2 The National Significance of Environmental Sustainability............. 20

1.4.3 The Regional and Local Significance of Environmental

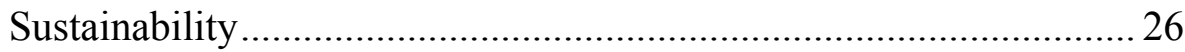

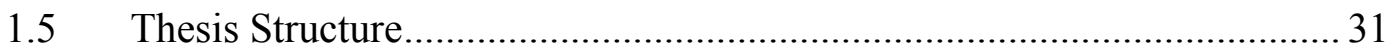

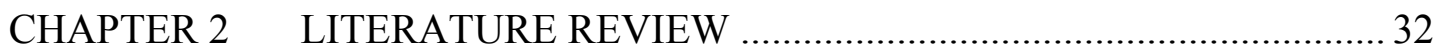

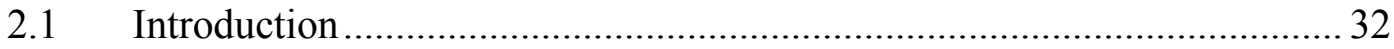

2.2 Sustainable Development: Tourism and the Environment ....................... 33

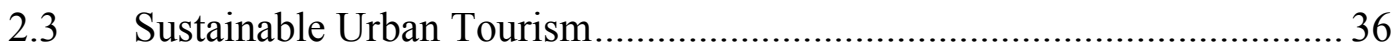

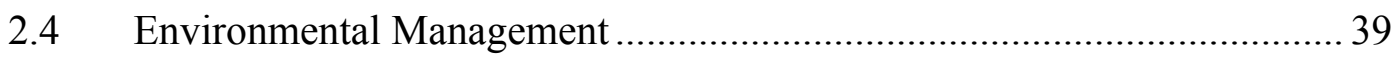

2.4.1 Environmental Management: Definition and Concept ..................... 40

2.4.2 Environmental Management Systems........................................... 41

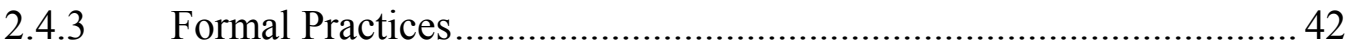

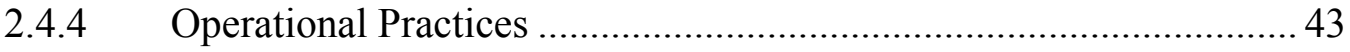

2.5 Environmental Management in the Tourism Industry …......................... 44

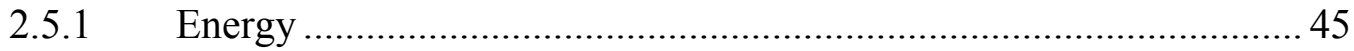

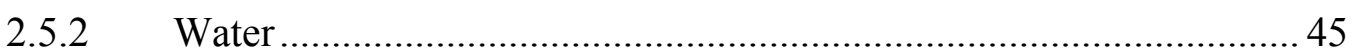

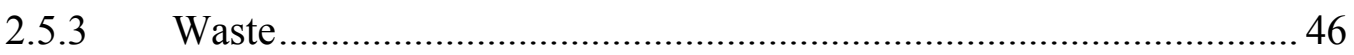

2.5.4 Environmental Supply Chain Management .................................... 47

2.5.5 Environmental Interpretation and Training in Tourism .................... 49

2.6 Factors Influencing Adoption of Environmental Practices...................... 50

2.7 Barriers of Environmental Management ................................................. 54

2.8 Benefits of Environmental Management ................................................... 56

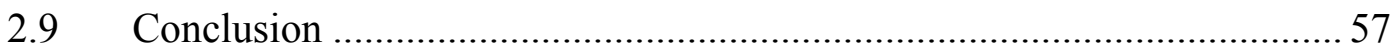




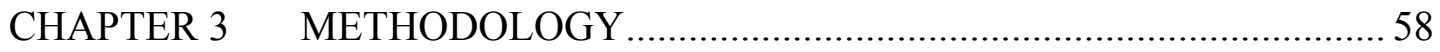

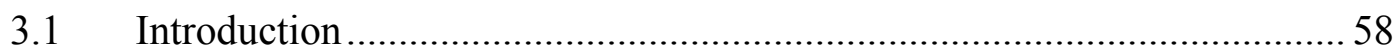

3.2 Research Framework........................................................................ 58

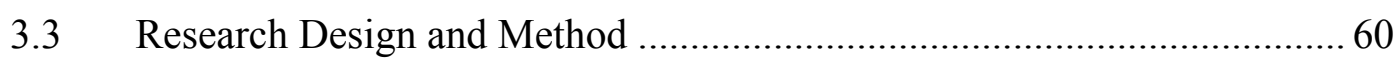

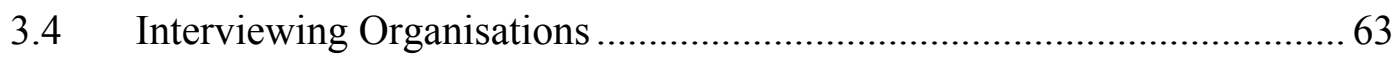

3.5 Sample

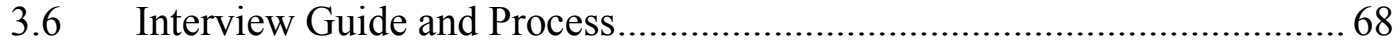

3.7 Data Preparation and Method of Analysis ............................................... 71

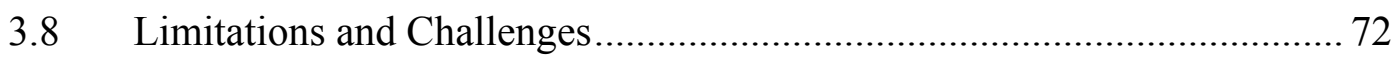

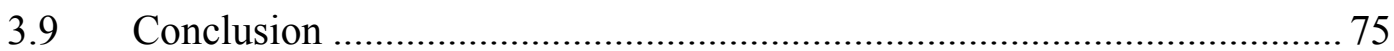

\section{CHAPTER 4 ENVIRONMENTAL MANAGEMENT APPROACHES AND}

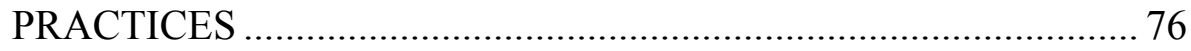

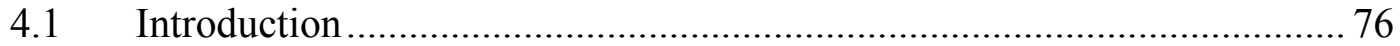

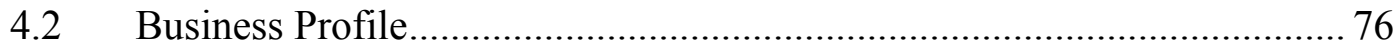

4.3 Environmental Management Approaches .................................................. 77

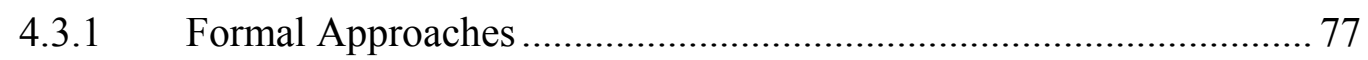

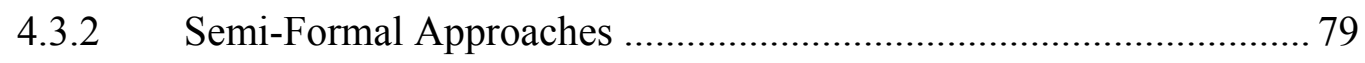

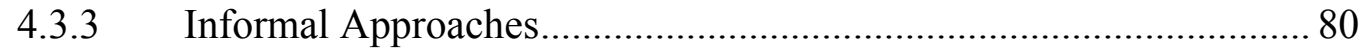

4.4 Environmental Management Practices................................................... 81

4.4.1 Supply Chain Management ……..................................................... 82

4.4.2 Environmental Awareness and Training ......................................... 84

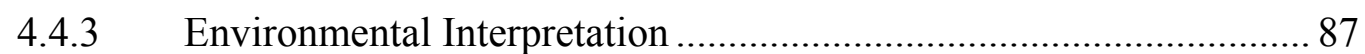

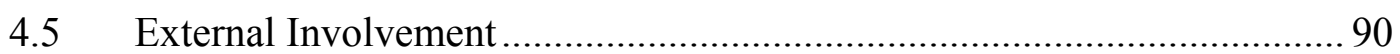

4.6 Importance of Environmental Management........................................... 94

\section{CHAPTER 5 INFLUENCES AND BARRIERS TO ENVIRONMENTAL}

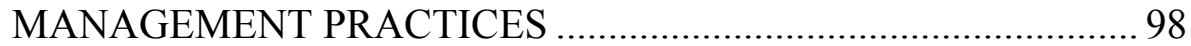

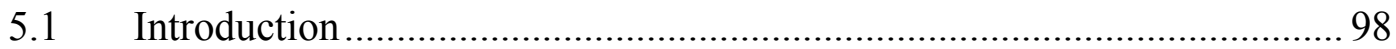

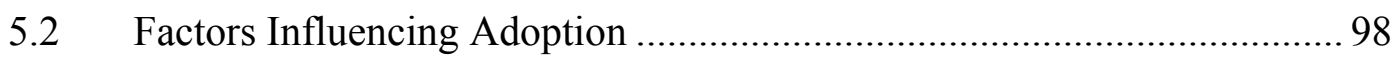

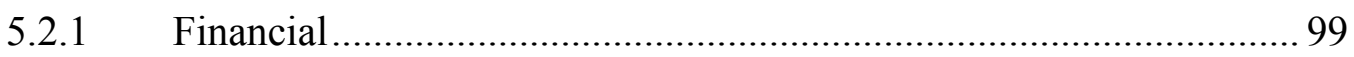

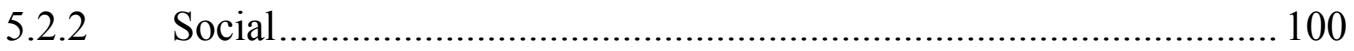

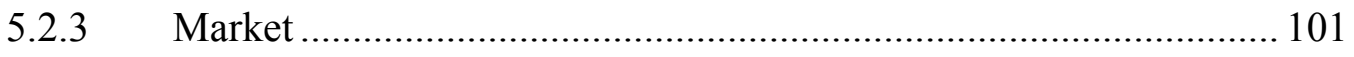

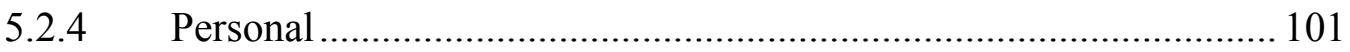




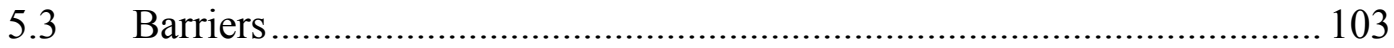

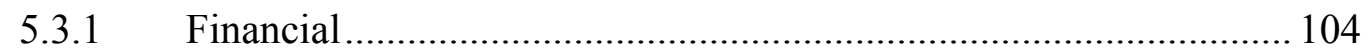

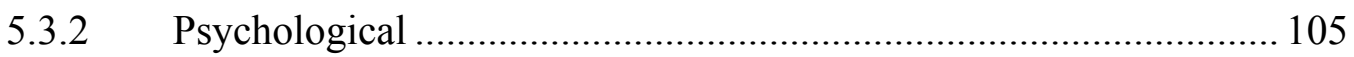

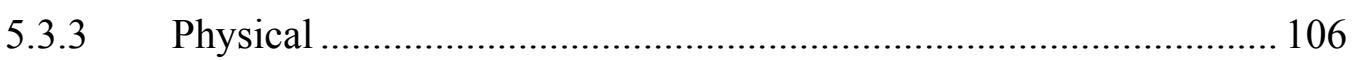

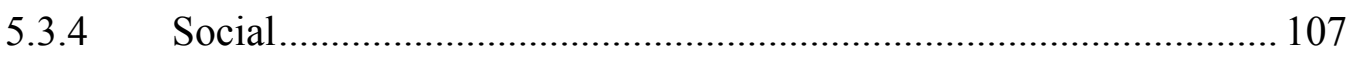

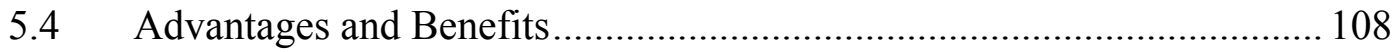

5.4.1 Marketing: Competitive Edge ........................................................ 108

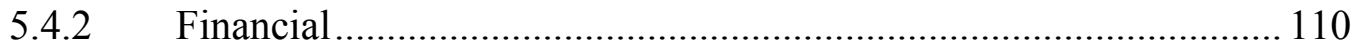

5.4.3 Organisational Culture ................................................................. 111

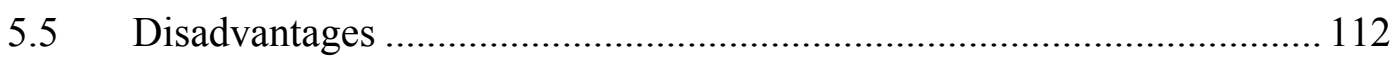

5.6 Role of Public and Private Sector Organisations ................................... 115

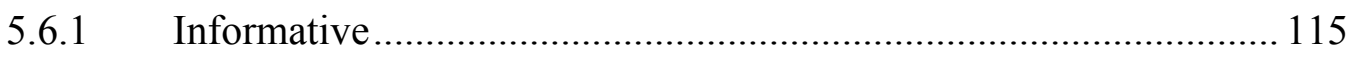

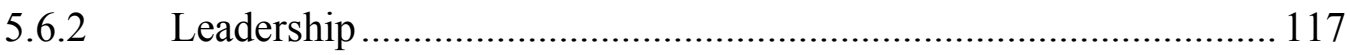

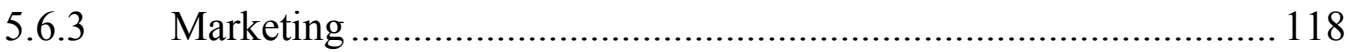

CHAPTER 6 DISCUSSION AND CONCLUSION_.......................................... 122

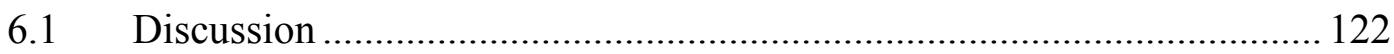

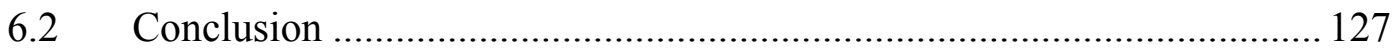

6.2.1 The Aims and Objectives of this Research ..................................... 127

6.2.2 Summary and Research Implications.............................................. 128

6.2.3 Recommendations for Industry ………………………………...... 131

6.2.4 Recommendations for Future Research ............................................ 134

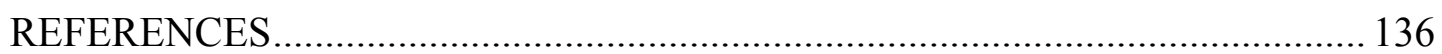

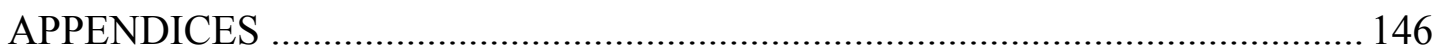




\section{List of Figures}

Figure 1: Tourism and the Global-Local Nexus ................................................... 13

Figure 2: Sustainable Tourism and the Global-Local Nexus ................................... 30

Figure 3: Organisational Approaches to Sustainable Urban Tourism ....................... 38

Figure 4: The Principles of Environmental Management Systems - ISO 14001 ...... 42

Figure 5: Drivers for Sustainable Business Practices ............................................. 51

Figure 6: Conceptual Framework towards the Likelihood of Adoption .................... 53

Figure 7: Regulatory Instruments for Environmental Protection.............................. 53

Figure 8: Location of Research Sample - Wellington, New Zealand........................ 65

Figure 9: Influences and Barriers of Environmental Management Practices .......... 126

\section{List of Tables}

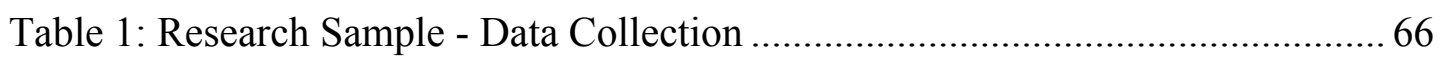

Table 2: External Involvement of Tourism Businesses ............................................ 91

Table 3: Factors Influencing Adoption of Environmental Management Practices.. 103

Table 4: Barriers of Environmental Management Practices .................................... 108

Table 5: Main Advantages of Environmental Management ................................. 112

Table 6: Public and Private Sector Role Regarding Environmental Management .. 121 


\section{CHAPTER 1 INTRODUCTION}

\subsection{Introduction}

The tourism industry, recognised as the world's largest industry plays an important part in New Zealand's economy. As well as tourism's economic significance, it is closely connected to the environment. The tourism industry is dependent on the environment and its resources. Therefore, actions taken to manage and protect the environment are crucial to ensure the sustainable future of the industry.

Tourism research provides an effective way to explore the nature of such actions at the level of organisations as all stakeholders in tourism have an important role to play in achieving environmental sustainability. The purpose of this study was to investigate environmental management by tourism organisations in Wellington, New Zealand by identifying and analysing the range of attitudes and experiences of tourism operators and the public and private sector.

In particular the key aims of this research were to:

- Identify and examine the extent of environmental management approaches by tourism businesses in Wellington.

- Explore and analyse similarities and differences across sectors, if any.

- Identify and analyse factors and barriers influencing the adoption of environmental management practices.

- Identify and discuss the role and relationship of the public and private sector with regard to environmental management.

In achieving the research objectives, this study seeks to provide a better understanding of the different approaches by attempting to address a gap in the body of knowledge concerning environmental management for tourism organisations within urban settings because most tourism studies on environmental management tend to focus on rural or protected areas. It is hoped that this study will contribute to 
the existing body of knowledge on this topic and continue to assist in ensuring an environmentally sustainable future for the New Zealand tourism industry.

This chapter commences by outlining the importance of environmental sustainability at the macro level of tourism by drawing on a number of chronological developments that have led towards the adoption of sustainability by the tourism industry. It then continues by presenting a framework which illustrates the operation of sustainable tourism at the global-local level. By using this framework the discussion is then focused on describing the various stages of sustainable tourism in order of the hierarchy - global, national, regional and local and in terms of the significant influences, policies and processes at each of the levels. In order to examine the environmental management approaches by tourism organisations one needs to account for what happens at each of the various levels. The chapter concludes with a description of the structure of this thesis which outlines the number of steps to be taken as part of the overall research process.

\subsection{The Importance of Environmental Sustainability}

The degradation of the world's environment constitutes a very real and important concern for today's society. There are currently a number of increasingly significant environmental concerns and threats to the future of society. At the global level these concerns include climate change, depletion of the ozone layer, over-consumption of non-renewable resources and air pollution. Among these global problems, climate change represents one of the most critical global challenges of time and according to the vast majority of scientists this has been a result of human activity and not a natural occurrence (An Inconvenient Truth, 2006). The evidence is both overwhelming and undeniable. According to the United Nations Environment Programme (UNEP, 2008) the impacts of climate change range from sea-level rise, the accelerated erosion of coastal areas, increasing intensity and frequency of natural disasters, species extinction, damage to ecosystems, through to the spread of diseases. 
Recent events have emphatically demonstrated Earth's growing vulnerability to climate change. Resources are being degraded to the extent that they have threatened the environment, livelihoods and economies of mankind around the world. For example, the number of Category 4 and 5 hurricanes has almost doubled in the last 30 years, the flow of ice from glaciers in Greenland has more than doubled over the past decade, hundreds of species of animals are responding to global warming, moving closer to the poles, and diseases such as malaria have spread to higher altitudes, as is the case in the Columbian Andes, situated 7,000 feet above sea level (An Inconvenient Truth, 2006). In fact, that is just the beginning. If the changes continue the world can expect greater catastrophic consequences such as the loss of more than a million species worldwide by 2050 , devastation to low-lying coastal areas as a result of a rise in global sea levels and even deaths.

Thus, over the last fifty years, a myriad of environmental problems has placed increasing pressure on the world to respond to the negative impacts by minimising them, and maximising the positive influence of industrial activities on general economic and social development. As the world has become more industrialised and environmental pressures have increased, humankind has recognised the need to reduce and contain the adverse impacts on the environment and take action in a way that is beneficial to our present needs, and for future generations. Sustainability of the world's natural and physical resources such as land, water, and energy therefore constitutes the way forward as sustainable development and enhancement or greening of the environment, are priority concerns that not only affect the global population but also worldwide economic growth.

\subsection{Tourism and Environmental Sustainability}

Tourism as a global economic activity is integrated with the wider economic and social environment. Therefore, the philosophy is no different. In fact, the nature of the industry depends heavily on the environment and the interactions which take place within it, as tourism and the environment are inextricably linked to one another. Almost no other industry is as environmentally dependent as the tourism industry. 
While this is true, at the same time if both tourism and tourism businesses are not managed appropriately it could result in the destruction of the resources that it fundamentally relies upon. Therefore, it is imperative to take the necessary steps to ensure the protection and enhancement of the environment through the concept of sustainable tourism. Concerted efforts commencing at the global (international) level through to a national level, right down to small tourism businesses demonstrate various concerns and perspectives at different scales. Milne (1998) notes an examination of the processes at these different scales aim to gain a better understanding of how different stakeholders at each of the various scales view the sustainable development process, and how their perceptions are influenced by the broader socio-economic and environmental structures in which they are embedded. Therefore, efforts should be made to ensure the world's environment is maintained in order to provide for a better standard and quality of living which will inevitably benefit our planet's future generations.

Edgell (2006) states it is evident that sustainability in general has become part of an overall shift in society that recognises that orderly economic growth, combined with concerns for the environment and the quality of life's social values will be the driving force behind long-term progress in tourism development and policies. The concept of sustainability as a resource development and management philosophy permeates all levels of policy and practice relating to tourism from the global down to the local level in the form of community initiatives towards planning for and protecting our earth's resources. In order to account for the significance of the global societal movement towards sustainable development one must identify the reasons which have led to the concept being established and widely accepted around the world in general and also in direct relation to the world's tourism industry.

The initial concept of sustainability has a long history. According to Swarbrooke (1999) its origins lie in the wider concept of sustainable development which has been around for many centuries, dating back to as early as the attempts undertaken by the Romans in their planning and developing of towns and cities. Through time, technological inventions, population pressures together with social and economic change led to the growth of industry and urbanisation transforming modern society as well as the natural environment. It was recognised from as early as the $18^{\text {th }}$ 
century that if industrialisation was not controlled the process could destroy the environment, resulting in a lowering in the quality of life.

Despite this, it was not until the late 1960s that the world began to take notice of the serious implications for the environment if it did not operate in a sustainable manner. For instance, arising from the work of a courageous woman and author of Silent Spring, Rachel Carson (1962) took on the chemical industry raising important questions about the impact of people on the natural environment which brought with it a legacy of a new public awareness that nature was vulnerable to human intervention (Natural Resources Defense Council, 1997). For the first time, the need to regulate industry in order to protect the environment became widely accepted and environmentalism was born. Lear (2002) notes that six years after her death, concerned Americans celebrated the first Earth Day and Congress passed the National Environmental Policy Act. From this, it was evident that the need to speak out and confront the issue over the destruction of the environment was imperative to frame it as a debate over the quality and future of all life.

The severity of the world's environmental problems continued to be recognised by the numerous reports warning that the Earth's future was under threat because the global population was growing rapidly, and was not sustainable in relation to the Earth's resources. From the 1980s the desire to safeguard the future of the planet and its resources had now become paramount. The next part in this chapter describes the development of sustainable tourism within a global to local framework.

\subsection{Sustainable Tourism Development and the Global-Local Nexus}

Tourism is undeniably a major global economic force with the tourism sector set to surpass a total of 1 billion international travellers by 2010, and reach 1.6 billion by the year 2020 (UNWTO, 1999a). From these statistics alone it is evident that the growth of world tourism is a cause for concern and due to its rapid expansion and increased development there is a need to manage the industry in a sustainable manner, beginning at the global (international) level down through to the local tourism 
industry and wider community. In order to conceptualise and better understand the links that exist between and within these various scales of the hierarchy it is necessary to adopt the notion of the global - local nexus framework by Milne and Ateljevic (2001) as illustrated by Figure 1.

\section{Figure 1: Tourism and the Global-Local Nexus}

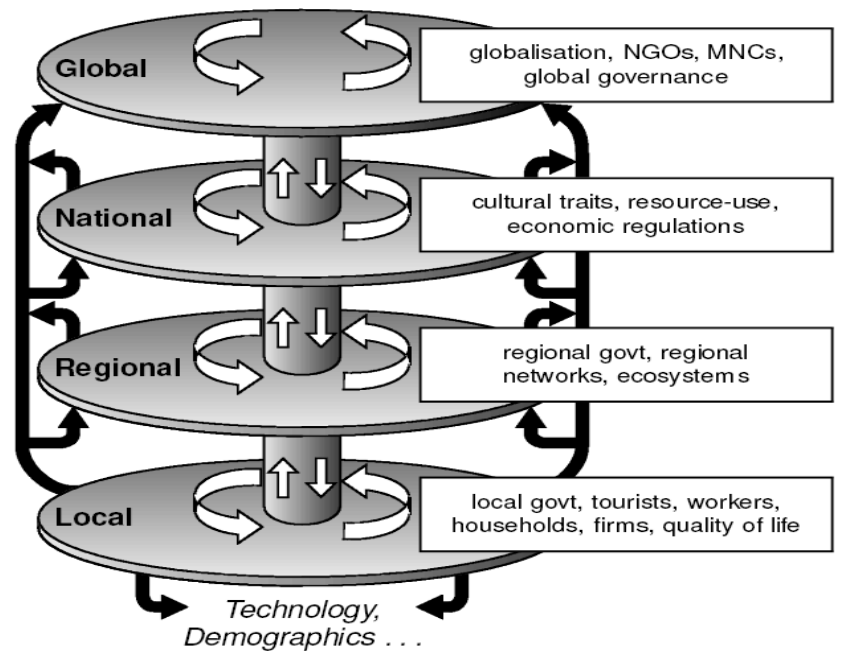

Source: Milne and Ateljevic (2001).

Milne (1998) argues that sustainability takes on different forms at various levels of analysis and must be studied at different geographical scales to account for the diversity and complexity of the industry. It is also vital to consider stakeholder (tourists, businesses, community and government) interactions that occur both within and between these multiple scales of analysis in order to create a clearer conception of how different stakeholders articulate with each other with regard to sustainable development in tourism. At the global (international) level the process of sustainable development is affected by a range of actors and issues.

In general, supra-national actors, such as trans-national companies (TNCs) and global financial institutions shape the nature and progress of tourism development. At this level the centralisation of decision making is high whereby actions are guided by the global priorities of multinational corporations, geo-political forces and broader forces of economic change. In other words, they set the policies and lead those below 
in the 'glocal' nature of tourism development processes. The complex links that exist between the tourism industry and sustainable development from a global-local scale will be outlined in detail below.

\subsubsection{The Global Significance of Environmental Sustainability}

The concept of sustainability is founded on global policies. It first appeared on the public scene as a result of the landmark study, Our Common Future, the 1987 report prepared by the World Commission on Environment and Development (WCED) to the United Nations General Assembly, otherwise known as the Brundtland Report (Brundtland, 1987; Swarbrooke, 1999; Edgell, 2006). Essentially the report is one of the most decisive and influential documents of the $20^{\text {th }}$ century due to its creating a global awareness of the enormous environmental problems facing the planet, and the need for global environmental action. The aims of the report were to re-examine the critical environment and development problems of the planet and to formulate realistic proposals to solve them. In other words, the report aimed to create a 'global agenda for change' within the principle of Environmentally Sustainable Development. The report awakened many to the impending crisis of the planet and the serious need to take action. It defined a sustainable society as one that: "meets the needs of the present without compromising the ability of future generations to meet their own needs." (Brundtland, 1987 in Herremans, 2006, p. 2)

The adoption of this particular definition has been carried forward into the $21^{\text {st }}$ century way of thinking. The Brundtland Report examined a number of different topics such as population and human resources, species, ecosystems, energy, industry, and the challenges facing people in terms of the urban or built environment (Brundtland, 1987). As a result, the report provided a foundation for many industries, including tourism, to set their own agendas and answer the call for a much needed global change. The report was a necessary call to international action on issues of common concern and most importantly, it encouraged the need to increase cooperation with industry. 
In the 1990s, a stronger connection was made between tourism and the environment and the sector's potential for more sustainable development. The tourism industry began considering how it could answer the call set out in the WCED report. The most important document of its kind to achieve widespread international agreement reflecting global consensus and political commitment at the highest level is Agenda 21 (UNWTO, 1996). At the United Nations Conference on Environment and Development (UNCED), namely the Earth Summit Conference held in Rio de Janiero on 14 June 1992, 182 governments adopted a comprehensive programme to implement the 1987 Brundtland Report whereby the sustainable development approach was further elaborated and expressed in Agenda 21 which was adopted by the conference. Agenda 21 was developed and intended to provide a blueprint for securing the sustainable future of the planet into the $21^{\text {st }}$ century. The complex document recognises that as the world's largest industry, tourism has a vested interest in protecting the natural and cultural resources which are at the core of its business (UNWTO, 1996). This notion relates back to the idea that tourism depends heavily on the natural resources of the environment. Thus, the tourism industry needs to ensure it works strongly towards sustainability.

It was here that the tourism industry exercised its ability to take a leading role in furthering the initiatives arising from the Earth Summit. In 1995, three international organisations, namely the World Tourism Organisation (UNTWO) and World Travel and Tourism Council (WTTC) joined forces with the Earth Council to launch and promote an action plan to improve the environment and make the tourism sector more sustainable. Herremans (2006) notes this action plan is called 'Agenda 21 for Travel \& Tourism Industry: Towards Environmentally Sustainable Development'. The agenda itself as described by Edgell (2006) establishes a systematic framework of action in the $21^{\text {st }}$ century, outlining main priority areas for governments and a tenstep programme for businesses to make the tourism industry more environmentally responsible: "As the world's largest industry, it [tourism] has the potential to bring about substantial environmental socio-economic improvements and to make a significant contribution to the sustainable development of the communities and countries in which it operates." (UNWTO, 1996) 
The Agenda states that in short, everyone is responsible. From governments, United Nations (UN) agencies, other intergovernmental organisations, businesses, the rest of the industry including tourists, right down to the general public (UNWTO, 1996), each of these groups must be involved in implementing the actions specified by the Agenda if it is to be successful. This point reinforces the fact that no matter how large or small an organisation is, every organisation or business can make its own contribution. While each group has an important role to play, the Agenda designates national governments as having the most responsibility for leading and thus guiding the process.

For tourism in particular, recognising the significance that it has a unique and leading role to play in achieving the aims of the Agenda, the document identifies nine priority areas of action - a comprehensive list for government departments, national tourism organisations (NTOs) and representative trade organisations and companies. The report goes into some detail about each of the main priority areas of action and the ways in which the various stakeholders can achieve the aims of each priority area to ensure the sustainable future of the world's tourism industry. Edgell (2006) states many national governments have now adopted sustainability as their fundamental development policy.

The main priority areas of action of Agenda 21 for government departments, NTOs and representative trade organisations are:

(i) assessing the capacity of the existing regulatory, economic and voluntary framework to bring about sustainable tourism

(ii) assessing the economic, social, cultural, and environmental implications of the organisation's operations

(iii) training, education, and public awareness

(iv) planning for sustainable development

(v) facilitating exchange of information, skills, and technology relating to sustainable tourism between developed and developing countries

(vi) providing for the participation of all sectors of society

(vii) design for new tourism products with sustainability at the core

(viii) measuring progress in achieving sustainable tourism 
(ix) partnerships for sustainable development

(UNWTO, 1996)

Meanwhile, for companies, the ten priority areas for action of Agenda 21 are:

(i) waste minimisation

(ii) energy efficiency, conservation and management

(iii) management of fresh water resources

(iv) waste water management

(v) hazardous substances

(vi) transport

(vii) land-use planning and management

(viii) involving staff, customers, and communities in environmental issues

(ix) design for sustainability

(x) partnerships for sustainable development

(UNWTO, 1996)

In addition, a number of key initiatives undertaken by the tourism industry have sought to ensure that sustainable tourism was considered in operations at all levels of planning and development. The WTTC has developed a set of environmental guidelines to help companies and governments develop policies that create a clean and healthy environment for all tourism activities. As noted by Herremans (2006) these guidelines have evolved into the Green Globe certification and benchmarking process for tourism organisations all around the world. In response to Agenda 21, the WTTC launched Green Globe, an international certification programme which provides guidance materials and support for industry members who are willing to make a commitment to their environmental performance over time by demonstrating more environmentally responsible behaviour (Green Globe, 2007), thus attempting to achieve the sustainable outcomes put forward by Agenda 21 for the tourism industry. Since its inception the programme has been expanded with the introduction of the Green Globe Standard and commencement of independent auditing, and continually upgraded as part of leading-edge improvement as it is the world's only benchmarking, certification and performance improvement programme based on the Agenda 21 principles for sustainable development. 
In 1999, as a result of synthesising various declarations and codes, the UNWTO established a global Code of Ethics for Tourism. The Code sets a frame of reference for the responsible and sustainable development of world tourism. Members of the UNWTO believe that the Code's purpose is fundamental to assist in minimising the negative impacts of tourism on the environment. Specifically, Article 3, titled "Tourism, A Factor of Sustainable Development," addresses the ecological considerations of sustainability in tourism. In particular, the article states that all stakeholders in tourism should safeguard the natural environment, ensure that all forms of tourism development that are conducive to saving rare and precious resources such as water and energy should be given priority, be encouraged by national, regional and local public authorities, and tourism infrastructure and activities be designed in such a way as to protect the natural heritage composed of ecosystems and biodiversity (UNWTO, 1999b). Furthermore, according to the UNWTO sustainable tourism development guidelines and management practices are to be applicable to all forms of tourism in all types of destinations whereby the principles that guide sustainability refer to the environmental, economic, and sociocultural aspects of tourism development. A suitable balance must be established between these three dimensions if future, long-term sustainability is to be guaranteed.

Thus, according to the UNWTO sustainable tourism should:

1) Make optimal use of environmental resources

2) Respect the socio-cultural authenticity of host communities

3) Provide socio-economic benefits to all stakeholders

(UNWTO, 1999b)

In order for its success, sustainable tourism development cannot be dependent on only one or two organisations, it requires the informed participation of all relevant stakeholders, supported by strong political leadership to ensure wide participation and consensus building.

On an international level, another initiative which seeks to raise awareness and introduce environmental practices into the tourism industry is the International Tourism Partnership (ITP), formally known as the International Hotels 
Environmental Initiative (IHEI). The ITP was founded in 1992 by HRH Prince of Wales in the belief that the tourism sector should and could do more to address the environmental challenges facing the world (ITP, 2008). Over the past 15 years the ITP has played a leading role in bringing major hotel and tourism companies together to strengthen their approaches towards environmental sustainability. The ITP has produced a number of publications related towards their goal in achieving environmental sustainability. For example, the Environmental Management Handbook which contains a comprehensive guide on how to incorporate environmental management within business operations and the Greenhotelier Magazine for people who care about a more environmentally and socially responsible hotel, travel and tourism industry. It aims to inspire, educate and challenge everyone connected with the hospitality sector and wider tourism industry to achieve more sustainable operation (Greenhotelier, 2008). These initiatives commencing at the global level further illustrate the worldwide significance of environmental sustainability.

Hunter (2002) points to the words of Secretary-General Kofi Annan, in that sustainable development has become the 'new conventional wisdom'. While the focus of most industries during the 1970s was almost solely on economic development, growth and financial gain, by the 1980s it was clear that the (tourism) industry must not only include an economic impact statement but also meet new and growing environmental regulations and concerns. At this period of time, society at large had become more aware and concerned about the environment leading to a number of global environmental conferences that included major segments devoted to the impacts of industry on the environment with tourism leading the way. By the 1990s, the social dimension as Edgell (2006) states was added in recognising the importance of community and stakeholder success in terms of performance. Therefore, witnessing a strong movement toward the management of all these three elements.

This 'new conventional wisdom' as Hunter (2002) explains, encouraged businesses to concentrate on a new concern known as the 'triple bottom line'; that is economic, social, and environmental performance. This section has addressed the origins of sustainability and the way in which it has evolved and been adopted by the tourism 
industry. It has also provided a discussion on the actions and the roles of various stakeholders at the highest, international level in regards to sustainability setting the scene for the way in which the national level and those levels below respond to this ever growing problem concerning the well-being of the planet's environment.

\subsubsection{The National Significance of Environmental Sustainability}

From the above section which covers the significance of sustainable tourism and environmental sustainability at the general or global level it is evident that reducing impacts on the environment is necessary in order to maximise the economic and social benefits to both industries such as tourism, and those that are affected by it i.e., tourism businesses at the 'ground level'. When assessing the significance of the environment at the global level it is clear that an examination of what is happening within a national context is essential because policy frameworks, environmental management issues, and recommendations made at the highest level should inevitably lead and thus guide the direction of national policies, reflecting somewhat of a hierarchical structure as tourism operates at different scales. Indeed, from a tourism perspective, national governments often appear to be playing a more active role in coordinating the tourism marketing campaigns and broad-based product development that play such an important role in shaping tourism demand and behaviour.

In the context of New Zealand there are a number of institutions or organisations that have been established to ensure New Zealand's own unique environment is managed and maintained to benefit future generations. These key players concerned with the management of New Zealand's environment include the Ministry for the Environment, the Department of Conservation (DOC), and the Parliamentary Commissioner for the Environment. From a tourism perspective, key players comprise of the Ministry of Tourism and Tourism New Zealand. While all of these actors are not directly related to tourism, they demonstrate New Zealand's ability to ensure the country's unique 'clean and green' environment is managed carefully and maintained effectively to assist in meeting the needs of future generations. 
Based on the recommendations outlined in the Brundtland Report, many international agencies and governments worldwide including New Zealand have adopted the principle of sustainable management (Memon and Perkins, 2000) within the context of their own environmental surroundings. In the late 1980s, New Zealand began drafting the Resource Management Act (RMA), a piece of legislation which embedded the concept of sustainability through management of natural resources. Two key pieces of legislation were also passed at this time. Both pieces of legislation set an institutional framework for environmental management within central government: the Environment Act 1986 and the Conservation Act 1987. The Environment Act was devised to ensure that the management of natural and physical resources take full consideration into:

(i) the intrinsic values of ecosystems; and

(ii) all values which are placed by individuals and groups on the quality of the environment; and

(iii) the sustainability of natural and physical resources; and

(iv) the needs of future generations.

(Ministry for the Environment, 2008a)

With the exception of the Treaty of Waitangi and its principles which were also considered under the Environment Act, the above four criteria are indeed a direct reflection of sustainability principles at the global level. At this point in time, New Zealand was beginning to see the importance of looking after the natural and physical environment.

However, it was not until the early 1990s when the concept of sustainability in New Zealand began to receive greater attention. In 1991 the RMA became law, providing a statutory framework for a relatively holistic and integrated approach to environmental planning and management which were rooted in both ecological and democratic principles (Memon and Perkins, 2000). Section 5 of the RMA states the enactment's purpose.

(1) The purpose of the RMA is to "promote the sustainable management of natural and physical resources". 
(2) In this Act, "sustainable management" means managing the use, development, and protection of natural and physical resources in a way, or at a rate, which enables people and communities to provide for their social, economic, and cultural well-being and for their health and safety while:

(a) Sustaining the potential of natural and physical resources (excluding minerals) to meet the foreseeable needs of future generations; and

(b) Safeguarding the life-supporting capacity of air, water, soil, and ecosystems; and

(c) Avoiding, remedying, or mitigating any adverse effects of activities on the environment.

(Taken from Table 4.1., Williams, 2002)

Again, this reinforces the notion that the Act is defined in terms of the principles of sustainability. Furthermore, it recognises that the government plays a vital role in environmental planning with decision-making being undertaken as close as possible to the level of community interest, encouraging individuals as well as whole communities to plan for the future of the environment in order to reach the benefits which may accrue. Therefore, central government's principal role is an overview and monitoring one, as councils (regional, district and city) are primarily responsible for preparing plans to help them manage any adverse impacts of activities on the environment.

As noted above, there are a number of organisations that are concerned for the environment in the context of New Zealand. The Ministry for the Environment is essentially the Government's principal adviser on environmental sustainability and international matters that affect the environment. The Ministry for the Environment also keeps a watch on the way councils do their jobs under the RMA. The environment is a significant part of New Zealand's economy and the Ministry for the Environment's vision is for a prosperous New Zealand where a healthy environment enhances social and economic well-being.

The role of the Ministry for the Environment is to: 
- Provide leadership on environmental sustainability across central and local government and the community

- Work in partnership with others in central and local government, business and the community to improve our environment and encourage sustainable practices

- Fix problems that require central government intervention

- Measure and report on the health of the environment.

Meanwhile, the main outcomes the Ministry for the Environment are working towards are:

- New Zealand's air, water, land and built communities are healthy

- New Zealand is able to capitalise on its natural environmental advantages

- New Zealand's natural resources are managed effectively and New Zealanders are encouraged to use resources in a sustainable manner

- Risks to people, the economy and the environment from pollution, contamination and other environmental hazards are minimised

(Ministry for the Environment, 2008b)

In the context of tourism, the Ministry for the Environment notes that few industries are more closely linked to New Zealand's unique environment than tourism. Visitors to New Zealand have high expectations in terms of New Zealand's landscapes and the general environment, which in part is due to the success of Tourism New Zealand's '100\% Pure' campaign. The Ministry for the Environment urges tourism businesses to play a lead role in supporting the promise made to our international travellers by becoming more sustainable in areas such as energy use, water consumption, and waste. By adopting new sustainable practices businesses can:

- Become more energy and waste efficient.

- Identify potential risks to the environment from their business and avoid those risks.

- Gain opportunities to position their business as more sustainable and support ‘ $100 \%$ Pure' New Zealand. 
- Identify beneficial partnerships.

(Ministry for the Environment, 2008c)

Furthermore, the Ministry for the Environment has joined forces with the Ministry of Tourism in undertaking the Sustainable Tourism Charter Project, a project which was funded by the New Zealand Tourism Strategy 2010 Implementation Fund. Fundamentally, the project aimed to increase the awareness of businesses about the importance of environmental management to the tourism industry, particularly to provide flexibility to regions acknowledging the majority of businesses are small to medium sized. The Charter Project focused on six tourism regions that were selected to take part in January 2005: Enterprise Northland; Destination Rotorua Tourism Marketing; Lake Wanaka Tourism; Latitude Nelson; Tourism Bay of Plenty; and Venture Southland/Destination Fiordland (Ministry of Tourism, 2008).

Essentially, the project takes a "bottom-up" approach that is intended to facilitate the creation of regional clusters of businesses that are adopting sustainable business practices. Businesses themselves are required to monitor and update their own progress on various areas of environmental management such as waste minimisation, energy efficiency, community involvement, supply chain management and sustainable design. The benefits that arise from the project are huge, as intangible benefits in the form of stronger relationships and improved understanding between central government, local government, tourism agencies and operators can be achieved. In addition, the project in turn, ultimately supports New Zealand's ' $100 \%$ Pure' brand. It attempts to deliver on the brand's promise by improving the environmental performance and standards of the tourism sector in New Zealand.

Tourism New Zealand, the country's NTO also sees sustainability as a pertinent issue. The latest update of the New Zealand Tourism Strategy 2015 puts forward two important values which are central to the document. The two values to the strategy are kaitiakitanga (guardianship) and manaakitanga (hospitality). To guide the sector towards its vision, the Strategy contains four key outcomes, and the priorities and actions needed to achieve them (New Zealand Tourism Strategy Group, 2007). Outcome Three puts the importance of the environment and the concept of 
sustainability into better perspective. It states that the tourism sector should take a leading role in protecting and enhancing the environment. More specifically:

- The tourism sector contributes to a whole-of-New Zealand approach to ensure that New Zealand's environment will continue to be enjoyed by future generations and visitors, in the spirit of kaitiakitanga (guardianship).

- The expectations of our visitors are clearly understood, and visitors are able to easily identify and select products that deliver good environmental performance.

- The tourism sector leads the way in introducing initiatives that will reduce carbon emissions and increase the energy efficiency of transport within and en route to New Zealand.

- The tourism sector improves its energy efficiency, energy conservation, and use of renewable energy at all levels.

- The tourism sector takes active steps to reduce and manage its waste, encourages other sectors to do the same, and engages with the local, regional, and national agencies that provide waste-management standards and facilities.

- Tourism businesses have the capability and knowledge to take a leading role in protecting and enhancing the environment.

- The tourism sector, DOC, and other key agencies continue to work together to make sure that conservation values are enhanced.

- Visitors' tourism experiences give them the opportunity to learn about and contribute to New Zealand's environmental and conservation goals.

(New Zealand Tourism Strategy Group, 2007)

It is clear that sustainability is at the core of this document as it not only constitutes the way forward but more importantly provides New Zealand with a unique approach based on the Maori principles of kaitiakitanga and manaakitanga. Kaitiakitanga refers to understanding the importance of the role of Maori in looking after the nation's natural resources for the collective benefit of mankind and ensuring the protection of Maori cultural practices in managing cultural sites, flora, and fauna. In other words, the relationship between people and the environment according to 
Tikanga Maori, or traditional values, is one that is not mutually exclusive but recognises that they are interdependent (Edmonds, 2006).

Manaakitanga translates into hospitality and facilitating mutual respect between host New Zealanders and visitors from overseas (New Zealand Tourism Strategy Group, 2007). Therefore, responsibility is assigned to people (as hosts) in safeguarding the environment for future generations. These key Maori values tie in closely with the tourism strategy and reflect the contemporary values of sustainability. They also reinforce the importance of cultural tourism as both correspond to New Zealand's unique positioning and furthermore contribute to the development of environmental sustainability in New Zealand from a unique and holistic perspective. The focus of this chapter now turns to describing and examining the regional and local significance of environmental sustainability in order to account for the complexities arising at the global-local level with regard to tourism and sustainability.

\subsubsection{The Regional and Local Significance of Environmental Sustainability}

The importance of environmental sustainability needs to be examined from global through national to regional and local levels. At the local/community level as noted by Milne (1998) the underlying goal is to maintain the life supporting capacity of the landscape, its resources and socio-economic regulatory structures so that future generations receive the benefits. The region has been seen as an increasingly vital component in the global-local context of development. Milne and Ateljevic (2001) point out that for tourism in particular, regions serve as an important driving force that links disparate segments of the industry thus enabling destination networks to form. Furthermore, most of the natural and cultural resources that the tourism industry relies upon are regional in nature. These resources range from complex ecosystems through to patterns of culture and economic identity.

From a government perspective, Regional Councils (RCs) are assigned the overall responsibility for the integrated management of natural and physical resources. This 
as Dymond (1997) describes, means that their role in tourism is limited to the core function of resource management. For example, in the context of this study the RC responsible for the Wellington region is the Greater Wellington Regional Council. As a regional council, Greater Wellington has certain statutory responsibilities such as producing a Long-Term Council Community Plan (LTCCP) with the aim of bringing economic, social, cultural and environmental benefits to the region as well as reaching community outcomes. According to the latest LTCCP for Greater Wellington Regional Council (2007), environment management is a core business which contributes to the community outcomes: healthy environment, sense of place and healthy community.

This core role refers to managing the region's key natural resources such as water, soil, air, and the coast under the RMA. It is evident that tourism relies upon a region's natural resources as they are a vital component of the wider industry. Tourism is shaped by and closely connected to the natural environment and the interactions which take place in it. This reliance on the environment means that in order to protect, enhance and maintain the environment it needs to be managed appropriately (New Zealand Tourism Strategy Group, 2007). Environmental management activities under the regional council's functions include environmental monitoring i.e., reporting on the state of the region's environment and assessing their progress in achieving the desired environmental outcomes; working within the community in terms of environment education among schools, businesses and community groups; encouraging the use of public transport; and water treatment as well as the management of this demand.

At the city level, Wellington City Council (WCC) represents the working face of local government and therefore it plays a multipurpose role. In particular, WCC has established several companies which have been set up independently to manage Council facilities, or deliver specific services and developments on behalf of Wellington's general public (WCC, 2008). In terms of protecting, enhancing and maintaining the environment, WCC has put together an environmental strategy, addressing a long-term direction for the city as well as shorter-term priority areas of action. The environmental strategy itself is based on the premise of sustainable development and seeks to take action on a number of important issues concerning the 
city's environment in order to provide residents, businesses and visitors with a range of resources, opportunities and benefits. The purpose of the environmental strategy is to recognise the inter-relationships which exist among the various elements of the natural environment and provide a holistic approach to the management of Wellington's natural environment. By developing a long-term approach based on the premise of sustainable development and identifying key priority areas for action (WCC, 2006), the Council can continue to help protect, enhance, and maintain the natural environment so that it will prosper and provide benefits to current residents, businesses and visitors for many years to come.

Furthermore, in recognition of the fact that sustainable growth depends heavily on the well-being of the natural environment, WCC has identified the need to tend to all phases of the resource cycle:

- protecting sensitive natural areas and resources from disturbance.

- reducing our resource use and relying more on renewable energy sources.

- minimising the impact of our resource use, including development, on landscapes and ecosystems.

- disposing of waste products in a way that protects the natural environment that provided the initial resources.

- providing quality, accessible open spaces to protect and engage with the natural environment.

(WCC, 2006)

Eight long-term outcomes support the city's overall goal to protect, enhance and maintain the city's natural environment. In particular, Outcome 4.5 refers to the importance of environmental sustainability as Wellington seeks to: "reduce its environmental impact by making efficient use of energy, water, land and other resources; shifting towards renewable energy resources; conserving resources; and minimising waste."

(WCC, 2006) 
This statement is very important because if action is not taken to combat the issue of using resources more efficiently Wellington faces several risks to its economy; creating more harmful emissions leading to poor local air quality and to climate change; and generating more solid waste which requires costly landfill expansion. The city's environmental strategy recognises that reduction, re-use, and recycling can help mitigate these risks and create economic opportunities based on waste reduction instead of waste generation. From this strategy, it is clear that WCC is well aware of the increased need to protect and enhance the city's development in a sustainable manner. Furthermore, the Absolutely Positively Wellington branch under the Council has drawn attention to the issue of climate change. The vision in response to climate change is carbon neutrality whereby the Council aims to identify revised carbon emission targets, and develop an expanded, integrated work programme across a range of areas and activities in the city (Absolutely Positively Wellington, 2007). Due to the Council's understanding of environmental sustainability and energy efficiency, it has already been involved in activities that reduce carbon emissions providing positive benefits to the city.

Examples so far include planning for a compact city, promoting the use of public transport, and working to reduce the Council's own energy consumption. An action plan for the vision was produced in December (WCC, 2007) with the primary focus of reducing greenhouse gas emissions from both Council and community activities building on Wellington's strengths, identifying its weaknesses, minimising risks and ensuring that the Council takes a leadership role to guide the actions of others in the corporate sector and wider community via reduction of the Council's energy consumption, ensuring sustainability is a key priority for Council procurement decisions and addressing other areas of environmental sustainability such as waste and water consumption. While the Council's activities regarding environmental sustainability are not directly associated with the city's tourism industry, one of its companies, Positively Wellington Tourism (PWT) plays an important role for visitors and tourism businesses as it is the Regional Tourism Organisation (RTO). RTOs are often comprised of representatives from local government, the tourism industry, businesses and community groups. Dymond (1997) asserts this integrative and broad reaching nature of RTOs means that they are well placed within the New Zealand tourism industry to assist in the development of sustainable tourism and act 
as a voice, existing specifically to serve tourism purposes. To date, PWT (2007) has the aim of becoming carbon neutral under the proposed vision of Wellington City Council and more recently began to increase the awareness of sustainability in tourism to visitors, businesses and the wider community. The organisation published the Green Edition of Positively Informed (an electronic newsletter) in late 2007 to further promote awareness of the issue and acknowledge it as being very pertinent to the local tourism industry.

It is fair to say that one cannot understand the context of local tourism development in regards to sustainability unless attempts are made to grapple with the complexities of the global-local nexus in order to identify and account for the interactions that take place both within and between the various levels of the spatial and temporal dimensions of the hierarchy. In order to conceptualise the complexity of sustainable tourism development, the global-local nexus framework (Milne and Ateljevic, 2001) has been adapted to the context of this study as demonstrated by Figure 2 below to summarise the significance of the range of organisations operating at the various levels. Appendix 1 summarises the organisations concerned for the environment and the range of influences present at the global-local level.

\section{Figure 2: Sustainable Tourism and the Global-Local Nexus}

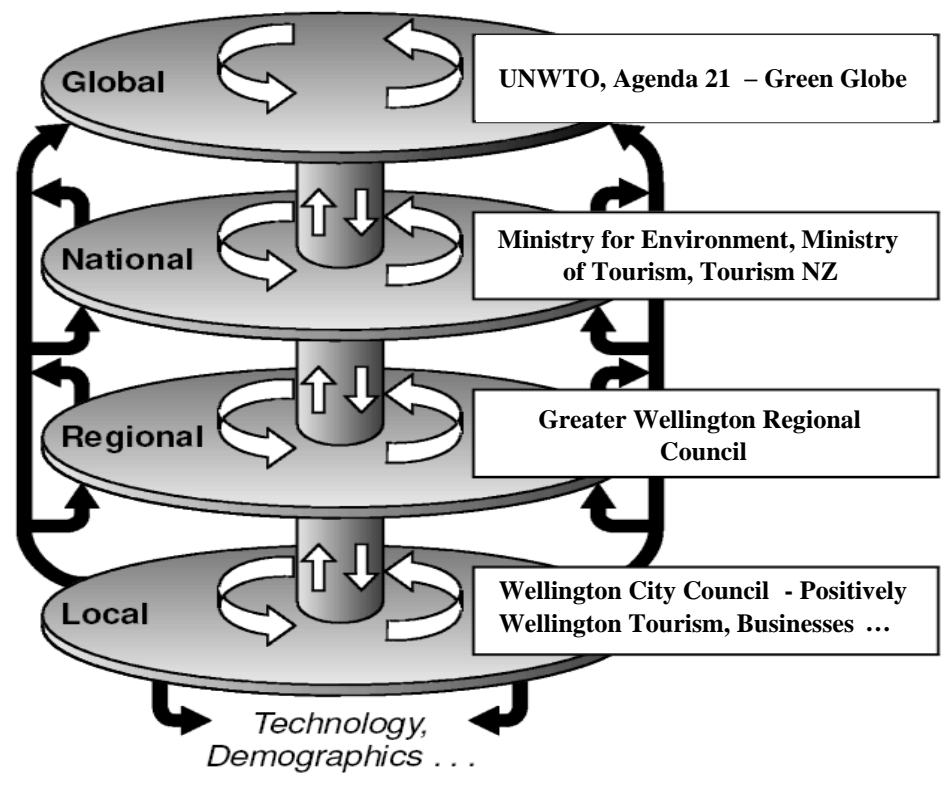

Source: Adapted from Milne and Ateljevic (2001) 


\subsection{Thesis Structure}

This opening chapter has described the significance of environmental sustainability by examining the actions being taken at the global-local level. This sets a framework in which to undertake the research as what happens at the global or national level may influence the decisions made at the regional and local level where the majority of individual tourism operators are based.

Chapter Two presents the various streams of literature that are necessary to review in answering the research objectives. It begins by outlining the concept of sustainability with a particular focus on its connection to the tourism industry and the environment and builds on these ideas by reviewing sustainability within urban settings. An overview of environmental management practices, factors influencing adoption, barriers, and benefits of environmental management are also described with a focus on identifying and explaining the relationships between these.

Chapter Three outlines and describes the methods used to collect the data required for this study and the way in which it has been analysed. It commences by describing the research framework with reference to the global-local nexus and research design. Further attention is given to discussing issues related to conducting interviews with organisations, sampling, data collection and method of analysis. This chapter concludes by discussing the challenges and limitations of the study.

Chapter Four and Chapter Five present the results of this study. The primary focus of these chapters is to identify and discuss the different environmental management approaches being undertaken by tourism businesses and examine the extent of such approaches. Chapter Five in particular, focuses on the factors influencing adoption, barriers to environmental management, and the role of public and private sector organisations in environmental management. Chapter Six concludes this study by discussing and summarising the key findings and relating these back to the research aims and objectives. It also redraws attention back to the literature, general context and ends by providing a number of research implications and recommendations for the tourism industry as well as avenues for future research. 


\section{CHAPTER 2 LITERATURE REVIEW}

\subsection{Introduction}

This literature review commences by outlining the concept of sustainability with a particular focus on its connection to the tourism industry and the environment. Drawing on the introductory chapter, this section sets out to explore the concept of sustainability from an academic perspective, in terms of its definition and use in tourism studies to date. This provides a context to explore the concerns for sustainable development and tourism. By gaining a deeper understanding of the concept of sustainability one is able to explore its use in context of an urban setting.

The second part of this literature review looks more closely at the evolution of sustainability in relation to urban settings and the concept of sustainable cities. While the majority of research tends to favour rural or protected areas there remains a need to investigate the concept of sustainable tourism within urban settings. From this premise, considerations can be given to earlier perspectives on sustainable tourism and how this concept has been applied to urban areas in tourism studies with a particular focus on the design of effective strategies and implications for stakeholders.

The third part of this literature review concentrates on the concept of environmental management. It attempts to define the term in reference to specific processes: environmental management systems, formal and operational practices, and other various aspects of environmental management such as environmental interpretation and training with a particular focus on the application of environmental management in the tourism industry. In addition, the chapter identifies the factors influencing adoption to environmental practices and the inherent barriers facing organisations. Finally, the benefits and significance of environmental management to an organisation are illustrated. These issues cover a range of topics and themes that are necessary in order to gain a better and in-depth understanding for this research. 


\subsection{Sustainable Development: Tourism and the Environment}

Since the 1990s the concept of sustainability has attracted interest among tourism researchers and in the tourism industry. The concept of sustainability and its derivative sustainable development, as suggested by McCool et al., (2001), are closely linked with management of natural environments, particularly protected areas, and human communities linked economically, politically and culturally to these environments. Consequently, sustainable development has been adapted over time into sustainable tourism. Thus, the underlying principles of the concept of sustainable development have been adopted by the tourism industry to fit the context of their needs (Hardy and Beeton, 2001; Weaver, 2006). Macbeth (2005) believes tourism has embraced a representation of one of today's most value-based concepts, sustainable development. In examining this application of the concept to tourism, Muhanna (2006, p. 19) lists reasons why tourism is most ideally suited to adopt sustainability as a guiding philosophy:

- Apart from transport, tourism does not consume additional non-renewable resources.

- A community's resources, its culture, traditions, shops, leisure facilities, etc., represent the core resources base for tourism.

- Tourism use of resources, both natural and cultural, should be non consumptive, making them renewable.

- Tourism represents one of the few economic opportunities available to remote communities.

- Tourism provides real opportunities to reduce poverty create employment for disadvantaged people and stimulate regional development.

- Tourism has proven to revitalise cultures and traditions.

- Tourism can provide an economic incentive to conserve natural and cultural assets.

- Tourism has been shown to foster greater understanding between people and a greater global consciousness. 
Since the 1990s the term 'sustainable tourism' has become more commonly used and accepted. Essentially, sustainable tourism involves the minimisation of adverse impacts and the maximisation of positive impacts. Like the overriding concept of sustainability, definitions of sustainable tourism are many and varied with many commentators such as Swarbrooke (1999) stating that there is no widely accepted definition of sustainable tourism. Therefore the idea and definition of sustainability remain major challenges for both tourism researchers and the tourism industry.

Much literature has been devoted to the concept of sustainable tourism, yet there is no accepted definitive meaning of the term, thus there is a high level of confusion and misinterpretation. The most commonly cited definition used among tourism researchers refers to the Brundtland Report (1987) which set out a global strategy to address environmental issues and to achieve sustainable development. It defined sustainable development as "meeting the needs of the present without compromising the ability of future generations to meet their own needs". However, this definition is general and does not provide a deeper meaning of how the concept of sustainability fits with the tourism industry. Broadly speaking, sustainable tourism has been defined by Swarbrooke (1999, p. 13) as "tourism which is economically viable but does not destroy the resources on which the future of tourism will depend, notably the physical environment and the social fabric of the host community."

Paskaleva-Shapira (2001) notes that a definition such as this emphasises the needs of the industry and its sustainable use of resources is required to achieving increased social welfare, greater and more equitably distributed economic wealth and enhanced integrity of ecosystems. Much attention has also been given to the description of different perceptions of sustainable tourism and its relevance to sustainable development. For example, McKercher (1993) simplifies views of sustainable development into two groups: economically sustainable development and ecologically sustainable development and proceeds to outline the threat to tourism's survival and continued growth should either of these approaches be imposed on the tourism sector. He recognises the natural link between tourism and the environment in that it provides an obvious self-interest for tourism to protect the environment but at the same time argues that tourism is vulnerable due to its lack of recognition as a resource-dependent industry, invisibility particularly in urban areas, the complexity 
of the tourism system, and lack of leadership. McKercher concludes by stating the tourism industry must become a proactive leader in shaping the debate on sustainability.

More conventionally, academics such as Farell (1992), in Hunter (1997), interpret sustainable development as the need to find a balance between economy, environment, and society, whereby no single aspect is regarded as more important than the other. Sustainable tourism entails adequate utilisation and management of resources to achieve economic, social and cultural needs while maintaining social cultural integrity, ecological processes as well as biological diversity and resources. However, this attractive notion of sustainable tourism as balanced development is challenged by Hunter (1997) who argues in reality that trade off decisions taken on a day to day basis will almost certainly produce priorities which emerge to skew the concept of balancing each of the elements. While it is recognised that all these issues - economic, socio-cultural and environmental are crucial for the sustainability of the tourism industry it is important to note this research is particularly concerned with the environmental dimension of sustainability. Tourism and the environment are inextricably linked and dependent upon the other. As Kirk (1998) points out, the tourism industry as the world's largest industry has been viewed as a leader or global vehicle for implementing change in the area of sustainable development.

Another key challenge which is very pertinent to this research is tied to the holistic nature of sustainability, especially in its spatial and temporal scales. In sustainable tourism, the issues of scale and the global-local nexus as suggested by Milne (1998) play a pivotal role in identifying the conditions that exist for sustainable tourism to take form. As stated, concern at the global level has arisen from major initiatives such as the Brundtland Report, in 1987, and in the 1990s, Agenda 21 for the Travel and Tourism Industry (UNWTO, 1996). Meanwhile at the national level, Williams (2002) recognises the Resource Management Act of New Zealand as representing nationwide legislation focused on promoting the sustainable management of natural and physical resources. Saarinen (2006) notes the importance of sustainability in that it is not a one-way street in the global-local nexus but a matter of local, national and global responsibilities whereby it urges different political and economic actors to place a much stronger emphasis on human relations and ethics at the various scales 
to work towards a holistic idea of sustainable development. Public sector bodies at the regional or local level may be responsible for developing tourism strategies for destinations but it is the actual tourism operators who are responsible for most of the tourism products and services consumed. The same could be said for a global organisation that has no real direct influence on what a local hotel or activity operator does with regard to managing their environmental impacts. This importance and recognition of a more holistic view of sustainable tourism reiterates the rationale for constructing a set of matrices (Appendix 1) outlining the environmental initiatives of an array of tourism and non-tourism organisations that operate on a global to local scale. The next section of this chapter builds on from the concept of sustainable tourism by applying it within an urban setting in the form of sustainable urban tourism.

\subsection{Sustainable Urban Tourism}

A large body of literature exists on the concept of sustainable tourism. However, the main focus of this existing research has been on rural and protected (more natural) areas, despite the fact that over $50 \%$ of the world's population lives in urban areas (ICLEI et al., 2007) and the majority of travel occurs in cities. According to Timur and Getz (2008) the application of sustainable tourism to urban settings is relatively new, though the significance of urban areas or cities as being central to the pursuit of sustainable development has been addressed globally since the late 1980s in Chapter 9 of the Brundtland Report (1987) as a result of the world's urban growth. Diamantini and Zanon (2000) add that the city plays a pivotal role in sustainable development as it is not only the place where most of the population lives; it is also the place where the most resource consumption and waste generation occurs. Hence there is clearly a need to address issues of sustainable tourism within an urban setting. However, because it is a somewhat new concept, studies concentrating on urban sustainability do not tend to explicitly look at tourism as an integral part of development and promotion of a city. Only a few studies, such as Hinch (1996), have drawn on perspectives of urban tourism and sustainability with many studies from other disciplines focusing on the concept of 'sustainable cities' (Satterthwaite, 1997; 
Haughton, 1999; Camagni et al., 1998; Mahadevia, 2001; Chiesura, 2004; Bulkeley and Betsill, 2005; McManus, 2005). The following section attempts to summarise these works and identify connections with the fewer, yet more recent studies that are relevant to tourism.

As mentioned there is no widely accepted definition of the term sustainable development. The same can be said for the concept of a sustainable city as the term is derived from that of the concept sustainable development. It is recognised that cities are the engine of economic growth, but the environmental implications of such growth need to be assessed and managed in an effective manner. Bartone et al., (1994) state that on one hand, cities are engines of growth, yet on the other hand they represent sources of concentrated environmental problems. By aiming to incorporate considerations towards the environment into urban development decision-making a definition towards the concept of a sustainable city is achieved. According to Haughton and Hunter (1994), in Hinch (1996, p. 99) a sustainable city is: "one in which its people and businesses continuously endeavour to improve their natural, built and cultural environments at neighbourhood and regional levels, whilst working in ways which always support the goal of sustainable development."

Furthermore, Bartone et al., (1994) assert the challenge of urban sustainability is to protect the health, productivity and quality of life of cities' residents that result from their interactions with the environment that surrounds them, as well as from the changes induced by human activities. Bartone et al., (1994) further identify the most important environmental problems that cities currently face. These consist of access to basic environmental infrastructure and services, pollution from urban waste and emissions, resource losses as a result of ground water depletion, land degradation, and those resulting from natural and man-made environmental risks. Besides environmental criteria (water and energy saving, waste minimisation, etc), Chiesura (2004) adds quality of life issues are central to the definition of a sustainable city as cities possess a number of economic, social and environmental interests that need careful consideration. The way in which this range of interests has been discussed and considered in the formulation of urban environmental strategies has been through local versions of Agenda 21. While the majority of guidelines for sustainability have been written by global organisations with universal agendas, effective local, city- 
specific sustainability strategies are required to protect the integrity of resources which vary from one destination to another.

Hinch (1996) in describing perspectives on urban sustainability from within tourism summarises four basic organisational approaches to tourism which emerge as a result of the interaction between the business and urban community. These four basic approaches consist of open market, public control, industry leadership, and regulatory partnership (Figure 3). It is important to note that a variety of options exist and there is no one right way as merits of each organisational approach will differ in the context of each unique area. Perhaps what Hinch's study demonstrates is the multitude of stakeholders involved in the process of sustainable urban tourism. More recent studies (Paskaleva-Shapira, 2001; Gindl and Wukovitsch, 2005) have concentrated on identifying the role of various stakeholders and partnerships in attempting to achieve sustainable urban tourism. Mwangi (2000) argues that sustainability in urban tourism cannot be successful without the cooperation and collective action between different actors. Mwangi's statement reinforces the findings of McKercher (1993) who emphasises the need for the tourism industry to take on a leadership role if the industry is to survive. While governments have been targeted as the solution to such problems, Paskaleva-Shapira (2001) asserts resolution requires the development of consensus, encouragement and promotion of public-private partnerships, and ultimately, the involvement of all stakeholders.

Figure 3: Organisational Approaches to Sustainable Urban Tourism

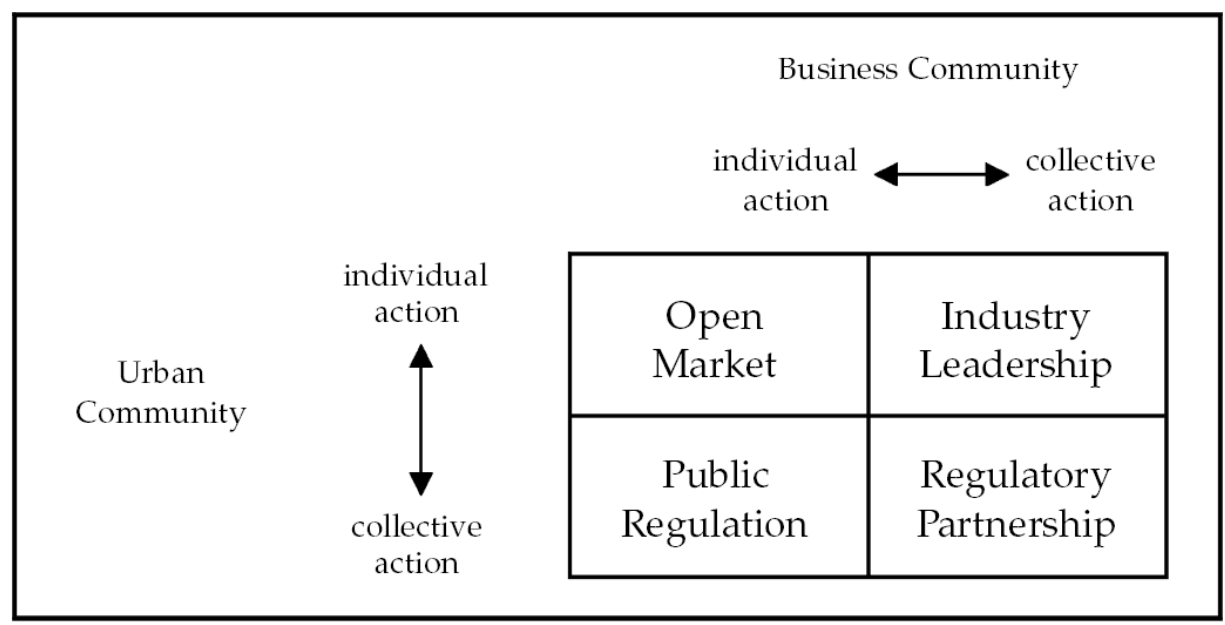

Taken from Hinch (1996) 
Stakeholder theory as noted by Sautter and Leisen (1999) suggests that an organisation is characterised by its relationships with various groups, individuals, including employees, customers, suppliers, governments and members of the community. Therefore, consideration of a wide range of interest groups is critical to identifying which stakeholders are pivotal to sustainable urban tourism. Timur and Getz (2008) reinforce stakeholder importance in sustainable tourism efforts by applying a network perspective on managing stakeholders in urban settings. Their study found destination management/marketing organisations (DMOs); hotels and attractions stakeholders have the most crucial roles in achieving inter-stakeholder collaboration for sustainable urban tourism. DMOs represent well connected players that are able manage information flows and influence others as they hold access to or possess critical resources, while hotels and large attractions may have an influence over others due to their corporate status, financial power and public image. It is evident that tourism organisations such as DMOs put emphasis on tourism marketing; however there remains plenty of scope for organisations such as this to reinforce the importance of destination development through activities which are designed to both protect and maintain the environment.

\subsection{Environmental Management}

As global environmental concerns and awareness increases, businesses cannot simply ignore such issues. There are currently a number of significant environmental threats to the future of mankind including climate change, depletion of the ozone layer, over-consumption of non-renewable resources, and global air pollution. Chan (2008) comments that due to the array of environmental problems, businesses have adopted various forms of environmental management practices as the moral, social, ethical and political arguments for taking action on environmental issues are becoming more persuasive and more widely accepted.

In order to achieve significant improvement, Ayuso (2006) claims organisations must be prepared and willing to commit to acting in an environmentally responsible manner, while Bohdanowicz (2006) suggests they also need to possess adequate 
knowledge of environmental issues pertinent to their activities and have sufficient funds to implement environmentally responsible practices. For example, Sandals and Beaches Resorts dedicate time and resources to creating comprehensive and effective environmental programmes that span all aspects of the organisation in becoming a responsible champion (Canadian Travel Press, 2007). Airlines such as Air New Zealand are making active attempts to minimise their impact on the environment and report on their progress thus far in ensuring New Zealand's clean and green image is maintained around the world (Air New Zealand, 2008).

\subsubsection{Environmental Management: Definition and Concept}

Since its emergence in the 1980s, environmental management has become a vital aspect of management for any business. Put simply by the Department of Conservation - DOC (2008a), environmental management consists of effective and active measures taken for the protection, conservation and presentation of heritage and natural resources for which a government, organisation or individual is responsible. This definition highlights the role of government at the national level in the context of New Zealand and recognises the responsibility bestowed upon tourism organisations.

For the purpose of this study, environmental management is defined as a continuous process adopted through management decisions by which a tourism organisation's activities are monitored and appropriate programmes or activities devised to reduce the negative environmental impacts (Mensah, 2006) in order to achieve and maintain a measurable improvement in its environmental performance. In developing this concept further researchers such as Meade and Pringle (2001); Melnyk et al., (2003); Hillary (2004); Mensah, (2006); Chan (2008); and Darnall et al., (2008a) have defined environmental management from the perspective of Environmental Management Systems (EMS). 


\subsubsection{Environmental Management Systems}

Meade and Pringle (2001) suggest that an important step in any organisation's implementation of EMS is to identify and introduce changes in its facilities and practices that minimise the impact of the organisation on the natural environment. Formal or strategic environmental management examine the interface between business strategy and the natural environment. Based on the Deming model of quality management, Melnyk et al., (2003) state EMS is a formal system which integrates procedures and processes for the training of personnel, monitoring, summarising and reporting of specialised information to internal and external stakeholders of the firm (Figure 4).

Meanwhile, Collins et al., (2007) notes EMSs are being adopted fast by organisations in response to heightened public pressure, economic incentives, and strong leaders with environmental values in the form of more formal strategies that extend beyond mere compliances with legal requirements. According to Chan (2008) an EMS is often developed as a response to pressure to show environmental performance and better control the organisation's environmental impact.

The ISO 14001 (International Organisation for Standardisation) EMS is globally recognised and represents the only standard against which an organisation can become certified for EMS (Chan, 2008). At its inception, scholars such as Jiang and Bansal (2003) expected firms, especially those in developed economies, to be keen to adopt it. ISO 14001 consists of five core principles: (1) environmental policy (2) planning (3) implementation and operation (4) checking and corrective action and (5) management review (Chan and Wong, 2006). Each of these core principles reiterates the cycle of the four phases: plan, do, act, and check as based on the Deming model. 


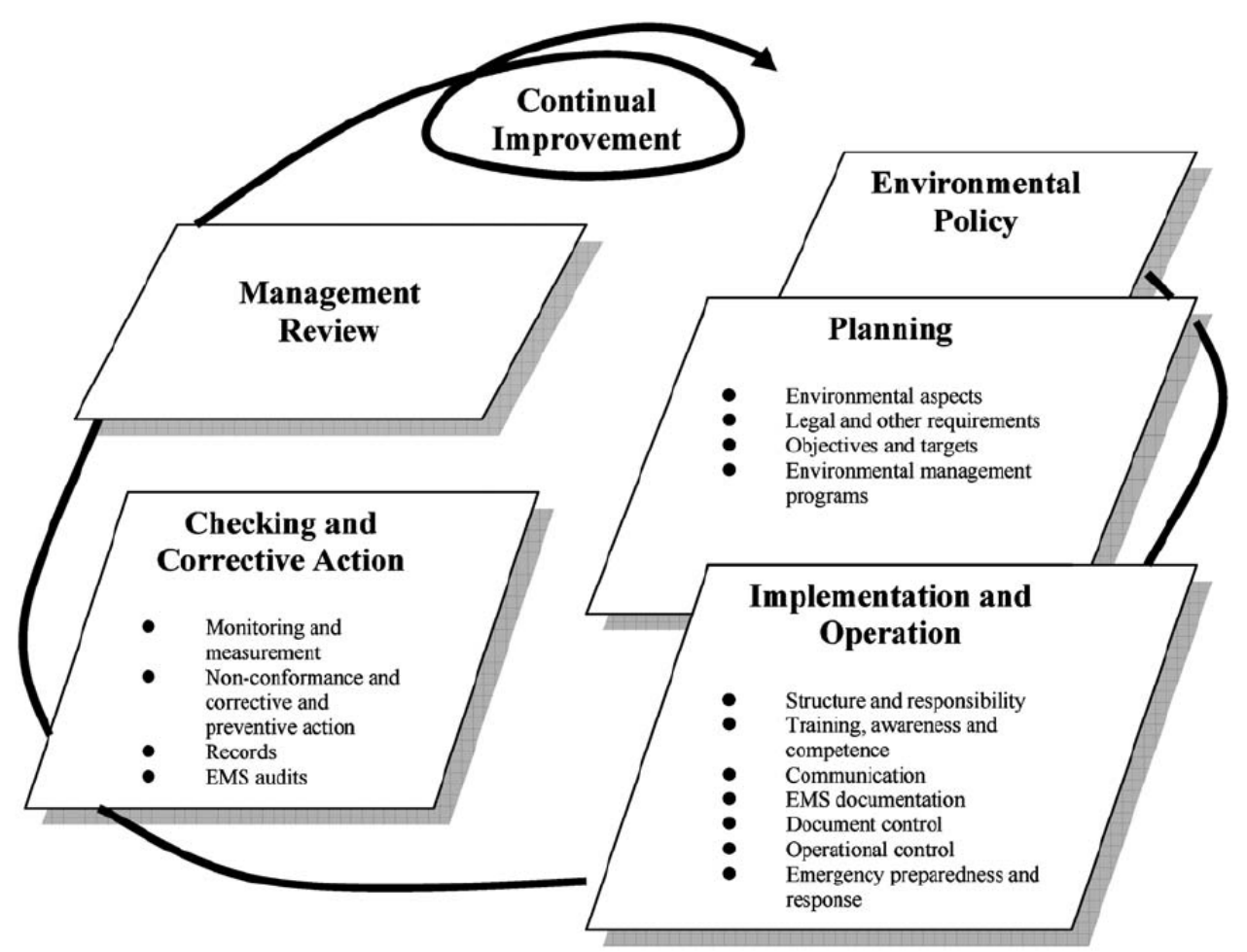

Source: Chan and Wong (2006)

While an EMS is supposed to define how an organisation will address its impacts on the natural environment some critics such as Krut and Gleckman (1998) in Darnall et al., (2008b) are sceptical of its adoption as they may only represent symbolic efforts to improve an organisation's image by merely focusing on creating and documenting environmental policies and procedures. Nonetheless, Meade and Pringle (2001) state EMS should be based on continuous improvement. In other words, organisations that set policies, objectives and targets, implement specific actions, measure the results and carry out a review of the overall effectiveness of such a programme will in the long-term optimise their environmental performance.

\subsubsection{Formal Practices}

Formal practices such as an EMS, along with others such as environmental policies (Garrod and Chadwick, 1996), codes of conduct (UNWTO, 1999b; DOC, 2008b) 
certification (Font, 2002; Tepelus and Cordoba, 2005; Font and Harris, 2004), ecolabels (Buckley, 2002), benchmarking and environmental performance indicators or auditing (Leslie, 2001; Ayuso, 2006) constitute the multitude of instruments available to tourism organisations. Chan and Ho (2006) assert the first and most critical step to implementing an EMS is to have a clear environmental policy with objectives and targets. Formal practices also referred to as planning and organisational practices by Gonzalez-Benito and Gonzalez-Benito (2005) note the extent to which organisations have defined an environmental policy, developed procedures for establishing environmental objectives, selected and implemented environmental practices, assessed outcomes of such practices and allocated responsibilities regarding the environment. All these practices are reinforced in some way or another by the presence of an EMS. Moreover, formal environmental approaches demonstrate environmental commitment as organisations' intentions are carried out, or existing actions are extended and continuously monitored (Goodall 1995, in Vernon et al., 2003) while at the same time, demonstrating their performance to the wider industry which may have the potential to influence others to adopt similar environmental courses of action (Grubb, 2007)

\subsubsection{Operational Practices}

Swarbrooke (1999) defines operational practices generally as short-term, day-to-day activities including reactive measures that usually require little planning. According to Gonzalez-Benito and Gonzalez Benito (2005) operational practices are aimed at developing and implementing methods and processes that reduce the impact on the natural environment through operational and manufacturing processes. Tourism organisations purchase and consume considerable amounts of energy and water resources therefore process related practices such as recycling, managing waste, reducing energy, and those related to purchasing are aimed at minimising the more direct impacts of a business. Activities such as these are referred to as informal or "technical or hardware" activities as opposed to the more formal "organisational or software" activities (Alvarez Gil et al., 2001) and are often synonymous with the label of 'best practice'. In reference to Mead and Pringle (2001) best practices represent the preferred actions from an environmental perspective, to perform a 
given function or service. The following section reviews issues of environmental management and formal and operational environmental practices undertaken by tourism organisations.

\subsection{Environmental Management in the Tourism Industry}

Studies of environmental management within the tourism industry have mainly focused on the hospitality sector, with a strong focus on environmental management practices undertaken by the accommodation sector and in particular among hotels (Kirk 1995; Stabler and Goodall, 1997; Alvarez Gil et al., 2001; Meade and del Monaco, 2001; Mensah, 2006; Bohdanowicz, 2006; Scanlon, 2007; Erdogan and Baris, 2007; McNamara and Gibson, 2008). This reflects the nature of the hotel industry's consumption of substantial quantities of natural resources such as energy, water and non-durable products. Kirk (1995) asserts that the industry uses considerable amounts of energy for transport, heating, air-conditioning, swimming pools, catering and laundry, all of which have a negative impact on the environment. Environmental management issues that have been of concern to the hotel industry include energy savings, water management and conservation, recycling, waste management, compliance with legislation, purchasing policy and environmental education.

Erdogan and Baris (2007) suggest that the hotel sector has been targeted as it faces increasing pressure to tackle environmental concerns as a clean environment is a basic component of quality service and part of the industry's overall perceived image. When examining the number of hotels possessing environmental policies, Mensah (2006) discovered only 58\% of hotels in Ghana had them, and Erdogan and Baris (2007) found $62.5 \%$ of hotels in Ankara, Turkey had no environmental protection programme. McNamara and Gibson (2008) in their study of accommodation providers along Australia's east coast contend larger sized facilities are more likely to have formal mechanisms in place for implementing environmentally-minded approaches. Both of these studies along with others also investigate the rates of participation of environmental management practices in relation to mainly energy, 
water and waste. As stated, these are common environmental areas of concern for the hotel sector and tourism industry at large.

\subsubsection{Energy}

Scanlon (2007) identified that $63 \%$ of hotels and resorts had undertaken energy conservation activities. Buckley and Araujo (1997) found these types of programmes to be widespread with tourism accommodation in Gold Coast, Australia. Out of 245 respondents, 56\% use energy efficient light-bulbs, $48 \%$ use energy efficient refrigerators, $31 \%$ use off-peak electricity, $20 \%$ have ceiling insulation, and $11 \%$ have key-card control systems. Energy saving potentials as Bohdanowicz (2006) discusses often depend on the size and age of hotel as well as the type of equipment installed, its maintenance and other operating procedures.

This author further adds while many people believe that newer equipment is more expensive, they are often aware that the running costs of dated appliances or machinery are frequently much higher than the initial cost of installing more modern and efficient equipment. Mensah (2006) and Erdogan and Baris (2007) reinforce this notion as using energy efficient light-bulbs and appliances were widely used to save costs in a hotel. In addition, Mensah (2006) found hotels engaging in other forms of energy sources such as gas for cooking and a much smaller number of hotels $(8 \%)$ were using solar hot water heating systems.

\subsubsection{Water}

The tourism industry relies upon the availability and quality of water as it is a vital resource to the running of a business such as a hotel. If the industry does not seek to manage and conserve water it could lead to over-consumption and higher costs to obtain quality water. Activities related to conserving water and managing it in a more effective way is common among hotels. Water conservation, as with energy, is also a cost saving mechanism. In identifying water conservation measures, Bohdanowicz 
(2006) reported the towel reuse programme, installation of water-saving fixtures, use of environmentally-friendly detergents and using an external company for laundry services. The towel reuse programme refers to guests choosing to not have their towels changed daily by accepting to use towels continually during their stay. Similar measures were also found in studies conducted by Buckley and Araujo (1997) and McNamara and Gibson (2008). Buckley and Araujo (1997) also note other measures taken such as having gardens designed for low-irrigation requirements and using dishwashers or in-house laundries with a water-saving wash cycle. All of these measures not only save water and electricity, they prolong the life of materials which has a significant influence on the total quantity of water used.

\subsubsection{Waste}

Environmental management practices have also been targeted at reducing wastage in the tourism industry. Buckley and Araujo (1997) note recycling programmes implemented by accommodation provides in Gold Coast concentrated on paper (72\%) and glass $(65 \%)$, while $77 \%$ of respondents indicated separating recyclable materials. Bohdanowicz (2006) reports similar findings with waste sorting frequently being carried out in kitchens and offices and $80 \%$ of hotels in Sweden having active wastesorting and recycling programmes. While these measures have proven popular, Mensah (2006) reports recycling of waste and composting was less common. One reason for this is managers claim recycling is expensive and not a core part in the running of their business.

When asked if governments should take an active role in waste sorting and recycling, Erdogan and Baris (2007) found many to agree with this statement indicating the wider responsibility for the public sector to take the necessary steps in order to encourage widespread activity of such measures among the tourism industry. In addition, Scanlon (2007) found 55\% of hotels participated in waste management. Common activities undertaken to minimise waste among tourism organisations include recycling, waste sorting, reusing products and materials, and composting of food leftovers. Another reason is based on the fact that managers do not possess the 
technology to perform such activities. As Dahlmann et al., (2008) stress, waste minimisation and prevention are one of several management strategies required in the process towards greater environmental responsibility for organisations.

These types of operational, resource saving programmes (energy, water and waste) as mentioned in Mihalic (2000) often result in cost reductions and are more attractive with 'environmental' managers as they are supported by greater business and political forces at the destination. However, tourism operators need to be aware of other environmental aspects that form the bigger picture of what environmental management should entail. In regards to the areas covered by environmental policies, Garrod and Chadwick (1996) point out firms place slightly more emphasis on operations, such as energy use, water, and waste management, than on marketing, purchasing and customer relations. This is often the case because businesses are more willing to implement policies concentrating on tangible cost-saving factors which show an immediate financial return. The next section attempts to summarise other initiatives that require a greater level of environmental knowledge. These are namely in the areas of supply chain management, environmental education, interpretation and training.

\subsubsection{Environmental Supply Chain Management}

The focus on environmental management has moved beyond just operational issues regarding resources such as energy, water and waste to consider the entire supply chain during the production, consumption, customer service and disposal of products (Sarkis, 2003; Jayaraman et al., 2007). The supply chain consists of all groups who are involved in fulfilling a customer request. The range of groups includes considerations with suppliers themselves, transporters, storage facilities, retailers, and at the other end, ultimately customers (Darnall et al., 2008b). Handfield and Nichols (1999) in Zhu and Sarkis (2004, p. 267), state "the supply chain encompasses all activities associated with the flow and transformation of goods from raw materials (extraction), through the end user, as well as associated information flows. Material and information flow both up and down the supply chain". As 
Seuring et al., (2008) put forward, sustainable or green supply chain management refers to managing these material and information flows as well as cooperating with other companies along the supply chain.

These activities or efforts by organisations should aim to reduce direct and indirect environmental impacts via practices involving assessment of the environmental performance of their suppliers, requiring suppliers to undertake measures that are environmentally sensitive, choosing suppliers who only demonstrate their commitment to the environment and through evaluating the cost of waste along the supply chain system. Darnall et al., (2008b) describe direct environmental impacts as those that exist due to waste during product storage, transportation, delivery, processing, use and disposal. Indirect environmental impacts refer to an organisation's suppliers or those supplies which produce inputs used in the final producer's goods, production waste and disposal. While, organisations can exert a greater level of control over their direct environmental impacts it is more difficult to ascertain levels of control in relation to indirect environmental impacts.

Nevertheless, studies like Bohdanowicz (2006) report hoteliers purchase local foods and other materials in bulk in order to decrease transport distances and many choose to align themselves with suppliers who demonstrate their commitment to the environment. In contrast, Erdogan and Baris (2007) discovered only 25.5\% of hotels in Turkey had considered the environment and local businesses in their purchasing activities. This result showed hotels had a lack of awareness in what constitutes an environmentally-conscious purchasing policy. The authors concluded that an appropriate purchasing policy which takes into account recycling, reusing, energyefficient equipment and reducing usage of materials will lead to effective waste minimisation. A well-designed sustainable supply chain management system aims to reduce costs while helping the environment. Zhu and Sarkis (2004) note that organisations take on green supply chain management practices in the hope they will actually improve environmental performance as firms form stronger linkages with their local community, develop closer bonds with suppliers who share similar beliefs and strive for similar positive outcomes. 


\title{
2.5.5 Environmental Interpretation and Training in Tourism
}

Ham (1992) and Palmer (1998) state environmental education, interpretation and training in tourism plays a significant role in working towards sustainable development. According to DOC (2005), in Grubb (2007), environmental education and interpretation refers to the communication of what is significant about places, people or events. Interpretation, in its earliest form was defined by Tilden (1957) in Ham (1992, p. 3) as: "an educational activity which aims to reveal meanings and relationships through the use of original objects, by first hand experience and by illustrative media, rather than simply to communicate factual information". As it applies to the context of the environment, and more recently sustainable tourism, a classic definition of environmental education is discussed by the IUCN (1970) in Palmer (1998, p. 7):

\begin{abstract}
"Environmental education is the process of recognising values and clarifying concepts in order to develop the skills and attitudes necessary to understand and appreciate the inter-relatedness of among man, his culture, and his biophysical surroundings. Environmental education also entails decision-making and self-formulation of a code of behaviour about issues concerning environmental quality."
\end{abstract}

In simpler terms, environmental interpretation involves translating the technical language of natural sciences into terms and ideas that are more easily understood by the general public. It also involves doing it in a way that is both interesting and entertaining to the audience. Key aims of environmental initiatives such as this are to hopefully change people's perceptions about the value of the natural world and its resources in order to teach individuals how to modify their own environmental behaviours and take on environmental activities such as recycling, reducing their own energy and water consumption, and general impact on the environment. It has been noted by Madin and Fenton (2004) that increasing the emphasis on environmental interpretation can help or reduce unfavourable impacts and foster a greater appreciation for the environment. 
What is less understood of these concepts (environmental education, interpretation, and training) is who should be accountable for implementing such environmental activities based on the recognition that tourism is a global industry operating at various levels, upon a vast range of economic, social and environmental interests. Gough and Scott (1999) recommend taking a broader view of tourism, indicating a number of target groups for sustainable tourism education and training should include employees and managers in the hospitality, travel and construction industries, government, and tourists themselves. Later research by Mensah (2006) found considerable levels of participation in environmental education and interpretation with just over $70 \%$ of hotels claiming they provided fair information to guests, and encouraged guests to try new experiences such as the culture of the fishing communities and cultural attractions around the region. The study also concluded while over half the hotels had educated guests on local customs and traditions, most hotels failed to display notices which promoted environmentally and culturally acceptable behaviour.

Bohdanowicz (2006) notes proper training and enforcement of behavioural changes among staff are potentially significant saving options yet low rates of participation reflect the lack of suitable training programmes and negative attitudes towards the effectiveness of such environmentally beneficial activities. Tourism firms who claim to be environmentally-friendly must not only undertake practices relating to natural resources such as energy and water, but strive to communicate their environmental commitment through environmental education, interpretation and training as environmental management practices should permeate all aspects of the organisation. Bearing this in mind, the chapter continues by looking at factors influencing organisations to take on environmental management practices.

\subsection{Factors Influencing Adoption of Environmental Practices}

This section will highlight the range of factors and barriers that have been identified in the literature as having influenced the adoption of environmental practices. Extensive research has been conducted on the wide range of factors or drivers influencing the adoption of environmental practices among organisations both in the 
tourism sector and other areas of business (Alavarez Gil et al., 2001; Zutshi and Sohal, 2004; Le et al., 2006; Lynes and Dredge, 2006; Kasim, 2007; McNamara and Gibson, 2008; Tzchentke et al., 2008). Previous literature has mainly approached this topic from two perspectives. The majority of studies investigating the factors influencing adoption of environmental practices tend to generally focus on one driving force at a time, while other studies such as Ayuso (2006) and Le et al., (2006) have taken a more theoretical perspective attempting to demonstrate that a complex set of interrelated motivations or factors play a role in the decision to adopt environmental practices. However, in most instances the actual influences or drivers are found to be similar and are only presented through the use of different methods. Organisations face mounting pressure from a number of sources to become environmentally-friendly. According to Bansal and Howard (1997) cited in Zutshi and Sohal (2004) these sources can be broadly divided into four main categories: the market, social, financial, and regulatory drivers (Figure 5).

Figure 5: Drivers for Sustainable Business Practices

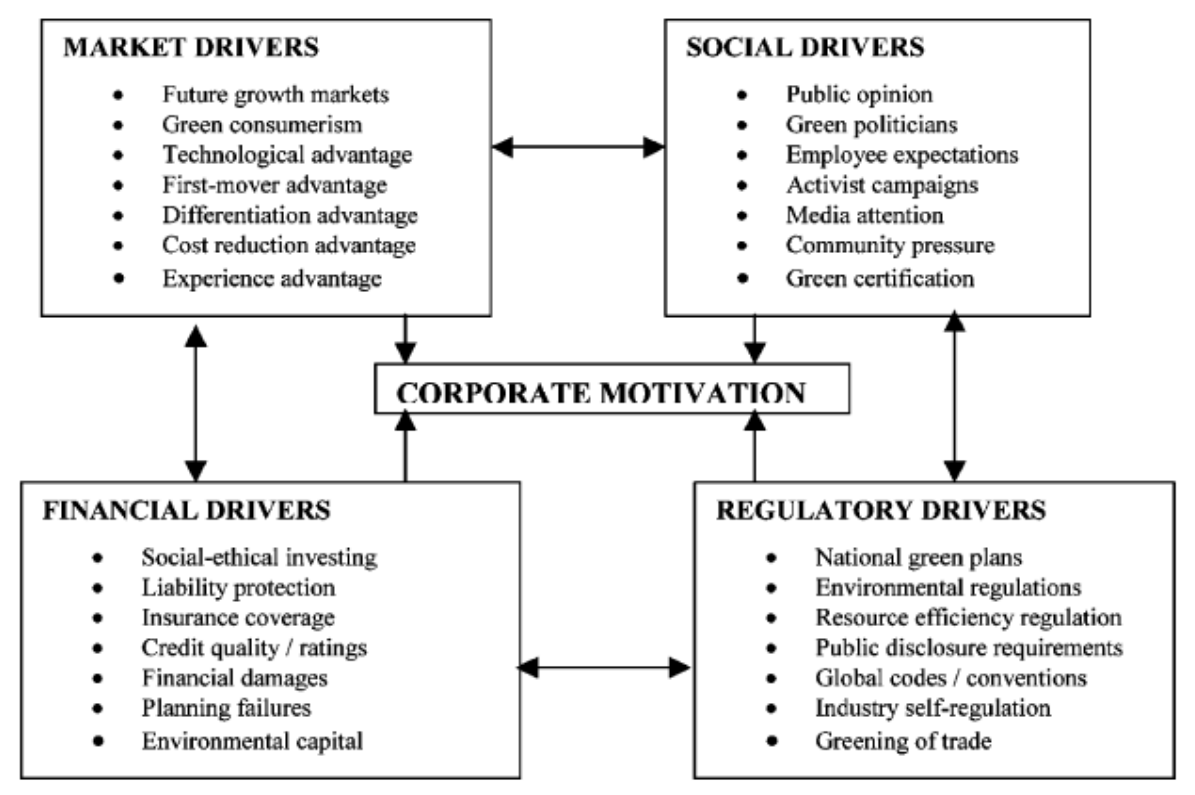

Source: Zutshi and Sohal (2004)

The market mainly refers to the outside forces which may directly impact on the competitiveness of the organisation. Chan and Wong (2006) suggest that demand for environmentally-friendly products has become a dominant force in the marketplace 
as a result of more and more individuals seeking to buy 'green' products. Due to this trend a greater number of tourism organisations are responding to consumer pressures and adopting environmentally-friendly practices to attract the so called 'green market'. This notion is reminiscent of social drivers as they include pressures from various groups such as the public, media and wider community. Other researchers such as Ayuso (2006) convey this idea through the perspective of stakeholders' influence whereby the theory suggests firms design their corporate strategies by considering the preferences of multiple stakeholders.

Tourism organisations deal with a large number of different stakeholders such as industry associations, chain affiliations, employees, customers, travel agencies, tour operators, governments, RTOs and NGOs. Kasim (2007) found that the most effective driver for hotels to adopt environmentally responsible behaviours was a top-down approach. This referred to the top-down instruction made by the head management office for all its hotels in Penang, Malaysia to be ISO 14001 certified by 2005. Moreover, evidence by Swarbrooke (1998), in Claver-Cortes (2007), claims that when organisations show a greater concern for the environment they enhance destination residents' quality of life. Therefore, locals are more likely to hold a positive view to further tourism activity in the area.

Economic or financial drivers sum up the third force. Chan and Ho (2006) identified a strong association between the economic interests of tourism firms with many organisations seeing the adoption of environmental practices as an efficient and effective way to save on costs both in time and resources. Ayuso (2006) and Le et al., (2006) record this notion from the perspective of competitive or relative advantages (Figure 6). The relative advantages mentioned most in adopting environmental initiatives are cost savings, improvement of the firm's reputation and market share. Best practices aim to improve and enhance the operational efficiency of facilities in areas such as energy, water and waste through minimising costs, allowing organisations to save more and see the benefits in the long-term. 
Figure 6: Conceptual Framework towards the Likelihood of Adoption

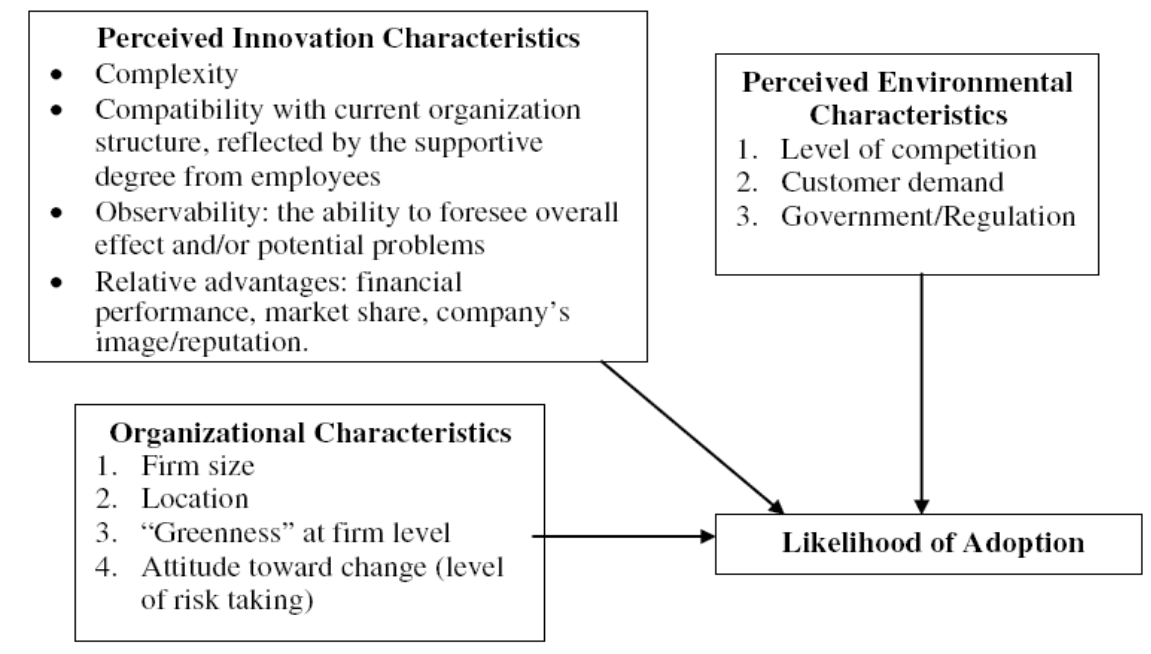

Source: Le et al., (2006)

Finally, regulatory drivers consist of the pressure from guidelines and regulations existing at the global-local level. Tourism organisations may be motivated to adopt environmental practices through self-regulation, industry self-regulation, or government regulation (Figure 7). Font (2002) and Tepelus and Cordoba (2005) report government involvement in environmentally-related matters but they both focus closely on the proliferation of environmental voluntary schemes available to tourism organisations. Darnall et al., (2008a) make reference to this driver as an institutional motivation which includes regulatory pressures, market pressures and social pressures. Again, the introductory chapter reinforces the significance of the global-local nexus to the regulatory drivers of adopting environmental management practices in the tourism industry.

Figure 7: Regulatory Instruments for Environmental Protection

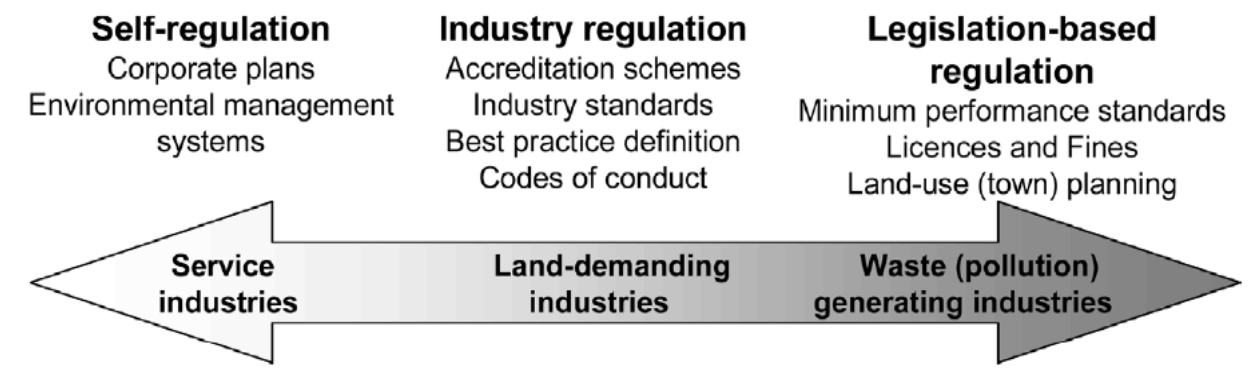

Source: Carter et al., (2004) 
Furthermore, Alavarez Gil et al., (2001) discovered that the internal characteristics of a hotel such as the age of facilities, size and chain affiliation along with stakeholder environmental pressures exert a lasting influence on the degree to which environmental management practices have been adopted by Spanish hotels. The study suggests that hotels that have been established more recently and utilise new technologies and more efficient machinery are likely to be more environmentallyfriendly than their older counterparts with less modern equipment. In reference to size, the study claims that larger-sized establishments are more likely to be environmentally friendly due to their exposure to a greater number of environmental pressures, their more visible impacts, and the role of larger organisations as industry leaders.

Larger businesses are also likely to have more resources available to them and exercise economies of scale. This idea fits in well with the third finding of the study which finds hotels under chain affiliations deploy more extensive environmental management practices. As stated by Mensah (2006) the functions carried out by hotels that refer to transfer of knowledge are vital to environmental management related matters. Hotel chains can take advantage of the successful practices of individual units and distribute them among other members of the chain. Le et al., (2006) summarise these attributes as organisational characteristics and adds to this a firm's attitude toward environmental protection and a firm's attitude towards change (Refer to Figure 6).

\subsection{Barriers of Environmental Management}

When examining the barriers to adopting environmental practices it is not surprising in the literature that there is a considerable level of overlap in previous studies' findings with the factors or drivers influencing adoption. Zutshi and Sohal (2004) discovered the costs or impediments to the adoption of EMS related to costs and time. While cost savings can be achieved as stated above, organisations often have to spend money on new and additional resources to implement systems, and allow time for employees to become familiar with the new changes. Hillary (2004) categorises 
barriers into external and internal barriers. As with factors influencing adoption, barriers to adoption of environmentally-friendly practices exist both within the workings of an organisation and also as a result of external forces beyond the control of the organisation.

According to Ayuso (2006) implementing new environmental programmes requires the unlearning of certain old assumptions and customs not linked to environmental considerations, and learning new ones that take into account the environment and the environmental impacts on the firm. Barriers to EMS have been extensively documented more recently by Chan (2008). The study which focuses on investigating the barriers for EMS adoption by the hotel sector in China reveals and interprets six factors that hinder hotels: (1) lack of knowledge and skills (2) lack of professional advice (3) uncertainty of outcome (4) certifiers/verifiers (5) lack of resources and (6) implementation and maintenance costs. These findings draw on those of Hillary (2004) as each of the six factors hindering hotels can be categorised as being either internal or external to the organisation.

Furthermore, McNamara and Gibson (2008) found that apart from high initial capital costs $(47 \%)$, other barriers included building structure (46\%), facility age/locale (34\%), uncooperative guests (22\%), lack of time (19\%), and lack of incentives (19\%). In regards to building structure the study found that many accommodation facilities were operating in heritage buildings making it difficult to alter its original and historic character. In all instances of studies which investigate the barriers to adoption the message is one of communication and cooperation. Barriers to practising environmental management need to be addressed while at the same time the benefits of adopting environmental initiatives beyond mere environmental ones need to be communicated through widely disseminated information to those operators at the 'ground-floor'. This can only be done if various stakeholders such as governments, industry bodies, NGOs, local communities and consumers themselves are prepared to formulate and effectively enforce such practices by designing various incentive schemes (Chan, 2008) that may highlight the perceived benefits of being eco-friendly. 


\subsection{Benefits of Environmental Management}

The benefits of being environmentally responsible have been widely cited in the literature and again bear considerable resemblance to some of the factors influencing adoption. Newman and Breeden (1992), cited in Scanlon (2007) suggest adoption of environmentally-friendly practices would have the following benefits: competitive advantage for green marketing, media recognition, minimisation of risks and future costs, and favourable recognition of environmental efforts by stakeholders. D'Amore (1993) reviewed Newman and Breeden's notion of benefits further by considering organisations with strong environmentally-minded leaders help build team spirit among employees, extending their environmentally-friendly behaviour to home and within the local community. Communities can benefit from organisations that demonstrate their commitment to the environment through various initiatives such as adopt a park, tree-planting, protecting a native species, donating sheets, blankets and old furniture to charities.

A study on hotel managers' attitudes towards the environment in Edinburgh by Kirk (1998) found the most significant benefits were improving public relations and fostering better relationships with the local community. The study also found hotels with an environmental policy saw the greatest benefits in relation to increasing profitability, gaining a marketing edge over competitors and favourable public image (Hillary, 2004). Other authors such as Gonzalez-Benito and Gonzalez-Benito (2005) and Bohdanowicz (2006) reaffirm these findings with Stabler and Goodall (1997) concluding businesses are more likely to take on environmental management practices if they can see the benefits in the form of reduced costs and/or higher revenues and profits. In order for tourism organisations to capitalise on the multitude of benefits of environmental initiatives, the design of appropriate mechanisms coupled with strong commitment to environmental management by all those involved, which communicate the advantages to the organisation is essential. 


\subsection{Conclusion}

This literature review has outlined the concept of sustainability with a particular focus on its connection to the tourism industry and the environment. Tourism and the environment are inextricably linked and dependent upon each other. Sustainable tourism also operates on a global-local scale indicating the need for all stakeholders to take part in the process. By exploring the concept of sustainability from an academic perspective a context by which sustainable development in tourism can be reviewed is achieved. It is recognised that sustainability is founded upon economic, socio-cultural and environmental concerns but the main focus of this research is particularly concerned with the environmental dimension of sustainability in the context of an urban setting.

While there is a large body of literature on the concept of sustainable tourism, the literature in relation to urban settings is scattered and largely focused on the concept of sustainable cities not specifically with tourism in mind. However, these studies point to a number of considerations of urban sustainability with a focus on the design of effective strategies and implications for stakeholders in tourism such as governments, businesses, employees and the wider community. Those studies with tourism specifically in mind indicate the various perspectives to approaching urban sustainability and reinforce the importance of stakeholders in sustainable tourism efforts by identifying which stakeholders are pivotal to sustainable tourism within urban settings.

In addition, this chapter has outlined the concept of environmental management. It has defined the concept in terms of specific processes: environmental management systems, formal and operational practices and highlighted the main findings of previous studies. A majority of tourism research with regard to environmental management has focused on operational practices with less emphasis on supply chain management, training and interpretation. It has also identified that the adoption of different environmental practices is dependent upon a range of different influences and barriers which to an extent are interrelated. The benefits of environmental management have also been discussed with reference to organisations. 


\section{CHAPTER 3 METHODOLOGY}

\subsection{Introduction}

This chapter sets out the methodology that has been utilised to explore the extent of environmental management approaches by tourism organisations in the urban setting of Wellington. Firstly, this chapter describes the research framework and its purpose in order to meet the research objectives as outlined in Chapter One. Secondly, attention is paid to the research design and method employed to collect and analyse the data. A qualitative approach used a face-to-face, semi-structured format to interview managers responsible for environmental management. The chapter continues by outlining and discussing a number of issues related to undertaking interviews with organisations and how to facilitate this often problematic situation. Thirdly, specific information outlining the sampling technique and reasoning behind it is discussed followed by further considerations given to data collection, data preparation and data analysis through the use of computer-assisted qualitative software. The chapter concludes with a discussion of the limitations of this study.

\subsection{Research Framework}

In order to identify and examine the environmental management approaches by tourism organisations in Wellington a number of steps were taken by the researcher. Extensive research was conducted through a wide range of secondary source material in order to build an overall picture of existing knowledge on the research problem which in turn informed the development of the primary research. This primary research was undertaken by a qualitative approach in the form of semi-structured interviews with individuals in charge of environmental management.

The first stage consisted of a review of the literature relevant to the concept of sustainability and sustainable development in terms of the concept, its definition and its use within studies to date, for example McKercher, 1993 and McCool et al., (2001). From this preliminary review, the researcher was able to narrow the focus of 
sustainability by looking deeper into the concept and how it has been adopted by the tourism industry. In particular, how environmentally sustainable tourism fits into an urban setting among tourism organisations and its implications for tourism organisations as discussed by Bartone et al., (1994); Hinch (1996); PaskalevaShapira (2001); and Timur and Getz (2008). On gaining an understanding of sustainability and all its related themes the researcher was able to extract the environmental dimension of the concept of sustainability and continue the literature review by looking more specifically at the concept of environmental management in terms of its type: operational or formal/strategic practices (Scanlon, 2007, McNamara and Gibson, 2008), factors influencing adoption (Alvarez Gil et al., 2001; Le et al., 2006) and barriers to environmental management (Chan, 2008). A review of each of these segments of literature enabled a more thorough and precise understanding of the concepts and examples which was required to build a sound knowledge of the current streams of literature and subsequently identify any gaps which are pertinent to the main objectives of this research.

Glesne and Peshkin (1992) argue that secondary research prior to the collection of data may contaminate primary research findings through leading the researcher to seek what was expected. However, in the case of this thesis, the importance of secondary data was necessary in establishing the spatial and temporal development of sustainability in tourism by accounting for the complex processes occurring at the global level, down to the local level as seen by Figure 2 in Chapter One. Hence, the major purpose of using secondary data was to gather broad information on the general setting of this area of study. To fulfil this purpose and facilitate further understanding of the area of study a series of matrices were constructed to both inform the direction and content of the interviews (Appendix 1).

At the global level, sources of information were based on TNCs and global financial institutions that shape the nature and progress of tourism development (UNWTO, 1996; Swarbrooke, 1999; Edgell 2006; Green Globe, 2007), and guide the processes occurring at the lower levels of the hierarchy. National sources i.e., those specific to New Zealand were focused on organisations that have been established to ensure New Zealand's environment is managed and maintained to benefit future generations (Memon and Perkins, 2002; Williams, 2002; Ministry for the Environment, 2008c), 
and the more specific tourism organisations (New Zealand Tourism Strategy Group, 2007; Ministry of Tourism, 2008) that aim to protect and enhance New Zealand's environment. Regional and local sources have concentrated on organisations such as the regional and local city councils with regard to their role and relationship with the environment through key policies and future priorities. Hence, the global-local nexus (Milne and Ateljevic, 2001) provided a useful framework for identifying issues at each of the various levels of working towards urban environmental sustainability.

\subsection{Research Design and Method}

The next stage consisted of undertaking primary research with a number of tourism organisations in Wellington. As a requirement for primary research, human ethics approval by the university was granted prior to any data collection. Primary research undertaken contrasts with the secondary as more intensive research through qualitative, face-to-face semi-structured interviews provided more detail and therefore aided further interpretation. The semi-structured interviews were conducted with managers responsible for environmental management in each tourism business or organisation. This method was aimed at gathering factual material and eliciting information on the motives and processes through which tourism organisations approach environmental management. Conducting interviews face-to-face (as opposed to other methods such as by telephone) was deemed to be preferable in order to gather and obtain information-rich data thus gaining a better insight into the organisations' perspectives on the approaches towards environmental management.

Employing a qualitative research design was believed to be most appropriate by the researcher. As Patton (2002, p. 341) states, "qualitative interviewing allows the researcher to enter into the other person's perspective - under the assumption that the perspective of others is meaningful, knowable, and able to be made explicit." Meanwhile, Davies (2007) suggests that the aim in qualitative research is not to emerge with findings that are statistically representative of a given population but rather explore subjective patterns. In this research, the aim referred to the experiences with regard to environmental management approaches by tourism 
organisations in Wellington and being able gauge what meaning they had for the people involved, to compare this with the views others have of them, and to properly account for and consider the situational context of the research problem.

Qualitative interviews can be likened to conversations (Rubin and Rubin, 2005) whereby a researcher gently guides a conversational partner in an extended discussion eliciting depth and detail about the research topic by following up on answers given by the interviewee during the course of the discussion. In contrast, quantitative survey research asks respondents exactly the same questions so unlike interviews, this method does not allow for a unique conversation whereby the depth of the discussion is open to what each interviewee knows and is willing to share. Furthermore, there are many approaches to qualitative interviewing that differ in terms of how narrow or broad the interviewer's questions are. Many contemporary texts such as Rubin and Rubin (2005) loosely differentiate qualitative interviews as unstructured, semi-structured and structured interviews.

According to Flick (2006), there are two broad categories of qualitative interviews that differ in how the overall research project is carried out: cultural and topical. While a cultural type of interview has no preset agenda of issues to cover allowing flexibility in what is discussed in any conversation, topical-research interviewing is based on an initial topic chosen by the researcher. A fair amount of time and effort in finding the right interviewees most likely to know the answers is required as the researcher tries to make sure the conversation stays on target whilst listening carefully to learn the various perspectives of the chosen respondents (Rubin and Rubin 2005; Flick 2006). The latter form of interview style relates to this particular research as the initial topic was environmental management and so the questions asked were related to various elements or aspects of environmental management which were developed as a result of the extensive literature review (Chapter Two) and background research concentrated on the broad context (Chapter One).

Another way in which authors have attempted to consider interview styles is summarised by Patton (2002). He refers to the general interview guide approach and the standardised open-ended interview. The former involves outlining a set of issues that are to be explored with each research participant before interviewing commences. 
Essentially, the guide serves as a basic checklist during the interview to make sure that all relevant topics are covered. In contrast, the standardised open-ended interview consists of a set of questions carefully worded and arranged with the intention of taking each respondent through the same sequence and asking each respondent the same questions. Based on the above interview types, a semistructured interview style was deemed to be the most appropriate for this study as the use of semi-structured interviews with a number of pre-determined questions allowed for some comparison between the responses of participants, and allowed for the opportunity to probe further when appropriate. As Flick (2006) states, semistructured interviews differ from unstructured interviews in that they have a flexible agenda or list of themes to focus the interview which enable the social interaction to be recorded authentically. This was of importance to the researcher as the questions were developed as a result of the themes or ideas outlined by various documents and the reviewed literature where tourism organisations should be taking responsibility for their environmental impacts. Moreover, as found by DiCicco-Bloom and Crabtree (2006), this interview style allows for other questions to emerge or prompts to be made from the dialogue between the interviewer and interviewee.

The standardised open-ended interview was felt to be best suited to this research enquiry because in most cases respondents were asked the same questions in the same sequence but bearing in mind that the interview might not always follow this pattern. The importance of a standardised open-ended interview rests in minimising variation in the questions posed to interviewees. Also, Patton (2002) suggests it makes data analysis easier because it is possible to locate each respondent's answer to the same question quickly and to organise questions and answers that are similar. Two interview schedules were designed prior to data collection (Appendix 2). One schedule was purposefully written for individual tourism operators (businesses) whilst the other schedule was fitted to the research requirements for interviewing external, industry or sector organisations. The questions posed in the former interview schedule were grouped accordingly into various sections i.e., business profile, environmental management issues, environmental management approaches, factors influencing adoption and barriers hindering adoption to ensure wide coverage of a diverse yet inter-related set of questions or areas of research enquiry. 
Furthermore, combining both approaches provided some flexibility in probing and determining appropriate times to explore some subjects in greater depth or to pose further questions that may not have been originally anticipated in the initial development of the interview schedules. For example, respondents were asked to outline the nature of various environmental management strategies and practices. Here, information specific to the organisation was anticipated to be found. So, by stating a general topic or issue to be covered the researcher could let the conversation flow much more freely and then probe respondents where it seemed appropriate. While the interview style and design have been outlined in general, more specific considerations by the researcher needed to be taken into account when conducting interviews with organisations to overcome this often problematic situation. The following segment of this chapter outlines some of these issues as found in the literature.

\subsection{Interviewing Organisations}

Previous literature has highlighted a number of issues related to undertaking interviews with organisations. Irvine and Gaffikin (2006) summarise these issues as getting into the organisation (getting in), conducting the research (getting on) and finally exiting the organisation (getting out). Firstly, getting access into the organisation can be constrained by the financial background of the research project, the nature of organisations, the role of individuals and 'gatekeepers'. A gatekeeper as described by Jennings (2005, p. 107), is "a person who may enable or prevent researchers gaining access to potential interviewees by way of sanction." In the case of this thesis, the overall diversity amongst the various tourism sectors meant that the researcher needed to allow a lot of time in overcoming this common issue. However, the researcher was fortunate in some instances whereby already existing contacts within the industry were able to alleviate this as they could suggest and forward research enquiries over to other relevant, prospective interviewees.

Another equally important issue refers to the social relationships between the researcher and those being interviewed. It is both crucial and ethical to allow 
respondents' understanding of the aims of the study and to develop their feeling of the researcher's trustworthiness. "The process of establishing rapport is an essential component of the interview as it involves trust and a respect for the interviewee and the information one shares." (DiCicco-Bloom and Crabtree, 2006, p. 316). For this research, all interviewees were briefed about the aims of the study prior to the interview over the telephone and again in person. In some cases, particularly with larger organisations, the interviewer had acquired some institutional knowledge on the background of selected organisations to achieve this sense of trust. The success of an interview will largely depend on the amount of time given to establishing rapport with the respondent.

Finally, a third issue recognised by Yeung (1995) related to interviewing in organisations is withdrawal. This refers to the way in which the researcher detaches one's self from the organisation and is often relevant in times of prolonged research. However, this research only comprised of one single semi-structured interview so getting out was not so much of an issue. Despite this, all respondents were informed that they would receive a summary of the findings at the completion of the research. Yeung (1995) suggests that these reports should be written in ways useful to the organisation; they should be narrative and descriptive, rather than academic. In other words, reports should be presented in a way that is both adaptable to the industry and is strongly targeted at the sample under investigation.

\subsection{Sample}

Collier and Harraway (2001) state that New Zealand's tourism industry consists of the following sectors: transportation; accommodation; attractions and activities; and sales (more commonly known as the travel sector). Based on this categorisation it seemed logical to concentrate on each of these sectors with the exception of sales as this sector is subject to different conditions from those businesses that are 'at the coal-face' of the tourism industry. By identifying the various tourism sectors a sample was able to be drawn out. The sample under investigation in this study consisted of tourism organisations situated in urban Wellington. In the context of this 
research, urban Wellington refers to Downtown Wellington city and the surrounding city suburbs (Figure 8). The sample was purposefully based on tourism providers across the main tourism sectors as mentioned above. Each of the organisations identified was drawn from the RTOs website with the exception of external agencies. To assist in the break-down of the number of tourism providers in each of the main sectors as noted above, the RTO, PWT, was contacted to seek the exact number of operators in each of the main tourism sectors in urban Wellington as at July 2008. The source by which the sample was drawn from confirmed the suitability of limiting the investigation to the transportation, accommodation, and attractions and activities sector; as it ensured that the diversity of the tourism industry in urban Wellington and their various perspectives in regards to environmental management was reached.

Figure 8: Location of Research Sample - Wellington, New Zealand

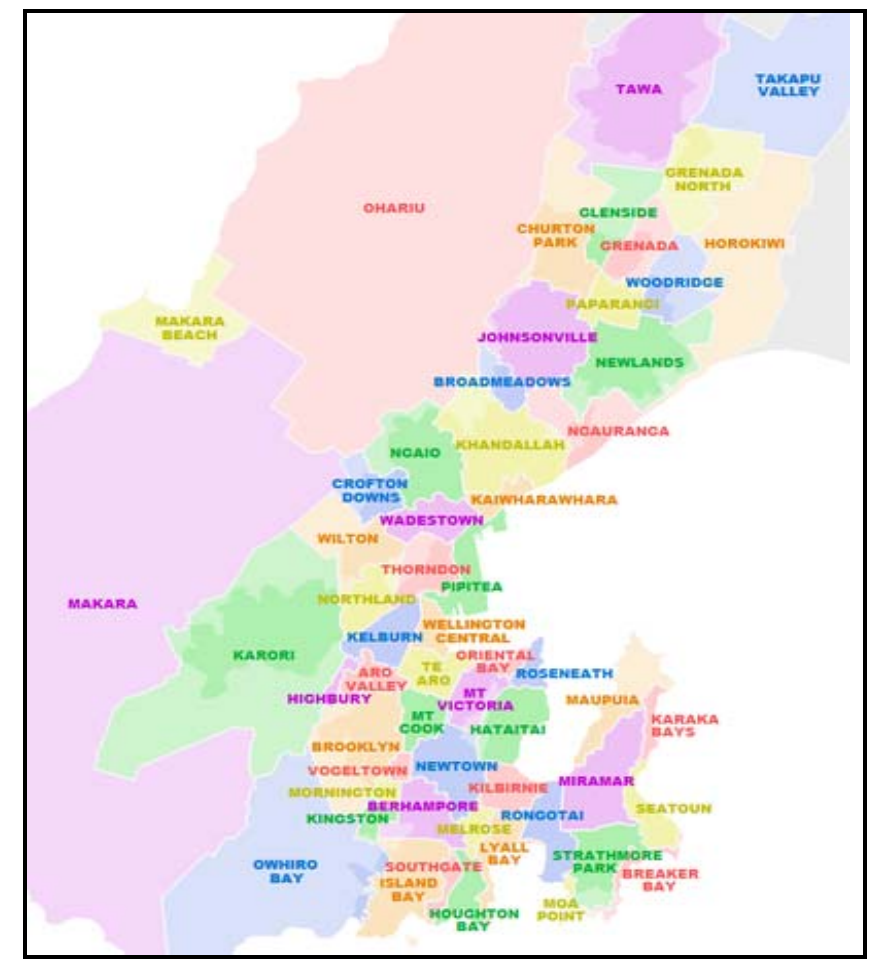

Source: WCC, 2008.

From the chosen three categories, a total of 111 tourism organisations were contacted and a total of 60 interviews were conducted. Fifty-five of these comprised actual tourism businesses or operators while the remaining five organisations were external 
agencies. Therefore, the response rate for this study was $54 \%$. The following table outlines the breakdown of the sample population and the amount of data collection.

Table 1: Research Sample - Data Collection

\begin{tabular}{|l|c|c|c|}
\hline \multicolumn{1}{|c|}{ SECTOR } & \multicolumn{2}{|c|}{$\begin{array}{c}\text { No. Contacted } \\
\text { from Sector }\end{array}$} & $\begin{array}{c}\text { No. of } \\
\text { Interviews } \\
\text { Conducted }\end{array}$ \\
\hline & $\mathrm{n}$ & $\%$ & $\mathrm{n}$ \\
\hline Accommodation $(\mathrm{n}=131)$ & 52 & 39.7 & 28 \\
\hline Attractions/Activities $(\mathrm{n}=140)$ & 34 & 24.3 & 21 \\
\hline Transport $(\mathrm{n}=40)$ & 20 & 50.0 & 6 \\
\hline External Agencies* $(\mathrm{n}=10)$ & 5 & 50.0 & 5 \\
\hline TOTAL $(\mathrm{n}=321)$ & 111 & 34.6 & 60 \\
\hline
\end{tabular}

* Estimate, not taken from Positively Wellington Tourism.

NB: Figures are rounded so may not add up to $100 \%$

A strategic and purposive sampling method was employed in this research. Davies (2007, p. 144) suggests this method is particularly used when the aim is to "quite explicitly select people, objects, situations, or experiences that will help explore the research problem and enable development of theoretical ideas, giving the opportunity to test them before reaching a conclusion." Meanwhile, Patton (2002) states that the logic and power of purposeful sampling lie in selecting information-rich cases for study in depth from which one is able to learn a great deal about issues or topics of central importance to the purpose of the enquiry.

"Studying information-rich cases yields insights and in-depth understanding rather than empirical generalisations. It focuses on selecting information-rich cases that will illuminate the questions under study. It is sometimes called judgment sampling, in that you decide the purpose you want informants to serve, and you go out to find some." (Patton, 2002, p. 230) 
A number of factors needed to be considered when gathering the sample in order to ensure a reasonable spread of expressed views and to maximise the depth and richness of the data to address the research question. Due to the diversity of the tourism industry the researcher considered a range of respondents based on different tourism product or service types, different sizes and scales (large and small), different locations within urban Wellington, and different sub-categories of each of the three sectors. For example, within the accommodation sector a range of hotels, motels, bed and breakfast operators and backpackers were considered. Also a conscious effort was made to select businesses or operators that were Qualmark rated (star graded) and those that were not. While one might assume that those organisations that were at the forefront of environmental management by reputation would be expected to carry out formal methods and practices, this perhaps may not have been the case in reality. As Davies (2007) comments, purposive sampling has the ability to challenge assumptions or on the other hand, confirm previously held beliefs of the researcher.

At this stage of the recruitment process it was also important to determine who the best person to interview would be e.g. managers in charge of environmental management. Identifying respondents for interviews can be problematic in some situations. Therefore, telephoning and 'fishing' (Healey and Rawlinson, 1993) for a named person who could best handle the enquiry was utilised in order to overcome the difficulty of finding the right person. Once a named person was located, a conversation over the telephone could commence to inform the potential respondents of the nature of the research and provide further information if it was needed. According to DiCicco-Bloom and Crabtree (2006) the sample of interviewees should be fairly homogenous and share critical similarities related to the research question. Respondents were also sent a copy of the information sheet and consent form (Appendix 3) outlining the nature of the research and its objectives via e-mail prior to the interview to familiarise themselves with the content of the interview and the amount of information and knowledge that it would entail. Prior knowledge of what is required of an interview is a common courtesy and can prove very helpful in setting the scene and guiding the respondent through the interview process. 


\subsection{Interview Guide and Process}

As noted above, two interview schedules were designed for this research in order to gather and collect relevant data and information into the various perspectives of tourism organisations and their approaches towards environmental management. The series of matrices constructed in the research (Appendix 1) and global-local influences described in Chapter One are reflected in the questions posed in the interviews.

At the outset of the interview, respondents received a verbal overview of the research being undertaken, the research objectives and in terms of how it would be of benefit and add to a better understanding of their approaches towards environmental management for the researcher and themselves. A wide range of questions being asked by the interviewer were designed and considered to explore the research problem. Firstly, mention is given to the interview schedule concerning individual tourism businesses i.e., tourism operators selected from the three sectors. Each interview commenced with a short series of questions related to the characteristics of the business (Section One of Appendix 2: Interview Schedule for Individual Businesses). Here, information sought by the researcher consisted of general information about the business.

Drawing on interview etiquette (DiCicco-Bloom and Crabtree, 2006), the first question was broad and open ended to reflect the nature of the research and be nonthreatening. To further stimulate a positive interview, a series of questions aimed to identify the business demographics was used to allow the subject to feel at ease and answer questions with which they were more likely to be familiar with e.g. type of product or service/sector, number of years of operation, and number of employees. This approach placed the subject in a relaxed frame of mind which allowed the interview to proceed with further open-ended questions with prompts where necessary. It also provided the researcher with background knowledge of the business.

The next series of questions focused on general environmental management issues in order to gain a preliminary awareness and understanding by the respondent for the 
topic under investigation. Participants were asked to define environmental management, describe global environmental issues and those more relevant to their business as well as comment on the impacts of their business on the environment and as a consequence, discuss their organisation's management of these issues. It was envisaged by the researcher that the data collected in this section would provide a frame for more in-depth discussion in the following sections of the interview schedule by obtaining a sense of the respondent's background knowledge of the topic.

The third section concentrated on questions that asked respondents about the types of approaches currently carried out by their organisation. The purpose of this section was to elicit more specific and in-depth information about the nature of their practices. At this stage respondents were also prompted on various aspects of environmental management such as the nature of their environmental strategies (if any), environmental impact assessment, and issues related to staff, visitors, and their supply chain. Operators were also asked about the type of outside involvement (if any) that they had regarding environmental management. To delve into this sub-topic further a more specific question was targeted at respondents to find out what they believed the role of RTO) or other external public and private sector agencies should be regarding environmental management for tourism organisations.

The fourth section dealt with the factors and barriers influencing adoption of environmentally-friendly practices and also sought to collect data on what respondents saw as the advantages and disadvantages of environmental management. It was assumed that there was likely to be some common responses among each of these questions but the purpose of asking about the advantages and disadvantages was to consider this from not only the perspective of their own organisation but also to think about the benefits for tourism businesses in general based on their own prior knowledge. Respondents were also invited to make any further comments on the topic at the conclusion of the interview. This was done to provide an opportunity for respondents to reflect on their words and at the same time explore any further relevant areas of research enquiry into the topic that otherwise may have been overlooked.

The interview schedule designed and targeted towards public and private sector agencies followed a similar format. However, it was more specific to the research 
requirements of identifying the role and relationship of these organisations to individual tourism businesses regarding environmental management. The first section, like the former interview schedule was concentrated on gathering business demographic data relevant to the organisation in terms of its current size, range of membership (if applicable), number of years of operation and number of employees. The second section dealt with finding out about the role each organisation played with regard to environmental management including what sort(s) of information and advice were provided to businesses and current environmental initiatives or activities in place.

Following this, further data was obtained on the nature of relationships with tourism businesses and environmental management. The fourth section of this schedule mirrored the third of the former schedule as it was believed by the researcher that if these external organisations were providing information and advice etc then they should realistically be consciously practising environmental management in their respective organisations. Again, at the conclusion of the interview with these agencies, respondents were given the chance to reflect on their words and offer any lasting comments that may have otherwise not been heard. By producing two interview schedules for each of the respondent categories it meant the researcher was able to identify any existing patterns and compare responses across both groups to either support and reinforce what tourism businesses had said, as well as contrast the various perspectives found as a result of this course of action.

The interviews were conducted at a steady pace which allowed time for reflection before opening new fields of discussion on the set of predetermined themes as set in the interview schedules. During the interview process the interviewer had to be prepared to depart from the planned itinerary during the interview because digressions at times proved to be very productive following the interviewee's interest and knowledge of the topic. Although quality information could be gathered, it was also necessary to direct the interviewee's attention back to the list of predetermined themes if they began to trail off topic in an unrelated manner. At the conclusion of the interview, subjects were personally thanked by the interviewer for their time and participation in the research process, followed by a verbal reminder that a summary of the results would be emailed after the thesis had been completed in keeping with 
the commitments of the university's human ethics approval which was formally obtained prior to any data collection.

\subsection{Data Preparation and Method of Analysis}

The majority of interviews were tape-recorded with formally written consent and later transcribed. According to Flick (2006) transcripts of audio recording provide superior accounts of the natural interaction within an interview. Furthermore, excerpts from transcripts allow the voices of the participants to be heard providing evidence in terms of the multiplicity of views. However, transcribers may often have difficulties capturing the spoken word in text form because of sentence structure, use of quotations, omissions and mistaking words or phrases for others. DiCicco-Bloom and Crabtree (2006) argue that people often speak in run-on sentences so at times the researcher was forced to make judgement calls which may have altered the meaning of an entire sentence. Audio recording is very common in qualitative methods because when one listens to an interview afterwards they will hear much more than one could have ever written down. Davies (2007) refers to this as the 'the art of hearing'. A conscious effort by the researcher was made to listen to the recordings while overseeing the transcripts in order to correct any inaccuracies and aid interpretation. The transcription of the data allowed credible conclusions to be made by the researcher.

For the remaining interviews the answers given by respondents were recorded in written form. This was often the case when respondents did not want to have their voice recorded. Written responses tended to be much briefer than those recorded so accuracy in noting exact phrases or sentences may not have been achieved in full. Nevertheless, a wide range of responses on the perspectives of environmental management approaches by tourism organisations were obtained by the researcher. Additional notes were also taken by the researcher when respondents referred to materials found online or showed various documents relevant to their environmental management strategies in person to serve as a reminder to follow up on these potentially valuable sources of extra information. All of the interviews lasted 
approximately thirty minutes and were conducted between 18 August and October 30, 2008 at each of the tourism organisations chosen or at a suitable location convenient to both the researcher and the prospective interviewee at the time.

A 'template approach' (DiCicco-Bloom and Crabtree, 2006) was used to code or theme segments with similar content into separate categories. The semi-structured nature of the interviews meant that this process was made easier by the fact that the themes or questions being asked reflected the structure of the interview schedules. After initial data preparation and reduction the researcher employed computerassisted qualitative data analysis software called NVivo 8. Sandiford and Seymour (2007) argue qualitative software programmes can be a very helpful tool in sorting, managing and querying data. Davies (2007) claims that software packages such as NVivo have transformed the time-consuming and often complex tasks of analysing qualitative data 'by hand' giving the researcher more time to think about the meaning of the data (Silverman, 2005) as the software will not analyse the data itself.

Firstly, themes had to be identified by the researcher. This was made easier by the fact that the research had employed a semi-structured interview technique. Moreover, the flexible nature of NVivo provides the ability for the researcher to alter original data files such as the transcripts of the interviews. In the case of this research, this was done after they had been coded by question number and exported from Microsoft Word. The final section of this chapter highlights the limitations and offers a critique of the methodology in light of the problems that were encountered particularly during the data collection stage.

\subsection{Limitations and Challenges}

As with any piece of research there are a number of inherent limitations that can be identified. It is recognised that qualitative research undertaken through semistructured interviews is not based on statistical evidence. Qualitative research compared with quantitative research is subjective and can often be very open and exploratory with a number of themes or sub-themes under investigation. While this 
research allowed for discussion to flow openly throughout the semi-structured interviews caution was made to ensure that respondents did not divert their attention away from the topic and answers were limited due to the need to retain the semistructured nature of the research.

In addition, this piece of research is not entirely representative of the general population. This point further reinforces the use of a qualitative approach. However, a conscious effort by the researcher was taken to consider the various tourism sectors and sub-sectors by working within a sample obtained from a reliable source, PWT. The research comprises operators of the three main tourism sectors, namely accommodation, attractions and activities and transport. Each of the operators is located within urban Wellington, and not the Greater Wellington Region as the purpose of this research was to investigate urban environmental management approaches. As a result, this research excludes holiday parks, a sub-sector of accommodation whereby these operators are situated outside of urban Wellington.

Data collection took place during the tourism off-season. Due to the fieldwork being carried out in winter between the months of August and October, responses may have partly excluded those operators affected more by seasonality. For this particular research it seemed this was the case with smaller operators such as B\&Bs who were unable to be contacted because they may have only operated during the summer peak. However, this constraint is counteracted by the fact that conducting the research during the peak season may mean that operators may not have been able to participate because of limited time due to a busy summer schedule.

Some businesses chose not to be interviewed as they may have felt that they were not suitable enough for the research. In other words, some may have thought they were not adequate in their approaches towards environmental management to answer the research questions posed by the interviewer, or they were too busy because they were in the process of implementing environmental management systems. However, a number of businesses and organisations that were interviewed were actively engaged in the process of establishing, implementing and upgrading their environmental management systems. It was noted that many businesses and organisations interviewed were in the early stages of incorporating environmental management 
into their organisation, while some were working their way through the process, others were well established in their methods of environmental management.

To ensure that a variety of businesses' perspectives and their respective level of environmental management were collected the onus was on the researcher to explain to potential respondents that the objective of the research was to explore current environmental management approaches and not to limit the investigation to those organisations who were only actively practising environmental management. One might assume that some businesses may have declined because they did not exercise any form of environmental management or did not have a sound knowledge or awareness of the topic (particularly smaller businesses). While, in contrast to this, it could be suggested that some businesses did not want to disclose information on their organisation's strategies if they viewed it as being commercially sensitive or a possible source of competitive advantage.

Many of the limitations that are outlined above are inherent to the research process. Despite this, researchers need to be aware of the effectiveness of their research by critically assessing their chosen methods and thinking about what they might do differently if they were to repeat the research. It is difficult to state any significant changes that would be made by the researcher as many of these are dependent on the circumstances at the time. However, consideration needs to be given in light of the research process.

The above section which details the choice of research design explains why the researcher has chosen this design. Conducting similar research by taking a more quantitative approach could be deemed as not suitable enough to capture the depth and openness of the topic as a semi-structured interview style offers flexibility in gaining the perspectives of a wide variety of tourism organisations. Furthermore, the views of organisations may not have been fully captured in their most authentic form if survey questionnaires were given to them to fill out on their own. Here, answers may have been much more brief and perhaps only cover possible intentions and not real actions. Dealing with organisations in a more in-depth, face-to-face approach also provided the chance to establish a rapport and a greater sense of trust with 
respondents so that the interviews could run smoothly, something which cannot be obtained as easily through quantitative methods.

\subsection{Conclusion}

This chapter has outlined the qualitative approach utilised as part of this research in order to address the research objectives described in Chapter One. It has identified that taking a qualitative approach through the use of semi-structured interviews is an appropriate method for exploring the perspectives and experiences of businesses with regard to environmental management. A semi-structured approach offers a degree of flexibility while at the same time has a number of predetermined themes. The range of themes that were included in the final interview schedule were a result of the themes or aspects of environmental management described in the literature and general context of this study.

The main issues related to conducting interviews with organisations have been discussed and can be summarised as getting in, getting on and getting out. It is important to understand such issues and the ways in which to overcome them to ensure a smooth interview process. This chapter has also explained the sampling process, appropriate use of NVivo for the analysis of this study and concluded with a number of research limitations, with reference to specific issues that were faced during the data collection phase. Many of which, are inherent of the overall research process and may possibly contribute to the findings of this particular study. 


\section{CHAPTER 4 ENVIRONMENTAL MANAGEMENT APPROACHES AND PRACTICES}

\subsection{Introduction}

This chapter focuses on the findings from the interviews. The results are presented under a number of themes. Each theme seeks to address the objectives of this study by investigating the extent to which tourism organisations in Wellington are practising environmental management. The chapter commences by outlining the characteristics of those interviewed to form a profile of the respondents. Next, this chapter focuses on the different environmental management approaches and draws on certain aspects of environmental management such as supply chain management, training and interpretation. At this point, the level of importance which tourism businesses place on environmental management and their level of involvement with other organisations are analysed. As it is not possible to report all responses a representative range of quotations from research participants are used to illustrate and capture the multiplicity of views held by tourism organisations in Wellington regarding environmental management. Respondents are identified by tourism sector and number to protect and maintain privacy.

\subsection{Business Profile}

As stated in the previous chapter, this research focuses on tourism organisations in Wellington. A sample of 55 tourism businesses and five industry organisations were interviewed to investigate the approaches towards urban environmental management. In terms of the age of tourism businesses, over half $(60 \%)$ had been operating for less than 20 years. Approximately $60 \%$ of businesses employed between 1-9 full-time people and just over 15\% of businesses employed between 10-19 full-time people indicating the significance of smaller firms in this research. Interviewees were also asked to identify their role within the business. General Managers, managers of a 
particular department among larger businesses and owner/operators for smaller businesses made up the range of respondents. Such diversity of interviewees relates back to the size of the business. In addition, while respondents were not asked about their location, the majority of businesses as expected, operated in a built environment with a small number of other businesses conducting all or part of their business in natural areas.

\subsection{Environmental Management Approaches}

Overall, respondents showed a high level of general awareness in terms of global environmental issues and in managing their firms' impacts on the environment. This finding demonstrates that there have been active steps taken towards environmental management. As Mensah (2006) suggests, environmental management is a continuous process consisting of effective and active measures taken to manage, protect and monitor activities undertaken to reduce negative impacts on the environment. To meet the research objectives set out in Chapter One, interviewees were asked to describe their approaches towards environmental management. Chapter Two identified two main methods for environmental management (1) formal and (2) operational practices. Therefore, it was necessary to find out whether organisations had employed formal and strategic environmental management systems, or at the other end of the scale, less formal, unwritten, operational practices in order to identify the extent to which tourism businesses in Wellington were actively engaging in the process of environmental management. The responses from both tourism businesses operating in the private sector and other key public and private sector organisations such as the RTO and WCC are discussed in the following subsection of this chapter.

\subsubsection{Formal Approaches}

Out of a total of 60 respondents, it was found that just under one-third (18) were carrying out formal methods of environmental management. As Gonzalez-Benito and 
Gonzalez-Benito (2005) point out, formal approaches or practices refer to the extent to which organisations have defined an environmental policy, developed procedures for environmental objectives, allocated responsibilities, selected and implemented environmental activities and monitored or reviewed such practices. In analysing any similarities and differences among the various sectors it was found that larger businesses, particularly chain hotels and well-known tourist attractions had implemented formal approaches as demonstrated by the following statements:

'Yes we've got our policy up there - so we have key performance areas and we formally have an action plan to work towards and how we can manage things. Each meeting we go through things, tick them off and identify things we can further work on...so it's very formal. There's quite a bit - it's not just a walk in the park." (Accommodation provider 8)

"Yes, absolutely. I wrote the policy actually. The environmental policy covers legislation, energy efficiency, the community, staff, environmental improvement and reporting. And this is put up, signed obviously by a general manager, put up, down in our lobby, and made public to our guests." (Accommodation provider 16)

"We have what's called an environmental management system... what you need to do is look at the roles and responsibilities - who's going to do what...and we look at what we want to achieve..." (Attraction operator 10)

The majority of public and private industry bodies also seemed to demonstrate this notion due to their size, greater exposure to a wide range of stakeholders such as government and because of their reputation as a key player in the tourism industry. As noted by Alavarez Gil et al., (2001) larger establishments are more likely to be environmentally-friendly and thus carry out more formal approaches as a result of having more resources available to them. Their study also found that hotels under chain affiliation are able to deploy more extensive environmental management practices as a result of transferring knowledge and experiences between properties and utilising economies of scale. Successful environmental initiatives by one member of the chain can be adopted by other members of the chain who modify policies to suit their own circumstances. McNamara and Gibson (2008) confirm this notion as they also found that larger accommodation providers are more likely to have formal mechanisms in place. 


\subsubsection{Semi-Formal Approaches}

A number of tourism businesses in Wellington are beginning to seriously consider the need to become more environmentally-friendly. Out of 60 respondents, almost a quarter (13) are in the process of employing a more formal and strategic approach towards environmental management. This suggests that the sectors are in competition with each other as illustrated by the following statements:

"It's just - it's starting to be developed to what we need it to be today rather than what we needed it to be 10 years ago. So the policy is changing. There's always been one but it's changing to suit the needs today." (Accommodation provider 7)

“...we're actually in the process of writing out the new policy and procedure with that. And also taking into account - well we started that but then things change so we need to carefully assess our situation..." (Attraction operator 2)

"It's developing, the policies change as more fuel efficient vehicles come about...because we're only at the initial stages we need to look at what we're doing, and where we need to head..." (Transport operator 4)

Tourism businesses in Wellington seem to acknowledge the importance of the environment and indicate their intentions of wanting to change in order to demonstrate their responsibility and commitment to the environment. They recognise that policies need to be well-designed and informed by an appropriate assessment of their current situation taking into account environmental considerations. Change is treated with caution as there is no use in carrying out more formal approaches if businesses do not seem to understand the full implications of what they are doing and as a result how they can measure such outcomes. While there has been pressure on the tourism industry to mitigate their environmental impacts, it appears that Wellington tourism businesses are recognising the need to perform environmentally sustainable practices as a result of recent public awareness and access to information that emphasises the importance of caring for the environment.

As noted in Chapter One, at the national level - the tourism sectors ability to take a leading role in protecting and enhancing New Zealand's environment is a key priority of the New Zealand Tourism Strategy 2015. This notion reinforces the 
significance of the 'global-local nexus' as Milne and Ateljevic (2001) note that key players at the national level may influence the decisions of those at the local level, which in this case refers to tourism businesses in Wellington. The focus of this section now turns to less formal approaches of environmental management being undertaken by tourism businesses in Wellington.

\subsubsection{Informal Approaches}

At the other end of the continuum it was evident from the responses of interviewees that they were tackling environmental management through the use of informal or operational practices. From the sample, almost half (29) of all respondents were found to be carrying out operational practices. As noted by Swarbrooke (1999) such practices consist of day-to-day activities including reactive measures that do not require much thought and as Gonzalez-Benito and Gonzalez Benito (2005) state they are aimed at developing and implementing methods and processes that reduce a firms impact on the environment, namely in the areas of energy, water resources and managing waste.

Therefore it was not surprising that those smaller operators in each of the sectors: accommodation, attractions and activities, and transport were carrying out less formal approaches towards environmental management. The statements below illustrate this idea:

"Well I guess for us the B\&B is actually just a side business for us. It's sort of an extension of our own home. So you know it's basically a lot of the domestic things..." (Accommodation provider 5)

"OK, so to manage it, it's a day to day ongoing thing...Although there is no formal policy that we put out to the staff with the expectations, they know my personal expectations; they know my business expectations..." (Activity operator 5)

"There is no formal strategy or policy in place, it's not necessary - it costs money and if anything uses up more resources." (Transport operator 3) 
Smaller tourism businesses in Wellington do not have the resources and formal management like that of larger businesses. Swarbrooke (1999) notes that many small operators lack the financial resources to implement environmental initiatives while at the same time due to their limited networks within the industry, smaller businesses may be less aware of their role in sustainable urban tourism as most respondents express the fact that their business is essentially an extension of their own home. While most small businesses are informally taking steps to mitigate their impact on the environment it is important to note that most identify their impacts on the environment as minimal. Regardless of this fact, Ateljevic (2002) states smallmedium sized businesses dominate New Zealand's tourism industry.

Small operators despite their perceived minimal impact on the environment should take steps to becoming more formal in their environmental approach as they are essentially a part of the tourism industry as a whole. Having said that, responses indicate tourism businesses are increasingly realising the serious need to undertake more formal approaches to environmental management despite their size. The attention of this chapter now turns to examining areas of environmental management that businesses may focus on in order to develop more formal methods.

\subsection{Environmental Management Practices}

Chapter Two identified that while there has been an emphasis on both formal and operational practices, there is a need to investigate other important aspects of environmental management that tend to require a greater level of environmental knowledge. These other aspects of environmental management as discussed in the literature review, focus on areas such as the supply chain, environmental awareness among staff, training and environmental interpretation. Such aspects tend to be considered in the design of formal approaches as noted above. However, regardless of this fact all tourism businesses were asked to comment on these aspects in order to identify and discuss further implications of both formal and operational approaches. 


\subsubsection{Supply Chain Management}

Supply chain management from an environmental perspective as noted by Seuring et al., (2008) takes into consideration the management of material and information flows, and cooperation with other companies. Tourism businesses were asked to comment on their own supply chain management with regard to the types of environmental activities undertaken. It was found that 36 out of 55 tourism businesses and most public and private sector organisations (4 out of 5) were taking part in green supply chain management practices but the extent of such practices was not surprisingly much greater in regards to larger businesses as demonstrated through the following quotes:

"We aim in getting producers that provide us with environmental responsibility. We've got like health pack suppliers, the shampoos and that using New Zealand made 100\% biodegradable products. It doesn't come from overseas. We work with like-minded suppliers that have good policies." (Accommodation provider 8 )

"We try to get our order once or twice. We don't have to make too many orders like other properties or other accommodation properties. So what we tend to do is, at the end of the month when we do stock-take, we do a bulk order which lasts us almost throughout the month and if we see during mid month that some things are going down at a higher rate, we do a second order but we do not tend to do it to soon as we like to do it on a bulk basis... and from time to time we have a look at our products and see what else is there in the market, what other properties are doing because it might be that we are not aware but there's another property which is doing something - within the group or even a competitor." (Accommodation provider 12)

"Yes, in the hotel we have a purchasing department. And so they look after basically the department - individual departments do like requisitions for what they need or whatever for the week. And the purchasing department will buy it. So it's up to them - and finance I should say - with the money - to arrange the contracts with the suppliers to go and get the best deal, support the locals, you know - all that sort of stuff." (Accommodation provider 16)

The quotes above indicate that large tourism businesses in Wellington particularly in the accommodation sector are undertaking sustainable or green supply chain management. As found in the previous section of this chapter, larger businesses take on more formal approaches and as a result of such environmental policies, most are 
likely to take into consideration supply chain management issues. In contrast, smaller tourism businesses demonstrated their individual supply chain management activities as well, but to a lesser extent than larger businesses due to resource and financial restrictions. Smaller businesses seem to be doing what they can with the money and resources available to them. For some what they do in their private lives determines whether they actively choose more environmentally-friendly alternatives as illustrated by the following responses:

"Well I am conscious of buying fresh foods. Not a whole lot of processed things. And certainly where they come from because I'm trying to buy New Zealand made. And as I say I buy mainly fresh things so I don't have a lot of cans. I mean you have to buy fruit juice and things like that which comes in plastic containers or cardboard but I recycle those...but it's pretty standard cleaning products - just off the shelf - I haven't gone too environmental. They're quite a lot more expensive really." (Accommodation provider 11)

We recycle cartridges, toner and ink and all that from within - in the office. We don't use any disposable equipment when we're out there in the field with the guests or around the picnic areas - biodegradable detergents, energy-efficient light bulbs, are all part of the consideration that we have. And it's part of living in New Zealand. It's less so a business option, it's more a lifestyle option for most Kiwis. So it just flows onto the business. (Activity operator 2)

The findings in terms of the examples of green supply chain activities undertaken by tourism businesses in Wellington seem to reflect the literature as Bohdanowicz (2006) notes that businesses select local produce and purchase in bulk in order to decrease transport distances and frequency of trips as well as making choices to align themselves with suppliers who share the same environmental values. In addition, there were a small number of tourism businesses who indicated that they had not considered this aspect or they were at the initial stages of looking into their supply chain and how they could possibly manage it in a more environmentally-friendly way as the responses below convey:

'I've never thought about it because we don't really use - the only real supplier is for some of our cleaning products but I don't really know where they have come from." (Accommodation provider 25)

"Yes that will come in time. I think it's a fair way down the track. We're approaching this very much incrementally rather than in one go because we want to - because of the significant expenditure we'd want to 
try and get it as right as we can, without potentially going down the wrong track and then having to spend a lot of money to get back on the right track. So it will be very much incremental and we consider that's will in the long run achieve a better outcome." (Transport operator 2)

"Up until recently, there has been very little regard given to things like that and that's one area where we need to get people thinking about it and becoming more aware of it. The things that we do - go for the most environmentally friendly paints - certainly for indoor stuff. Everything else that we do is so minor." (Attraction operator 5)

As an aspect of environmental management that seems to require greater knowledge, tourism businesses are less inclined to undertake green supply chain management practices. This finding is supported by Erdogan and Baris (2007) who found that most tourism businesses in Turkey had a lack of awareness as to what constitutes an environmentally focused supply chain. Furthermore, a small number of businesses indicate they are only in their planning stages; therefore they may not have all the answers to fully implement such practices. Some businesses want to be assured that they are doing things the right way before they make any final decisions as such systems require careful consideration of a business's values and objectives for the long term. Authors such as Zhu and Sarkis (2004) substantiate the thoughts of tourism businesses in Wellington as well-designed sustainable management systems may improve a firm's environmental performance, reduce costs, and assist in forming stronger linkages between suppliers and the wider community for the benefit of each of these groups in the long-term.

\subsubsection{Environmental Awareness and Training}

Drawing on literature that identifies the importance of environmental training, respondents were asked to describe the types of environmental activities they undertook in terms of awareness, communication and training. Again, it was not surprising that larger businesses with formal approaches had implemented a much greater number of activities or initiatives pertaining to employees than their smaller counterparts. This section seeks to outline and discuss the various ways in which Wellington tourism businesses address environmental awareness and training among their staff. 
Out of all 60 respondents, just over half of tourism businesses (29) and three industry organisations respectively expressed their efforts in providing their staff with environmental knowledge and training. For most of these businesses, particularly larger ones, these activities are undertaken via a formal approach as they are likely to be part of a firm's overriding environmental policy or strategy. This notion is captured through the following interviewee responses:

"Everyone that works here knows what our mission is, what our goals are. Its part of our environmental policy - we communicate the reasons as to why we do things." (Transport operator 1)

"As I mentioned earlier, it's part of our overall policy. We make sure that staff are aware of our environmental commitment, and as best as we can, we communicate this message to them..." (Accommodation provider 9)

The above statements show that tourism businesses recognise the importance of communicating their environmental values and commitment to their staff. Employees are vital to the smooth operation of a business and therefore such environmental values need to be shared among all. The ways in which businesses try to achieve this may differ but nevertheless some businesses are emphasising the importance of their environmental beliefs by putting them into action as found below:

"It is a big thing. There's an awareness thing. We have meetings all the time with staff. We ask staff for ideas. We actually have a green team on board and we look at ideas, we look at suggestions and motivation. How do we motivate them? Give them something if they do something right...A lot of the environmental thing; it's all about awareness and keeping it in front of them. And it's my job to try and keep it in front of them, mostly through the computer or at all staff meetings." (Attraction operator 10)

"...every quarter we meet and tell the story to staff as well we try to make them aware of what's going on... and we've got an induction pack about the policy and they get to know where everything is." (Accommodation provider 8)

For tourism businesses undertaking more formal methods of environmental management, awareness and communication among staff is very important. Common ways in which Wellington tourism businesses seem to be approaching this issue are through regular staff meetings and staff incentives. Larger and medium-sized businesses in particular have established green teams which are made up of members 
from different departments that discuss ways in which they can reduce their firms' negative impacts on the environment and at the same time continue to communicate such environmental issues to all areas of business. It is important to note that some respondents were in fact taking on this additional role of an environmental manager or officer. Moreover, some tourism businesses, as part of their staff induction and training programmes are emphasising their businesses' environmental responsibilities at the outset to instil such knowledge into new members. Proper communication, training and enforcement of behavioural changes among staff as noted by Bohdanowicz (2006) may lead to significant saving options as expected attitudes and behaviours are well informed.

In contrast, smaller tourism businesses in Wellington are implementing such staff awareness and communication programmes where they can. While such methods are much less formal as a consequence of size, smaller businesses seem to recognise the need to spread their environmental initiatives to include all employees as seen by the statement below:

"I think it's something that we've discussed and we certainly talk about what we're doing as far as the place is concerned and we're having a look at the moment of changing all our products to environmentally friendly products...so maybe that will make a little bit of a difference too." (Accommodation provider 17)

Another small establishment emphasised the informal nature of their business in relation to staff suggestions:

"It's again probably back to that informal thing. If someone comes up with an idea we'll generally run with it, give it a crack. If it's going to benefit us then why wouldn't we..." (Accommodation provider 10)

Small businesses may not be doing as much as their larger counterparts but they are making an effort where it is possible. In addition, from the responses it seems that overall tourism businesses are becoming much more aware of the fact that they need to consider their own actions in working towards sound environmental management. This feeling is expressed through the following responses:

“Here its something we'd like to do and get more involved in but I've got to have a proper frame of reference or idea in terms of what we could be 
doing and then communicating that to staff. In terms of staff coming to us - no - but it's something we have to, because of the direction businesses are going..." (Accommodation provider 2)

"Well, probably not much at the moment because it's at such an embryonic stage. But I think as it develops we'll definitely be going out to the general staff... and because it will impact on so many people on so many day to day operations, everyone does need to be aware of it. And that's a key point as well. To make it work you need buy-in from all levels too. So that will be a key focus." (Transport operator 2)

These statements point to the stage of environmental management that some Wellington tourism businesses are at. Due to a lack of information or proper framework in which to guide them, some businesses struggle to put their intentions into action. Nonetheless, firms are increasingly realising the need to follow the 'green path' as a result of where the market is heading. However, firstly businesses need to consider their environmental impacts and the potential impacts of such change on existing business processes as it is important to get staff on board at all levels so that there is a shared environmental vision right across the company. In turn, such an environmental vision as part of sound environmental management should extend to tourists and the wider community through environmental education and interpretation.

\subsubsection{Environmental Interpretation}

Tourism businesses who claim to be environmentally-friendly should strive to communicate and interpret their environmental values. According to Madin and Fenton (2004) emphasising such interpretation can help to reduce negative impacts by generating a greater understanding of environmental issues. Tourism businesses in Wellington were asked to comment on the existence of such practices. From the sample, the results show that well less than half of all businesses interviewed (18 out of 60) are engaging in environmental interpretation. The responses also indicate the variety and extent of such environmental practices. Again, not surprisingly large tourism businesses particularly chain hotels consider environmental interpretation an important part of their overall environmental policy or strategy. This view is expressed through the statements below: 
"Well first of all we have the environmental policy that's available - well it's actually placed at the reception area. On there it's got information about the Green Globe and also about our environmental strategy... and also on there there's a part that informs guest of how to be shall we say a bit more environmentally friendly, you know, walking around town and things like that. Also in the rooms we promote what we're all doing and it's pretty much about if they want to join us then they can do." (Accommodation provider 22)

"Yes. Absolutely. I mean apart from that, like I said, we put the environmental policy up and that invites guests to ask us for any more information if they would like to see it. We have the stuff in the rooms and also - our sales and marketing department within their proposals and contracts they send out the policy along with like initiatives that we have in place. So that goes out to the wider community...I mean it's not just [that] we want to be seen in a good light, we want to be able to say we are doing something and showing it through these initiatives." (Accommodation provider 16)

The above statements also reveal some of the ways in which they seek to interpret their commitment to the environment. By way of displaying environmental policies in public areas where guests can see them and providing information pertaining to the environmental values of the business in guest rooms, visitors are made aware of the various ways in which tourism businesses are trying to actively reduce their negative impacts on the environment. Furthermore, it invites guests to ask for further information if they wish to find out more about such initiatives. Environmental interpretation requires businesses to identify ways that are both interesting and entertaining to the audience. While larger businesses are providing good examples of the ways in which such initiatives can be carried out, smaller businesses who take on a less formal approach to environmental management are finding more creative ways to express their stance as seen by one business:

"We try and make it a little bit of fun. We have green days once a month where we decorate the reception area green and all the staff wear green. We keep the lights off during the day and we burn candles on the reception desk. We put up big notices saying to people the reason we're doing this is because, you know, we've got to protect the environment. So we make it in a fun way... because that's when they're going to pay attention to us. People aren't going to pay attention to us if we try and drill them when they check in." (Accommodation provider 7)

Palmer (1998) describes key aims of such environmental initiatives are to hopefully change people's perceptions about the value of the natural environment and teach 
individuals how to become more environmentally responsible. In particular tourism operators who conduct their business in natural areas of Wellington recognise the importance of being environmentally responsible thus communicate this to their visitors as much as they possibly can. The following responses illustrate this recognition by a few tourism operators:

"Oh yeah, we do a lot of it - nature interpretation. One of our biggest contributions - the geological, the animals, we go past a number of significant natural areas - we talk about problems about the introduced species. A huge amount of interpretation goes on - because that's part of our business." (Activity operator 4)

"Yes - for some particular products. The guides who do those tours need to learn the principles behind each of those stations so that they can become tour guides. And the environmentally sound practices, that's talked about - it's discussed and presented to the guests as well....explaining the reasons why and the importance of maintaining those and the importance of keeping those areas pretty free of pests." (Activity operator 2)

Tourism businesses, particularly activity operators that offer nature as part of their overall product are actively interpreting the environment to their visitors. This is mainly carried out by providing information to guests on appropriate behaviour while on the trip and informing visitors on how they can minimise their direct impacts on the natural areas that were apart of their trip. Grubb (2007) reports similar findings among activity operators in the Nelson/Tasman region of New Zealand which in turn reinforces the strong connection that tourism has with the environment. Other responses in particular among small tourism businesses in Wellington indicate the current lack of environmental interpretation practices. The following statements demonstrate this finding more clearly:

'Not really. I wouldn't go round preaching the environmental message to my guests. I think a lot of them here are that way inclined anyway. I think I said that in the beginning. I think the people who come and stay here - are more concerned about the environment and they do want to make less impact on the environment, that's why they come and stay here. As I said many of them - they walk a lot, they take the bus they use the cable car a lot. Yeah then they're the sort of people who are the middle class people who have read the right things and are very aware of the environment..." (Accommodation provider 11) 
"Well I guess I would say not really. Since, it's not something that really - I guess we haven't really marketed ourselves in that way. So in some ways it's - I guess unless it comes up in conversation, it's not something you'd kind of be preaching to the guests." (Accommodation provider 5)

These quotes suggest that there may be underlying reasons as to why tourism businesses are lacking in environmental interpretation. Some businesses simply believe there is no need to bring up such issues as they recognise that those already coming here are environmentally aware. New Zealand's ideal traveller, the 'Interactive Traveller', respects the environment, culture and values of others (Tourism New Zealand, 2004), In addition if businesses are not actively marketing themselves as being 'green' then it is something they feel is not necessary. At the most, tourism businesses may only deal with such issues if they are prompted or brought up in conversation. Grubb (2007) identifies this as 'passive' interpretation and suggests that such forms of interpretation hold great potential in becoming more active with stronger support.

\subsection{External Involvement}

Tourism businesses can work towards environmental management by becoming involved with or working alongside other organisations that deal with environmental management related matters. These other organisations operate in the greater external business environment as opposed to the internal workings of an individual business and include both tourism and non-tourism entities that operate in the public (e.g. RTO, WCC) and private sector (industry associations). For the purpose of clarity, such organisations in this section will be referred to as external or 'outside' organisations. Individual businesses were asked to comment on any involvement they may have had in working with external organisations regarding environmental management.

The results show that tourism businesses had been in contact with a number of organisations directly involved in tourism such as the RTO and those with an interest in environmental management related matters e.g. Green Globe, Ministry for the Environment, and Sustainable Business Network (SBN) as illustrated in Table 2 
below. It was also found that the extent of involvement with outside organisations varied among tourism businesses. Regardless of which tourism sector, just over half of all respondents expressed little or no involvement with external organisations. Fifteen businesses indicated higher levels of involvement. The following subsections attempt to categorise these various scales of external involvement.

Table 2: External Involvement of Tourism Businesses

\begin{tabular}{|c|c|c|c|}
\hline $\begin{array}{c}\text { Level of } \\
\text { Involvement }\end{array}$ & Description & $\mathrm{n}=55$ & Example \\
\hline High & $\begin{array}{c}\text { Involvement with three } \\
\text { or more external } \\
\text { organisations }\end{array}$ & 15 & $\begin{array}{c}\text { Involvement with } \\
\text { Qualmark and Green Globe } \\
\text { and RTO }\end{array}$ \\
\hline Medium & $\begin{array}{c}\text { Low } \\
\text { Zero or little involvement } \\
\text { with external organisations }\end{array}$ & 33 & $\begin{array}{c}\text { Involvement with either } \\
\text { Qualmark or RTO or WCC } \\
\text { or none }\end{array}$ \\
\hline
\end{tabular}

A number of respondents indicated no involvement in working with other organisations on environmental management. Some simply stated 'no involvement' and others indicated that they had no influence on the way they operated or mentioned the fact that they had never been approached. However, while this was the case for some businesses, others who stated no involvement were at the beginning stages of assessing alternatives in becoming environmentally sustainable. This was particularly in relation to Qualmark, New Zealand's official mark of quality for tourism (Qualmark, 2008a), that has recently extended and enhanced its environmental criteria to recognise tourism businesses actively engaging in areas such as energy efficiency, waste management, water conservation and community activities. The following responses convey this notion:

"No involvement at the moment. We're working towards being part of Qualmark - we're looking forward to becoming apart of that. But if we're with a more locally recognised one then that's probably better. (Accommodation provider 24) 
"We're looking at joining Qualmark but I'm sort of just investigating what their requirements are -and whether we, at present can fit into their criteria." (Accommodation provider 2)

Tourism businesses are feeling the pressure from both the industry and market to become more involved in minimising their own impacts on the environment. Therefore, they turn to external organisations which may be able to assist them. The above quotes suggest that as a result of the introduction of Qualmark's 'green' rating, businesses feel even more pressured to meet the minimum requirements related to energy, water, waste and community activities. Nevertheless, businesses firstly need to seriously consider where they're at and realistically what they can do with the money and resources available to them. Levels of low involvement with WCC were also evident among tourism businesses. However, the extent of the Council's involvement with operators merely refers to the interaction they have in regards to their recycling policy and collection. Moreover, businesses expressed a low level involvement with the RTO, stating they did not seem to do much from an environmental point of view. This poses the question as to what extent external organisations such as the RTO should be involved in working with tourism businesses on issues related to environmental sustainability.

While a number of tourism businesses indicated a low level of involvement with external organisations such as Qualmark, in contrast some tourism businesses had expressed a greater level of involvement with Qualmark particularly with reference to the newly introduced environmental criteria as demonstrated by the following participants:

“There's Qualmark. Qualmark's a big one! With Qualmark obviously when they come and rate us and I believe that this year it's - obviously to get your rating you are rated on a million different aspects. A part of that now though which seems to be getting more important is, you know, are we being as eco-friendly as we can be." (Accommodation provider 7)

"Qualmark are probably making the strongest stand which as I said before has an environmental consideration requirement within it. We work with them and will continue to be endorsed by them and work to that endorsement." (Activity operator 2) 
Qualmark has been recognised for establishing the world's first fully integrated quality and environmental system, reinforcing the vital need to protect the environment (Qualmark, 2008b). Tourism businesses that are already qualityaccredited are more likely to continue involvement in such schemes because they recognise that environmental concerns are an even more critical aspect of quality in terms of being certified as a sustainable tourism business. Greater involvement with outside organisations was also found amongst those tourism operators who had been dealing with other environmental organisations such as Green Globe, SBN and industry associations. Involvement came in the form of having contacts with such organisations, seeking out information, attending seminars and presentations which highlighted environmental issues, to more one-on-one interactions as some businesses were actively engaging in becoming affiliated with organisations such as Green Globe or taking part in environmental activities alongside organisations like Keep New Zealand Beautiful and the Ministry for the Environment.

In particular, larger businesses or those with an 'eye' for sustainability were most likely to be involved with a range of organisations supporting sustainable business practices. From this finding, it could be suggested that the level of outside involvement may reflect the extent of environmental management practices as larger organisations such as hotels tend to take on more formal approaches as opposed to smaller operators who carry out more informal, operational practices. As noted, just over half of the sample reported little or no involvement with external organisations. The majority of these were in fact, smaller businesses such as motels and B\&Bs in the accommodation sector and small attraction/activity operators. In contrast, chain hotels and larger attraction operators were more likely to have a higher degree of involvement with a range of external organisations. Mensah's (2006) study in Ghana found that hotel chains benefit from the success of individual units and therefore they transfer this knowledge to other members of the chain. McNamara and Gibson (2008) who studied coastal tourism accommodation in Australia reaffirm this notion as larger facilities are more likely to practice environmental management due to their exposure to a greater number of environmental pressures and because they have greater resources and networks available to them. 


\subsection{Importance of Environmental Management}

Those being interviewed were asked the question: how important do you think managing the environmental impacts of your business is now, and into the future? This was asked in order to discover the level of importance tourism businesses in Wellington place on environmental management and more importantly investigate the factors which affect an organisation's perspective on this matter. The results show that most tourism businesses view managing their environmental impacts as being important now, and even more so important in the future. While environmental issues in tourism have been around since the 1980 s, it seems only more recently that such issues are beginning to be taken more seriously among New Zealand's tourism industry. A number of factors being identified by interviewees relate to the level of importance they place on environmental management.

Some tourism businesses not surprisingly, identified that managing their impacts on the environment was very important due to environmental issues such as global warming, resource consumption and their dependence on resources in order to continue business as shown by the following statements:

"It's definitely, most important. Global warming is such a big issue these days. If you don't then you're in the Stone Age really. It's the next big issue so it's important." (Accommodation provider 24)

"How important, vitally important - electricity and gas are only going to get more scarce and then there's the carbon footprint." (Accommodation provider 14)

Tourism businesses recognise their dependence on the environment for its resources and therefore it is crucial that they find effective ways to minimise their impacts. Coupled with the need to reduce resource consumption, and contribute to the environmental cause in their own way, tourism businesses also recognise the cost implications associated with the scarcity of resources as summarised by one respondent:

"I think it's very important really, particularly power and water resources because they're not unlimited and I think if we're not careful then things are just going to become so expensive and the resources so scarce that we'll do ourselves out of business in the end. So I guess it's like 
somebody once told me it's a bit like maggots in a sack of flour, they multiply and multiply until eventually they produce so many poisons in the flour they die. That's the end of that. So, I guess we're a bit the same really on our own planet. If we don't do something about keeping our environment clean, we're all going to end up with so many toxins in the environment that we'll wipe ourselves out." (Accommodation provider 17)

Tourism businesses also place a high level of importance on environmental management based on their knowledge of changing market trends and social attitudes. Businesses have to retain a firm hold on the market and so by knowing what market trends are out there, they are likely to attract more potential customers. This notion is evident from a considerable number of tourism businesses in Wellington:

"Considering the market trend and what is going around everywhere, everyone is becoming more and more aware and it's good that they are because it will - or should have a positive impact on the environment." (Accommodation provider 12)

"It will become quite important going further forward - there will be more pressure from people I want to do business with. I could probably say that they will definitely want to see what our practices are in terms of environmental management. It's something we'll have to do as we go forward." (Accommodation Provider 2)

"Of course it's really important. It has to be a priority because, like I said, the people trends are changing. They are looking for greener places you know like it's this green bug I think and it's just going to get more severe, you know, as time goes. Media is really spreading the word and people are really buying into it which is rightfully so, they should buy into this Clean Green idea." (Accommodation provider 19)

Due to changing consumer demands and preferences, tourism organisations are under greater pressure to become environmentally-friendly. Furthermore, respondents emphasise the need to manage their impacts as a result of travellers' impacts and the fact that New Zealand is marketed as a clean and green destination:

“...tourism in New Zealand has a big impact on the environment, like I mentioned earlier, for tourists to come to New Zealand, that's a big carbon footprint in itself - the flight. And then, of course, there's impact that tourists have when they're here in terms of using up resources and impacting on the local environment." (Accommodation provider 5) 
International tourists travel long distances to visit New Zealand and so the flight in itself can be considered as a huge impact on the environment. Therefore, some respondents believe that guests looking to reduce further impacts while here might choose to stay with them as it is a good look with some travellers, and due to the fact that some businesses feel it is their responsibility as part of the tourism product and delivering upon Tourism New Zealand's '100\% Pure' promise. Although the majority of tourism businesses interviewed seemed to place a great level of importance on environmental management, a number of respondents acknowledged the fact that environmental management related matters need to be considered carefully alongside company objectives as essentially businesses want to make a profit. The statement below points out this reality:

"...we have a lot of travellers come here so it's important that we do our bit to ensure that we can still get the business. Because in the end, bottom line, we are a business and we want to make money." (Accommodation provider 16)

Tourism businesses need to weigh up their options when it comes to environmental management because if they decide to spend large sums of money on such initiatives they need to see a return on their investment to justify such spending. The quote below illustrates this notion effectively:

"We're a commercial organisation. And we're here to survive - be profitable. But if there were to be a choice between a non-environmental position, a sound position and an environmentally sound position at the same net cost, then clearly you would take the environmental position. That's the importance that you put on it." (Activity operator 2)

It is generally perceived that environmentally-friendly practices tend to be more expensive with some businesses taking more caution in implementing such practices. On one hand, environmental management practices can be seen as important and viable, yet on the other hand, they may be seen as a huge cost to businesses especially when they are unable to see the long-term benefits. As previously stated, the current price rises in commodities and resources such as energy create further difficulties for tourism businesses looking to implement environmental initiatives as they need to carefully consider their options in order to reach a decision which reflects the overriding objectives and values of the organisation. 
On the whole, tourism businesses in Wellington recognise the important responsibility of managing their firms' impacts on the environment and that they need to continue this change in working towards a sustainable future. This chapter has presented the results of the study in relation to the overall environmental management approaches being undertaken by tourism organisations in Wellington. The following chapter continues to examine environmental management approaches further with reference to the range of different influences and barriers to environmental management practices including the role of public and private sector organisations with regard to environmental management. 


\section{CHAPTER 5 INFLUENCES AND BARRIERS TO ENVIRONMENTAL MANAGEMENT PRACTICES}

\subsection{Introduction}

This chapter focuses more specifically on the influences and barriers to the adoption of environmental management practices. The results are again presented under a number of themes which seek to address the objectives of this study by investigating the range of different factors influencing the adoption of environmental management practices and barriers that relate to perceived advantages or disadvantages. The chapter also examines the role and relationship of the public and private sectors for tourism businesses with regard to environmental management to further analyse the influences and challenges being faced. As in Chapter Four, a representative range of quotations from the interviewees, again identified by sector and number are used to present the range of views of environmental management held by tourism organisations in Wellington.

\subsection{Factors Influencing Adoption}

Previous literature on environmental management has examined the key factors or influences in the adoption of environmental practices. For tourism researchers, examining such influences of adoption provides another means to explore and better understand the concept of environmental management. The main factors influencing the adoption of environmental practices among tourism organisations in Wellington are identified as financial, social pressures from consumers and within the tourism industry, personal and market image. 


\subsubsection{Financial}

Tourism organisations in urban Wellington recognise the economic incentives in undertaking environmental management practices. According to respondents, not only does employing various environmental initiatives reduce the amount of resource consumption e.g. water and energy, some respondents believe it can result in longterm savings for the future of the organisation:

"There's a cost benefit there in terms of saving on water and energy." (Activity operator 3)

"Oh it's financial. I mean if you don't have to poke as much electricity into the house to heat it and light it and heat your water then that is a great incentive to try and do those things." (Accommodation provider 17)

"... in any business you spend money to get, you know, a return back. So some of the things we do for recycling, waste to landfill, energy reduction and things like this, that's fine. We do see returns on our investment, whether it be two years, five years or 10 years." (Accommodation provider 22)

Respondents who share similar views in terms of reducing resource consumption and saving money also indicated their adoption of environmental practices was due to higher costs of electricity:

"Its probably more the power going up, that kind of thing you know, or price rises all round, so that makes you cut back on everything. It's the cost effectiveness of those types of practices." (Accommodation provider 25)

As discussed by Zutshi and Sohal (2004), economic factors play a significant role in the adoption of environmentally-friendly practices. The above results reinforce Le et al., (2006) as the relative advantages in adopting environmental initiatives are mainly cost savings, improving the operational efficiency of resources and improving a firm's reputation. 


\subsubsection{Social}

Authors such as Ayuso (2006) have found that pressures from consumers and those stemming from the wider tourism industry have an influence upon the adoption of environmental practices. Tourism organisations highly value their customers and acknowledge the fact that public awareness of environmental issues is much higher and so tourism businesses are being pushed by their clientele to adopt environmentally-friendly practices:

"Probably what our customers want. We give them what they want or otherwise you're going to be two steps behind". (Attraction operator 5)

"It's something about the public being aware of it so we need to be seen to be green." (Accommodation provider 14)

Other tourism businesses indicate part of their reason in adopting environmentallyfriendly practices as a result of consumer pressures is their linkages with government and within the corporate sector:

"We do a lot of work for government and corporate businesses, and a lot of them are trying to reduce the emissions too. So by us being able to offset ours helps them out too." (Transport operator 4)

This notion is very relevant due to Wellington being the capital city of New Zealand. Government departments and those within the corporate sector make up a large majority of customers for some of the larger inner-city hotels and transportation companies in Wellington. It is no surprise that as a result of this relationship, businesses feel an even greater push by these clients to commit to being eco-friendly. These social pressures on tourism organisations also extend to the wider tourism industry. Where some businesses have commented on the overall constant pressure from the industry as a whole due to expectations from Tourism New Zealand and the latest New Zealand Tourism Strategy 2015, others have noted specific industry pressures arising as a result of the newly introduced 'green' rating from Qualmark, which emphasises the environmental responsibility of tourism organisations. 


\subsubsection{Market}

The role of the market also proved an influential factor among tourism organisations in Wellington. In recognition of the growing social pressures facing tourism organisations to become more environmentally-conscious, many firms identify having environmentally-friendly practices can provide a marketing edge and boost one's corporate image within the marketplace:

"We recognize that there's a point of difference at the moment. If you can actually prove - then that gives you a marketing edge". (Accommodation provider 2)

"It gives us an edge over our competitors. Say, if I'm doing things to protect the environment I can go out and speak and promote myself, which is always an advantage." (Accommodation provider 12)

For tourism businesses, gaining a competitive advantage over others is also good for business. Some Wellington tourism businesses, particularly chain-affiliated hotels have adopted environmentally-friendly practices in the hope of attracting the ever growing green market segment (Chan and Wong, 2006). They may very well be seen as the business of choice if they can demonstrate their environmental commitment to their customers. If tourism businesses do not undertake such practices then they fear they will be left behind as the 'green' trend only continues to increase.

\subsubsection{Personal}

Personal reasons were also found to be a quite popular response among tourism businesses in Wellington in adopting environmental management practices. Individuals' knowledge of the environment, their own beliefs and values towards protecting it, education and a sense of 'doing the right thing' are all factors which play a role in the decision-making process by businesses to adopt environmentallyfriendly practices. The following quotes sum up these ideas:

"It's probably just education really. The knowledge of how the environment's changing and the knowledge we have as a group of people. 
It's being aware and making a decision to do as much as you can about it." (Accommodation provider 6)

'I think it's just - I don't know where we got all our general awareness from but, you know, it's been a movement I guess that's been going on for more than 10 years anyway - way before that really but people never took it with the same seriousness. So yeah I'm a person who reads and is just aware of what's going on." (Accommodation provider 11)

Other less common factors influencing adoption of environmental practices as reported by respondents were those more internal to the firm, regulatory requirements and health. A small number of businesses had adopted environmentally-friendly practices because they saw it as good business practice. One organisation in particular was able to see the advantages in saving money in the long-term and in reducing resource consumption. This notion reinforces the significance of financial factors and is summed up by the following statement:

"I think what's influenced it really is - it's good for business. It's good business practice. I mean a lot of people think oh, sustainability or environment, you know, is it good for your business? Yes it is. It's good because it saves you money. Maybe not in the short-run, you have to pay a little bit out. But certainly in the future, it saves you money." (Attraction operator 8)

In terms of regulatory measures, only one business out of 55 made reference to the RMA and the ways in which they had to conform to the district controls, and one smaller operator made mention of the fact that living in a cleaner environment was likely to result in better health. Whilst regulation has been identified by authors such as Zutshi and Sohal (2004) as a main factor of adoption it has not been a significant one for tourism businesses in Wellington. Whether most respondents seemed to overlook this factor is unknown as tourism businesses may be motivated to adopt environmental practices through self-regulation, industry self-regulation or government regulation. Though not stated by respondents as clearly, the previous section outlining involvement with external organisations suggests Qualmark's environmental guidelines are beginning to play a much bigger role for tourism businesses wanting to be more environmentally responsible.

Overall, the main factors influencing adoption were found to be consistent with previous studies (Alavarez Gil et al., 2001; Zutshi and Sohal, 2004; Ayuso, 2006, Le 
et al., 2006) with the possible exception of personal reasons. While it could be suggested that personal reasons may be attributed in part to one's social values, the results above show that individuals' prior knowledge, beliefs and values of environmental issues may influence adoption. Table 3 below summarises the main factors of adoption.

Table 3: Factors Influencing Adoption of Environmental Management Practices

\begin{tabular}{|l|c|c|}
\hline \multicolumn{1}{|c|}{ Factor Of Adoption* } & $\mathrm{n}$ & \% $(\mathrm{n}=69)$ \\
\hline Financial & 18 & 26.09 \\
\hline Market & 14 & 20.29 \\
\hline Social & 12 & 17.39 \\
\hline Personal & 11 & 15.94 \\
\hline Organisational Culture & 3 & 4.35 \\
\hline Other & 11 & 15.94 \\
\hline TOTAL & 69 & 100.00 \\
\hline
\end{tabular}

*Based on multiple responses

\subsection{Barriers}

The previous section of this chapter identified a number of key factors that influence the adoption of environmental management practices. The examination of such factors provides a means of identifying the underlying reasons that drive businesses to become more environmentally-friendly. At the opposite side of this argument as seen previously in Chapter Two, there are also factors which may hinder the adoption of environmentally-friendly practices. These factors are known as barriers. This section identifies the barriers and discusses their implications for tourism businesses with regard to environmental management. The main barriers which hinder the adoption of environmental management practices by Wellington tourism businesses can be categorised into four main groups. These groups consist of financial, psychological, physical and social barriers. 


\subsubsection{Financial}

Financial barriers are those relating to the amount of money available in the business and the cost of implementing environmental initiatives. It is recognised from a number of tourism businesses that the initial cost of undertaking environmentallyfriendly systems is relatively high. McNamara and Gibson (2008) support this notion. Also, costs increase for those businesses that have had to spend money renovating old properties in order to become more eco-efficient. Both of these notions are further compounded by the fact that environmentally-friendly products such as energy-efficient lights or recycled paper also tend to be more expensive and so businesses see this as an obstacle:

"The only barrier would be in terms of cost, I don't think there would be any others. It's about the cost of products and services, and weighing this up. Recycled paper is more expensive than the normal paper we use." (Accommodation provider 13)

Furthermore, businesses are not as willing to invest in environmental management practices if they are unable to see a return on investment. While the introduction of environmentally-friendly practices such as solar heating may seem attractive, it may not be economically viable for a tourism business if the costs seem to outweigh the benefits. The following quote demonstrates this idea:

"So you have to look at that and say OK how much is it going to cost? What benefits are we going to get? And what kind of impact could we have or what reduction would we show? So it's all about cost. But, if we had a blank cheque book - we would do it." (Accommodation provider 22)

Tourism businesses already have to consider a number of other costs, and if environmental management is not deemed a central focus of the organisation then it is much more difficult to obtain the money for implementing such practices. This idea that organisations are unable to see an immediate outcome relates well with the psychological barriers that some tourism businesses in Wellington seem to face. 


\subsubsection{Psychological}

Psychological barriers in the context of this research refer to those present in the attitudes, values and behaviours of tourism businesses. For tourism businesses in urban Wellington, many seem to battle with not only the fact that they cannot see an immediate outcome but also the amount of time taken to plan for and implement environmental management practices as illustrated by these participants:

'I mean it's very easy to spend time on banking or making a reservation because you know you're going to get an immediate outcome. With this you're not getting an immediate outcome. So sometimes you feel like you're doing all these things but you're not seeing the results straight away so it's a little bit frustrating." (Accommodation provider 7)

"We've all got jobs doing hotel work and then factoring that time aside to work on the environmental side of things and getting started with that can be an issue." (Accommodation provider 24)

Here it is identified that tourism organisations are practising environmental management yet the barriers which may face them refer to the time that they have available to commit to their environmental initiatives as they already have other paid roles and responsibilities within the organisation. Also, a small number of tourism businesses wanting to actively engage in environmentally-friendly practices were dealing with issues of confidence or trust in 'getting it right'.

"It took me a long time to figure out the right business to go with. I mean you're spending a lot of money and a lot of it is trust based, [in] that you actually get what you want at the end...” (Transport operator 4)

Because businesses believe there is no easy road map available to them in becoming more environmentally-sensitive they have a lot of questions and doubts as to which path they should follow in becoming 'green'. There seems to be no single 'right' way to becoming green with a large number of organisations currently providing products, services and advice about environmental issues looking to acquire business. This finding is supported by Chan (2008), and McNamara and Gibson (2008) who respectively note the uncertainty of outcome and basic lack of time is a key barrier of environmental management for tourism businesses. However, while time or trust can prove a barrier it may be seen as a better way of doing business as one wants to be 
assured that they are 'getting it right' the first time, thus making a wise decision for the long-term benefit of the organisation.

\subsubsection{Physical}

A similar number of tourism businesses expressed physical barriers in terms of location and size, relative to the limited space or land and existing buildings they operate within. Due to these barriers, businesses feel they are somewhat limited to the amount of what they can do from the perspective of environmental management and emphasise that they try to do what they can with the space and resources available to them.

"A main barrier is probably our infrastructure, so we cant - we're a concrete building so we cant you know use grey water and all those things because we don't have the infrastructure." (Accommodation provider 8)

"You can't adopt everything. You just have to do what you can. You only have so many staff members, land, power..." (Accommodation provider 19)

This finding is self explanatory as businesses only have a set number of resources such as employees, and a set area of space or land in which they operate. However, this feeling seemed to resonate more with businesses that operated in older buildings as some participants expressed the fact that part of operating in an older building was essential to the historical character of the business therefore they did not want to tamper with this. These findings are well supported by McNamara and Gibson (2008) who found that accommodation facilities operating in heritage buildings felt it was more difficult to employ environmental initiatives. Consequently, tourism businesses such as this face the issue of whether to implement environmental practices in order to follow the 'green' trend at the cost of upsetting or damaging the reputation on which their business is founded upon. In addition, there may also be a cost factor as seen with those businesses wanting to upgrade or renovate existing structures. 


\subsubsection{Social}

Social barriers in the context of this research refer to those in the form of resistance to change by employees, visitors, and in general society; and a lack of knowledge, education or support for the environment. If visitors in particular do not possess enough awareness or support for the environment it may prove very challenging for a tourism business who may want to go 'green' to actually enforce such an approach.

"The main one is other people not caring, you know. Just because you care about something, you can't force someone else to care about it, especially guests that check in, you can't force them to care about something that you're trying to do." (Accommodation provider 7)

"I mean if you have people staying with you and they create a lot of rubbish or, you know stay in the shower forever and those kind of things, it's not an easy thing. People are only staying with you one or two nights; I'm not going to say anything to them. Maybe in another kind of conversation you can just raise the issues but not attack a person personally." (Accommodation provider 11)

Visitors are paying for a service so environmental issues are unlikely to be at the top of their minds. The last thing that some visitors may want to do is consider how long they should spend in the shower or whether they should be separating out their rubbish. As much as tourism operators indicate their interests in protecting the environment, their main aim is to ensure the comfort and relaxation of the guest and whether or not this is at the expense of such resources as energy or water they believe there is little they can do about changing consumer habits. The same might be said for businesses whereby only a small amount of employees are in support of an environmentally-friendly approach. In some instances, as Ayuso (2006) notes, there may be a lack of motivation or resistance to change as organisations are stuck in their old ways. The old way of doing things versus the new way can prove daunting for many people, especially for those who have been with an organisation for a long time. This is made even more difficult when senior management are opposed to such changes. The barriers to practising environmental management need to be addressed by coming up with possible solutions that will require greater communication and cooperation among key stakeholders in sustainable urban tourism. Table 4 illustrates the main barriers to environmental management. 
Table 4: Barriers of Environmental Management Practices

\begin{tabular}{|l|c|c|}
\hline \multicolumn{1}{|c|}{ Barriers* } & $\mathrm{n}$ & $\%(\mathrm{n}=72)$ \\
\hline Financial & 24 & 33.33 \\
\hline Physical & 16 & 22.22 \\
\hline Psychological & 18 & 25.00 \\
\hline Social & 8 & 11.11 \\
\hline Other & 6 & 8.33 \\
\hline & & \\
TOTAL & 72 & 100.00 \\
\hline
\end{tabular}

* Based on multiple responses

\subsection{Advantages and Benefits}

Based on the literature concerning environmental management respondents were asked to identify the advantages and benefits for tourism businesses practising environmental management in general, as well as comment on any disadvantages in order to consider various perspectives of this question. It was perhaps not surprising that respondents mentioned the benefits associated with the environment in terms of reducing consumption of resources and doing their part for the betterment of the environment. Tourism businesses that are practising environmental management recognise their positive impact on the environment and feel good about contributing to the cause. Besides this more obvious benefit, the following analysis focuses on the other advantages found which include those associated with marketing and image, saving money in the long-term and in fostering organisational culture.

\subsubsection{Marketing: Competitive Edge}

As expected, tourism businesses believe practising environmental management can have huge marketing benefits by attracting more business and providing a point of difference. Tourists are now even more discerning and as awareness on 
environmental issues has increased there has been a noticeable rise in the number of travellers who are actively seeking out services which promote sustainability and are engaging in environmental initiatives. Stanford (2006) comments on the awareness of tourists to New Zealand in terms of their environmental impacts and identifies that they choose tourism products that are more environmentally-friendly. This notion was effectively captured by the following respondents:

"The benefits we get - like I said, it's becoming a bit of a fashion really, a trend to be environmentally friendly among businesses. So I suppose guest preferential - we want to be the preferred company. And so being a leader in the environmental type of initiatives and sustainable business practices is a benefit for us - because guests will choose to use us. Same with a lot of other companies that we have functions with, they choose to use us because of certain initiatives that we do." (Accommodation provider 16)

"Well I think increasingly there'll be a better take up of your product by the public, so [it] makes good commercial sense to be clean and green. Well, a spin off I believe is that increasingly what'll happen is people will only go to those being kind to the environment." (Activity operator 4)

Tourism businesses that undertake environmental management practices see this as a chance to be able to get one foot ahead of their competition and promote themselves as being environmentally-friendly in order to capture the increasing 'green' market. Furthermore, respondents indicated the benefits linked to leveraging off New Zealand's perceived clean and green image. Due to New Zealand being promoted to the rest of the world as a destination which is recognised for its natural and untainted landscape, a considerable number of Wellington tourism businesses were well aware of the serious need to maintain this wholesome and favourable image:

"Well, it's funny because especially in New Zealand we try to project this huge clean and green image. It's just for me personally as a whole - it seems like how could you not do it if that's the image we're trying to project to the world. Anyone in the tourism industry should be at the forefront of being clean." (Transport operator 1)

"One thing is we do need to protect our clean and green image and if environmental management achieves that then that achieves a lot. So that'd be the biggest benefit achieving some form of environmental consideration and maintaining our priceless positioning." (Attraction operator 3) 
'From a New Zealand perspective it's good. It's bringing the people to us. And if we can actually keep that ' $100 \%$ Pure' thing rolling on and that ideal, I guess, it's a good thing." (Accommodation provider 9)

While this feeling was shared widely among tourism businesses, one respondent in particular expressed concerns with the reality of the situation:

"It's a sales talk. It's about marketing. It's about positioning, you know. And that's where you come back to the bit there - the role of the RTO and Tourism New Zealand. Yeah if you think it's 100\% pure, yeah it's great environmental marketing. It's a dangerous one just as any marketing is because you find you can get tripped up by it. But it's a great position to have and this country's benefited a great deal by it because it's perceived to be green and marketing is all about deception. So irrespective of whether you're doing it or not, if you market that one and it's successful and you get away with it then more luck to you." (Activity operator 2)

The above quote suggests that while New Zealand has been marketed as a clean and green destination, some businesses may only claim to be environmentally-friendly through their marketing in order to gain this advantage. This notion reinforces the need for tourism businesses to visibly demonstrate their active involvement in environmental management. The majority of businesses interviewed recognise the importance of this expectation and are well aware that they need to move far beyond simply claiming to be environmentally-friendly by looking at various aspects of their organisation and how they can minimise their impacts to ensure they retain their positive public image.

\subsubsection{Financial}

As earlier discussed, tourism businesses indicate a key factor in adopting environmental practices is associated with minimising costs and saving money in the long-term. It is not surprising that respondents expressed similar views in terms of this notion as being an advantage of environmental management due to a considerable overlap of each of these themes. The links between cost savings being a factor influencing adoption as well as a benefit were acknowledged from the following statements: 
"I guess again it comes down to cost. Because in the long run it would have a benefit in that you're not actually spending more money, such as heating your house for instance." (Accommodation provider 5)

"You've also got the cost, as I've mentioned, there are cost savings to be made if you look at it, you know, your consumption of paper or, water, energy, things like this, you can really see it reduce your costs ." (Accommodation provider 22)

In addition to this, one respondent commented effectively upon the consequences of saving costs leading to a possible increase in profitability and improving yield:

"I think there are good economic benefits to us as a business by carrying out those practices. I think in the longer term, not only can we perhaps increase our revenue because we'll get more guests or not lose some of our guests; we can actually reduce the costs of running the business." (Accommodation provider 20)

This finding reinforces the significance of saving money as being a key factor in adopting eco-friendly practices and also illustrates that on the whole tourism businesses are becoming more aware of the fact that they really can reduce their costs and as a result see a positive return on their investment. Businesses are always looking at ways to reduce costs and if undertaking environmentally-friendly practices can achieve this then it makes good sense to invest in such practices that are inevitably going to sustain the resources on which tourism businesses fundamentally rely upon in order to operate.

\subsubsection{Organisational Culture}

Tourism businesses also indicated the benefits associated with organisational culture. Businesses can create a good feeling among their staff through the environmental activities they undertake. This feeling was expressed through the following responses:

"I think it does create, as far as staff culture goes, it creates good feeling. You know, they buy into it and they feel that they are doing something good because they are doing their part as they do at home." (Accommodation provider 10) 
"I think it results in a better culture through the organisation as well. It's empowering to people working in that culture knowing that they are contributing towards an organisation that's doing something. I think that's very important." (Transport operator 2)

A small number of tourism businesses think that through their environmental activities they can create a positive atmosphere among their colleagues. If doing things for the environment makes people feel good and everyone is contributing to the same important cause then it can really result in a strengthening of relationships among staff members as such activities can bring people together. Simultaneously, building team-spirit among employees is possibly achieved through a different, yet fun way in which employees are able to carry forward this crucial knowledge into their work and if not already, into their homes and wider community. Table 5 presents a summary of the main advantages of environmental management.

Table 5: Main Advantages of Environmental Management

\begin{tabular}{|l|c|c|}
\hline \multicolumn{1}{|c|}{ Advantages* } & $\mathrm{n}$ & $\%(\mathrm{n}=60)$ \\
\hline Marketing & 28 & 46.67 \\
\hline Economic & 16 & 26.67 \\
\hline Organisational Culture & 6 & 10.00 \\
\hline Other & 10 & 16.67 \\
\hline TOTAL & 60 & 100.00 \\
\hline
\end{tabular}

*Based on multiple responses (excludes purely environmental advantages e.g. 'feel good' factor, doing the 'right' thing).

\subsection{Disadvantages}

In order to gain an understanding of all perspectives, a question was designed to ask respondents about the disadvantages of environmental management. While it was no surprise that many organisations mentioned the initial costs involved, and the fact that environmentally-friendly products tended to be more expensive, most saw this as a barrier rather than disadvantage: 
"There may be some cost factors for some businesses but I think people are prepared to pay the extra. I mean we know that some of the things that are coming in for us are going to cost more, and people will have to pay more when they are travelling and visiting. And I think people are accepting that that'll have to happen." (Accommodation provider 11)

"I would think probably if there are any disadvantages in environmental management it would be financial. I can't honestly think of any other reason why people wouldn't be careful with their environment and look after it - apart from ignorance." (Accommodation provider 17)

"No disadvantages - just cost and resource issues which have to be balanced. It's got to take its place with the other functions that need to be performed." (Attraction operator 6)

Similar views were also expressed in regards to the amount of time consumed by undertaking environmental practices as illustrated by the following response:

"I think in some cases Kiwis are a bit lazy. You have to do just that little bit extra to - to make sure you're following the environmental sustainability approach, and that probably puts some people off...So, I think it's probably just getting people past that first step, and if they're already doing some stuff, it's basically about informing them - well you're already part of the way there." (Accommodation provider 20)

Tourism businesses see these factors as only short-term obstacles to overcome and duly note the benefits far outweigh the costs. In fact, many respondents believe there are no real disadvantages of environmental management as demonstrated by these statements:

"No, I don't think there are any disadvantages. I think it's all a better step really, like it's all a step in the right direction and it's all good for our future, so it's not a disadvantage at all." (Accommodation provider 16)

"I can't think of any off the top of my head, no, because it's -the old adage really that, if you get into good practices and good management, then it spreads down into an everyday thing into other people's lives and their own lives, not just that sort of business or organisational level." (Attraction operator 2)

'If it's done properly and everyone's honest about it I don't think there are [any disadvantages]. If it's not done honestly then I believe there are costs." (Attraction operator 5) 
The last sentence of the last quote above fits in well with the less mentioned disadvantages relating to scepticism, being publicly scrutinised and/or criticised on environmental management. A few tourism businesses note that as a result of practising environmental management, they can be targeted by the media or public in general because their approaches are made more conspicuous through such materials as website information or company policies that may be available to the public. At the same time there remains a level of 'fuzziness' in what environmental management entails which can affect an organisation's efforts as witnessed by the following respondent.

"It's still - it's not that straightforward - in the way of, what people are measuring, what people are offsetting in all areas. What your claims are - you have to be really careful about that." (Transport operator 4)

The same respondent further adds to this notion:

"Well I mean if you claim that you're carbon neutral, that's quite a general statement. I mean, is that our whole company? Is that what we actually have to put on our vehicles or if we do...because then you've got the production of the car before you buy it. Then you've got what happens to it afterwards. I mean, how far do you actually go?" (Transport operator 4)

While this feeling was only evident for a few organisations in this study, it shows that there is a level of confusion surrounding environmental terms as with the concept of sustainable development discussed in Chapter Two. This level of confusion may represent the lack of public awareness as the extent to which environmental management practices should be carried out is not clear. While it may be seen as a good thing to catch out businesses that are not upholding to their claims of being environmentally-friendly, for tourism businesses who are in fact trying to do their part, unfair accusations as a result of media or public criticism may discourage their actual efforts. Therefore further questions remain to be answered in reaching a consensus as to what environmental management for businesses should entail. Businesses cannot do everything, and at present are seeking to do their best with the resources and time available to them. An increase in public awareness, effective communication of such issues and greater cooperation among key stakeholders will be a pivotal step in the right direction for the future of environmentally sustainable tourism. 


\subsection{Role of Public and Private Sector Organisations}

As previously stated, effective urban environmental management might only be achieved through the cooperation of all stakeholders. Various concerns of tourism stakeholders need to be considered. Thus, it seemed fitting for the researcher to include a question to investigate the role of tourism organisations in Wellington such as the RTO, WCC and other recognised industry/sector organisations as a source for environmental management. Tourism businesses were asked: 'what do you believe the role should be regarding environmental management?' From their responses, it was found that tourism businesses believe the role of public and private sector organisations is to provide information and guidance, lead by example, and promote environmentally-friendly operators. Other less popular responses indicate that the public and private sector play an infrastructural, financial and regulatory role in regards to environmental management. The interviews with the five tourism organisations in the following section will be presented in light of these findings to further examine the relationship between such organisations and tourism businesses.

\subsubsection{Informative}

Most respondents believe the role of the public and private sector with regard to environmental management should be to give advice to tourism businesses and guide them in their approaches towards being environmentally-friendly. Public sector agencies and public-private partnerships such as the RTO need to encourage tourism businesses as well as provide relevant information and guidelines in becoming more environmentally-friendly. Some tourism businesses even suggested this could be achieved through the sharing of knowledge and ideas of other businesses in the area that had already been recognised as leaders in sustainable tourism practices:

"It's like - the thing with the environment is that, there's so much information out there. And everyone's doing their own thing. And I suppose for the tourism industry specifically, it would be really good for there to be one, information site or link or whatever, for us to all network with. There's a lot of healthy competition I suppose between [operators], so there's certain information that people keep close to their chests and don't really want to share but it's important that we look at the 
environment as something that's not competitive. It's something that we should be - we should share our ideas with because it is for the better of everyone really." (Accommodation provider 16)

Tourism businesses feel that these public bodies need to be doing much more than they are at present by establishing such networks so that businesses can share ideas openly and work towards a more sustainable future for Wellington. Also, individual businesses believe that the information being provided by the likes of the RTO and other tourism bodies need to be aimed at educating operators in understanding the cost implications of undertaking environmentally-friendly practices, that in fact they can save money in the long-term.

Other types of information that need to be disseminated among tourism businesses that they identified included sustainable visitor trends. Information such as this may highlight to tourism businesses that in fact there is an increase in those visiting Wellington who are looking for 'green' operators thus encouraging them even more so to undertake such practices. In examining the responses of tourism organisations, each expressed their role was to offer support to tourism businesses and provide advice to those wanting to become more sustainable as seen by the statement below:

"We see our role as being primarily about promotion and advocacy - part of that moving forward is that we've identified that the promotion of environmental sustainability is going to be an important issue going forward." (Tourism organisation 2)

Some made mention of the fact that they were able to direct businesses to environmental 'best practice' guides for the various sectors of the tourism industry and inform them on other sustainability related information and websites such as Green Globe and the SBN. Tourism organisations in Wellington are striving to put out sound information to the rest of the industry in recognition of the importance of the environment and actively working towards the key outcomes related to the environment and sustainability as outlined in New Zealand's Tourism Strategy 2015. 


\subsubsection{Leadership}

Tourism businesses believe the role of public and private sector organisations is one of leadership with regard to environmental management. Tourism businesses felt they need to take more action, due to the importance of sustainability within New Zealand and to the industry itself. The Tourism New Zealand Strategy 2015 outlines the significance of sustainability to the tourism industry and therefore businesses expressed the need for the public sector to administer what has been set down as a high level of guidance is required. The following quote illustrates the significance of the leadership role for the public sector:

"I think they should set a standard. I think that they should like enforce it probably a little bit more than they do. I don't know whether our formal approach to this has come about because it's been told it has to, but I don't feel like it has. I think that if we really want to change, the change could be made. And everyone could make change. But I feel like sometimes that the approach is sort of: Oh we don't have to do it! So if we don't have to do it, why should we do it? I think there should be some sort of formal approach to it, some sort of report should be made or everyone should be told this is what we expect of you; this is how it has to be done. And I think that then it's possible that everyone will do it where everyone will have to do it." (Accommodation provider 7)

Another respondent expressed similar views of this type of role and made comment on how they need to be demonstrating such leadership:

"They should be looking at a leading edge world - establish world standards in sustainability and carbon responsibility. They should be establishing a programme that will encompass the key world leaders in that area. The government has yet to lay down the law on what the standards are. We don't have a governmental standard. Some countries do. New Zealand doesn't yet." (Activity operator 5)

From this, one could suggest that while the tourism industry needs to take on a leadership role in sustainability there are even greater implications stemming from national and international bodies. This notion reinforces the global-local nexus as what operators at the local level can do may be a result of the policies in place at a higher level. Nevertheless, tourism businesses believe that there place within the tourism industry hierarchy reflects their potential as a leader to develop a clear 
message for where the sector is heading and guiding them in achieving pro-active environmental management. Having said that, these influential players should come in and coach businesses rather than become heavy-handed and forceful as this may result in losing all the 'good will' that seems to exist among tourism businesses in Wellington. The interviews with tourism organisations discovered that two out of five tourism organisations believe their role is one of leadership as shown by the following quotes:

"We take on a leadership role, as we need to be more on the front foot about what is happening in the industry, so we can drive behaviour and hopefully change the way that businesses operate in keeping with the environment." (Tourism organisation 3)

"Our role is to take a lead and ensure that tourism businesses are operating in an environment that is profitable to them." (Tourism organisation 5)

While few tourism industry organisations recognise their role regarding environmental management for tourism businesses is one of leadership; there remains somewhat of a mismatch between business concerns for what organisations such as the RTO should be doing by what they actually say they are doing. Even though two tourism organisations indicate the need to take the lead, the responses by tourism businesses show that they do not see a clear leader. This finding suggests that because there seems to be no clear leader; businesses may act in own interests in wanting to protect the environment. While there is external pressure for businesses to become more eco-friendly, without a clear message and someone from within the industry to enforce it and guide the tourism industry, there is less likely to be change.

\subsubsection{Marketing}

A similar number of respondents recognised the marketing role public agencies such as the RTO need to play in environmental management. As noted, market image is a key factor in influencing the adoption of environmentally-friendly practices for tourism businesses in Wellington. Drawing on this finding it is no surprise that tourism businesses expressed their views in regards to this role, also bearing in mind 
that the role of organisations such as the RTO is essentially to market the destination. Therefore businesses believe that the RTO should promote the movement of visitors to New Zealand who are seeking or wanting 'green' or sustainable experiences. The following quotes elaborate on this notion:

"...they should like advertise, you know, the green factor. Like whichever activities which are not involving any wastage of the resources, they should promote those activities; highly recommend to tourists, even at the hotels." (Accommodation provider 12)

"Their job is simply to promote it. I mean irrespective of what is done, their job is to go out and tell people that it's being done. So they're marketing organizations... they provide an image of this country offshore or in the markets that they're targeting. So their job is purely to talk about it and present it." (Activity operator 2)

Moreover, tourism businesses indicated the need for the public sector to be promoting the sustainable aspect as a result of the ' $100 \%$ Pure' New Zealand branding. If New Zealand is supposed to be promoted as being clean and green to the rest of the world then businesses who are actively engaging in environmentallyconscious initiatives should be recognised for their efforts and more importantly all tourism businesses should be making sure they are living up to the ' $100 \%$ Pure' identity. At the time of the interviews, some tourism organisations had also recognised the advantages associated with environmentally-friendly businesses and marketing as summed up by the following response:

"As the environment is becoming even more important for the tourism industry we recognise it is important to communicate and promote what the industry is doing and what we're doing... and then with those good stories, we can really push that out to the visitors in terms of what Wellington is doing." (Tourism organisation 2)

Other marketing activities that the public and private sectors need to be engaging in include market research on sustainable trends as well as monitoring and communicating this information back to individual businesses as they feel they do not have the resources to undertake such data collection. As the trend for those seeking 'green tourism' products increases, tourism businesses believe that efforts being made to become environmentally sustainable need to be acknowledged and thus promoted by the wider industry. 
Less frequent responses revealed that the public sector should play a financial, an infrastructural and regulatory role particularly in the case of local government. The financial role refers to providing support and incentives in the form of grants or a subsidy scheme to businesses that go down the 'green' path. As previously found, a large barrier for tourism businesses is the cost of implementing environmentallyfriendly systems or activities so incentives such as these may alleviate this common barrier. The following quote sums up the feeling from a smaller number of respondents:

"I think the companies that do actually want to go down that road I think, you know, there should be some grants or some help or something should be subsidized because they are actually making that effort. I mean at the moment it's up to the choice of the actual company that's doing it. There's no force to do it. So I think the ones that are actually getting off their backsides and actually doing something, they should actually be patted on the back and given a little bit of a help." (Transport operator 4)

Businesses are already overwhelmed with a range of other expenses and those who want to undertake more environmentally sound practices feel that if they do then they should at least be rewarded in some way, especially if it is one way in which they are helping to contribute to the success of Wellington becoming a sustainable tourism destination. Financial incentives may provide the means for other businesses especially smaller ones with limited resources and funding to realistically implement practical ways which minimise their firm's impact on the environment. Public and private sector organisations also stated they had a financial role to play in light of the fact that the region's tourism industry had recently received government funding to put towards sustainable tourism. It was noted that individuals known as Sustainable Tourism Advisors would be employed to assist businesses in their sustainable efforts. Respondents also felt the local city council in particular should be playing a bigger role in providing infrastructure to support the city's goal in becoming sustainable. Issues included increasing recycling services by allowing more grades, providing more efficient public transport and ensuring there are enough recycling facilities around the city. While city councils do not have direct involvement with the tourism industry they are responsible for the management of resources in the region on which tourism relies upon. As well as this, councils have a role in providing for the needs of residents, businesses and the general community. 
Some tourism businesses feel that because the environment is a serious issue, the public sector should be offering more assistance and introducing stricter regulations. One business even made mention of enforcing a penalty e.g. a fine on those who do not comply with environmental standards. In summarising the role of the public and private sector (Table 6), and their relationship with tourism businesses with regard to environmental management, business concerns to some extent are being matched by what public and private sector organisations are doing though there remains a need for greater communication in terms of the activities that are undertaken under the various roles of such organisations. Communication seems to be lacking as the public and private sectors are still coming to terms with understanding their own requirements for environmental sustainability so that they can effectively communicate this back out to the wider tourism industry.

Table 6: Public and Private Sector Role Regarding Environmental Management

\begin{tabular}{|l|c|c|}
\hline Role of Public and Private Sector & $\mathrm{n}$ & $\%(\mathrm{n}=68)$ \\
\hline Informative & 26 & 38.24 \\
\hline Leadership & 14 & 20.59 \\
\hline Marketing & 11 & 16.18 \\
\hline Financial & 10 & 14.71 \\
\hline Infrastructural & 6 & 8.82 \\
\hline Regulatory & 1 & 1.47 \\
\hline TOTAL & 68 & 100.00 \\
\hline
\end{tabular}

*Based on multiple responses 


\section{CHAPTER 6 DISCUSSION AND CONCLUSION}

\subsection{Discussion}

This study found that the approaches towards environmental management by tourism businesses in Wellington were mainly informal. The approaches often consist of businesses undertaking operational practices that are essentially daily reactive measures taken by businesses in order to reduce a firm's impact on the environment. Such an approach was as expected, common with smaller businesses. As noted by Swarbrooke (1999) small businesses lack the resources and formal management structures in contrast to larger business. However, a high level of general awareness of global environmental issues and the need to manage their firm's impacts indicates that tourism businesses in Wellington are beginning to move slowly towards adopting more formal approaches to environmental management. This is evident as a result of the number of businesses that are undertaking activities with regard to supply chain management, environmental awareness and training and environmental interpretation.

As noted in Chapter Two, such aspects of environmental management often require a much greater level of environmental knowledge and commitment. Coupled with the size of most small firms in particular, their less formal management structure and dominance within New Zealand's tourism industry presents an issue. While there is evidence of increasing numbers of tourism businesses attempting to address issues of environmental management, most are only in the early stages of incorporating more formal initiatives into their business because of a lack of knowledge and resources. This suggests that tourism businesses are not ignoring environmental concerns they just feel as if they do not have all the information, tools and a proper framework to guide them. Tourism businesses in the initial stages of becoming more formal are trying to assess their current situation, consider their environmental impacts as well as the potential impacts of such change but without a clear path through which to achieve sound environmental management practices, businesses continue to struggle to put their intentions into practice. 
One way in which tourism businesses are moving towards becoming more environmentally responsible is through their involvement with external organisations. In particular, the extent of involvement with organisations such as Qualmark and Green Globe indicated that tourism businesses were attempting to seek out answers to becoming more environmentally-friendly. With the introduction of Qualmark Green, a number of tourism businesses are recognising the need to become more formal in their approach. While most tourism businesses have little involvement with external organisations, many have recently turned to Qualmark for information and assistance. Once again because many tourism businesses are in the early stages of implementing formal environmental management practices they have to step back and assess their current situation as to whether they can actually fit the criteria before they can make a proper decision to commit to such a scheme.

Another significant finding related to the level of involvement with external organisations. Most businesses expressed either little or no involvement with WCC and from a tourism perspective, the RTO. The attitudes of businesses suggested that the RTO was doing little from an environmental point of view. This notion does not concur with Timur and Getz (2008) who found that DMOs have the most crucial roles in achieving inter-stakeholder collaboration due to their available resources, financial power and ideal position or centrality within the tourism industry. From a national perspective, the New Zealand Tourism Strategy 2015 has recognised the need to protect and enhance the environment. Yet from a more regional viewpoint the responses from businesses suggest that the RTO needs to take on a greater responsibility in terms of environmental management. This notion was further emphasised with regard to identifying the roles of public and private sector organisations including the PWT, Ministry for the Environment and industry sector associations.

Most tourism businesses believed the role of the public and private sector was to provide reliable information and advice to businesses in guiding them to becoming more environmentally-friendly. As tourism businesses do not have all the answers they feel that public and private sector organisations need to do a lot more with regard to environmental management. Organisations such as the RTO need to encourage businesses to take up environmental initiatives and provide sound 
information to the rest of the industry. While the role of providing information proved the most dominant response by tourism businesses, the role of leadership by the public and private sectors as identified by individual businesses draws a strong connection to their greater environmental responsibility in working towards the wider goal of sustainable urban tourism. Based on their position within the tourism hierarchy, businesses believe the public and private sectors need to actively lead the sector by example in terms of where it is heading and administering what has been set down in the New Zealand Tourism Strategy 2015. This point reflects the globallocal nexus (Milne and Ateljevic, 2001) as what is done at the national level may inform or influence what occurs at the regional or local level. Essentially, what this means is that the public and private sectors need to be much more proactive in their role regarding environmental management for tourism businesses.

As above, the findings demonstrate a number of interactions taking place between the different aspects of environmental management. In attempting to further understand and contribute to existing knowledge in this area of study, the factors influencing adoption and barriers to environmental management were examined in Chapter Five. A number of interrelated motivations or factors were also found to play a role in the decision to adopt environmentally-friendly practices. The main factors influencing the adoption of environmental management practices by tourism businesses in Wellington were consistent with existing literature. Zutshi and Sohal (2004) broadly divided these factors into four main categories: the market, social, financial and regulatory drivers.

Of the four drivers, financial influences played an important part in the adoption of environmentally-friendly practices as described by the businesses that were interviewed. A number of businesses had recognised they were able to save money in the long term as a result of the reduced consumption of resources. Past studies conducted by Chan and Ho (2006) and Le et al., (2006) confirm this finding as a strong association exists between the economic interests of firms and their adoption of environmental practices as they save both time and resources. Moreover, tourism businesses identify the financial benefits as an advantage of practising environmental management because they are able to keep their costs down and as a result sustain the natural resources that they are dependent upon. 
Social and market factors were also a common response among tourism businesses. While both of these factors were treated separately in the previous chapter, the responses indicate a level of interaction between them. As a result of pressures from consumers and the wider tourism industry, businesses are responding by adopting more environmentally-friendly approaches to meet the needs of their clientele and to attract the 'green' market. Wellington tourism businesses recognise the marketing advantages associated with becoming more environmentally responsible while at the same time they are being pressured by their customers to become 'green'. Both of these forces are important because tourism businesses want to retain their existing customers as well as attract potentially new ones. This is reinforced by the fact that tourism businesses expressed the most common advantage of environmental management was associated with gaining a marketing edge.

The only factor that was not prominent in this study compared with Zutshi and Sohal (2004) was regulatory drivers. Existing pressure from guidelines and regulations at the global-local level may motivate tourism businesses to adopt environmental practices; however this was not the case for Wellington tourism businesses; at the national level, the Ministry for the Environment is currently developing a package of national environmental standards under the RMA. These standards will represent mandatory "bottom line regulations" that apply nationally (Ministry for the Environment, 2009). Also, in terms of industry self- regulation, it seems that accreditation schemes such as Qualmark Green are likely to have a greater effect on tourism businesses in New Zealand in the near future, as evidenced by the number of businesses that are becoming involved with this external organisation or are in the process of obtaining the environmental mark of quality.

In analysing the barriers, the results resembled some of the factors influencing the adoption of environmentally-friendly practices as found in the literature. While businesses recognise the opportunity to cut costs and save money in the future, initial costs or costs of upgrading existing facilities to become more eco-efficient prove to be a common barrier as found by Chan (2008) and McNamara and Gibson (2008). To further compound this situation that many tourism businesses face, not seeing an immediate return on investment is a psychological battle. Businesses unable to see a clear path to becoming 'green' do not want to invest considerable amounts of time 
and money into a decision that could prove costly to the organisation. This finding is reiterated by Chan (2008) who finds hotels in China may doubt the ongoing effectiveness of environmental programmes and have difficultly in maintaining continual improvement. Managers and employees can become uncertain and less motivated when there seems to be no single 'right' way to becoming environmentally responsible. Consequently, this may lead to tourism businesses putting off the development and implementation of such environmental strategies, once again reinforcing the significance of informal environmental management approaches being undertaken by tourism businesses in Wellington. Figure 9 attempts to illustrate the complexity of the multitude of interrelated factors that influence the decision to adopt environmentally responsible tourism practices.

\section{Figure 9: Influences and Barriers of Environmental Management Practices}

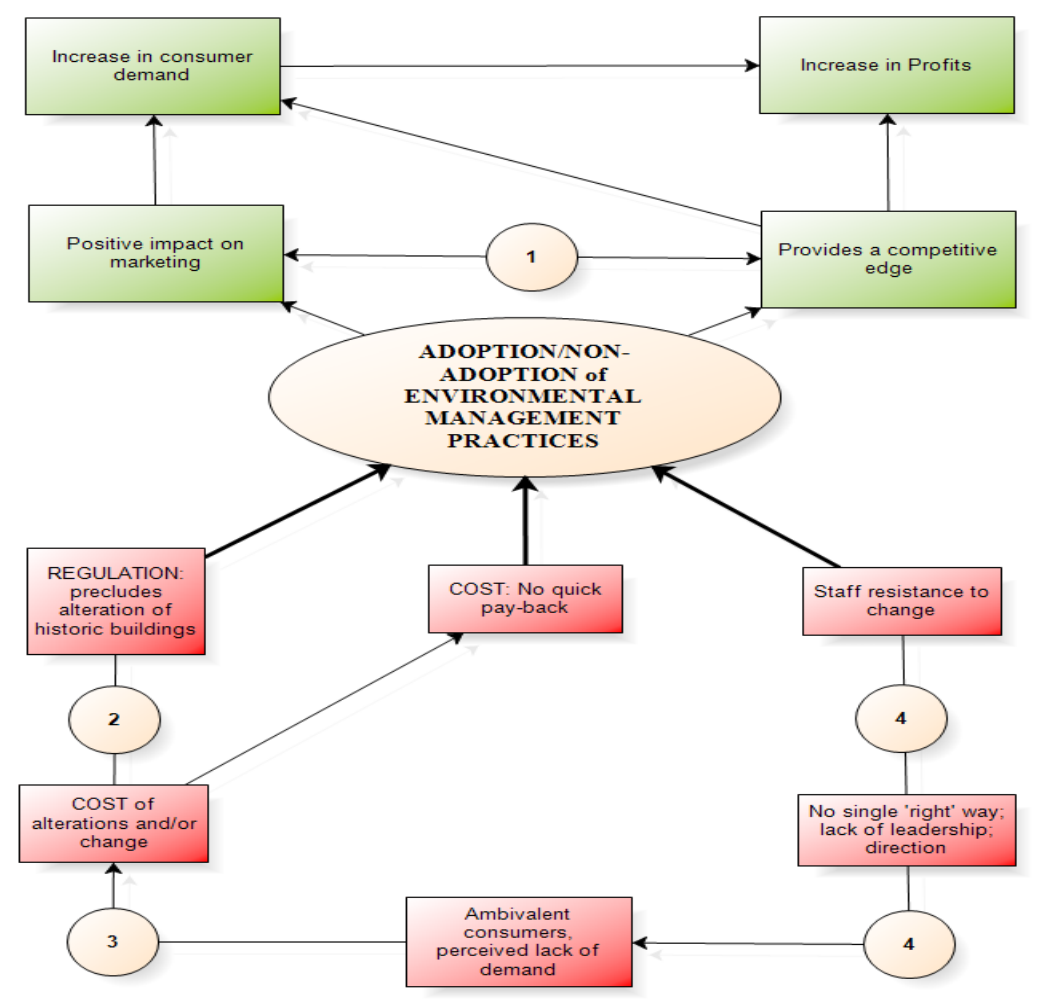

Notes:

1. Positive impact on marketing creates a competitive edge which in turn impacts on marketing that increase niche consumer demand.

2. Changes to circumvent regulation add to cost of alterations, will be prohibitive for small businesses.

3. Perceived lack of demand does not encourage change, i.e. no return on costs, investment is a loss.

4. Lack of guidance or leadership of staff to adopt change; lack of positive guidance or marketing by agent. 


\subsection{Conclusion}

\subsubsection{The Aims and Objectives of this Research}

The purpose of this research project was to investigate the extent to which tourism businesses in Wellington are undertaking environmental management. In order to address this problem, qualitative research based on semi-structured interviews were conducted with individual tourism businesses and tourism industry organisations to gain an overall idea of their environmental management approaches and in terms of what stage they are at in the process. In particular, this research sought to identify factors influencing the adoption of environmental management practices, barriers, and the role of public and private sector agencies with regard to environmental management. This was necessary in order to gain a greater understanding of such a complex topic.

The broad objectives of this research project were as follows:

- Identify and examine the extent of environmental management approaches by tourism businesses in Wellington.

- Explore and analyse similarities and differences across sectors, if any.

- Identify and analyse factors and barriers influencing the adoption of environmental management practices.

- Identify and discuss the role and relationship of the public and private sector with regard to environmental management.

As found in Chapter Two, most tourism studies have focused on rural or protected areas, thus there is a need to investigate environmental management by tourism organisations within urban settings. This research attempts to take a step towards addressing a gap in the literature on environmental management for tourism businesses as it seeks to not only document approaches but also to explain them in order to contribute to the existing body of knowledge on this topic and provide some insight into sustainable urban tourism in New Zealand. 


\subsubsection{Summary and Research Implications}

This study has been conducted in order to explore the reality and extent of approaches towards environmental management by tourism organisations in Wellington. It has sought to provide a better understanding of such approaches by recognising the actions and attitudes of individual tourism operators and industry organisations. As stated above, this study has identified the range of factors influencing the adoption of environmental practices, barriers, and analysed the role and relationship of public and private sector agencies in environmental management for tourism businesses. From the outset of this research project, the focus has been on the awareness of the environment in terms of global issues, the importance of managing the negative impacts and capacity to respond to such impacts by taking corrective action. The global-local nexus framework (Figure 2) and construction of a series of matrices (Appendix 1) provided an appropriate illustration of how tourism operates at various scales of sustainable development and has shaped the structure of this study.

An extensive review of the literature has further demonstrated the complexity of this topic and in turn led to the development of a suitable methodology. A qualitative approach and analysis through the use of NVivo has been carried out in order to report the range of perspectives based on the overall aims and objectives of this research. While this study, like any other carries with it a number of related limitations, it nonetheless attempts to investigate the extent to which tourism organisations in Wellington are practising environmental management and explains the reasons behind this in order to provide a better understanding of this topic. The study also reveals further research implications and issues that may contribute to how future studies in tourism are conducted with regard to environmental management within urban settings.

From the results of this study it is apparent that tourism businesses in Wellington, regardless of sector are mainly taking an informal approach towards environmental management. With the exception of large tourism businesses e.g. chain hotels in Wellington that operate at a multinational (global) level, the majority of tourism businesses have adopted a broad range of operational practices in the areas of energy, 
water and waste minimisation representing a series of reactive measures taken to reduce a firm's immediate impact on the environment. Whilst such an approach was expected, and proved to be consistent within the literature, employing a qualitative and more open method of enquiry revealed that tourism businesses in Wellington were slowly moving towards change. This was evident from the number of businesses that indicated they were undertaking environmental activities related to supply chain management, employee awareness and training, and interpretation; the literature considers these as requiring a greater level of environmental knowledge and thus may form part of a more formal approach towards environmental management. Moreover, the main factors influencing the adoption of environmentally-friendly practices have provided reasons for this change. Tourism businesses are able to see the financial benefits such as saving money in the longterm, the positive impact on positioning from a marketing perspective and as a result see a potential increase in consumer demand. However, due to a lack of resources and guidance, tourism businesses continue to face a range of difficulties, which again affects the pace of change.

The main barriers to environmental management as reported by respondents demonstrated a relationship between financial, physical and psychological factors as tourism businesses may find it difficult to cover initial costs. The problem becomes even greater when businesses have to factor in the physical nature of the premises available to implement new methods with an environmental focus. In a period of economic downturn costs in an increasingly competitive market are further exacerbated. Additionally, tourism businesses are less likely to invest funds into environmental initiatives where they are unable to see an immediate outcome. To add to this, tourism businesses express concern that there is no single 'right' way to becoming green so tourism businesses remain uncertain about putting money into such programmes or strategies. At present, the tourism industry has been slow to adopt national strategies or apply them at the regional and local levels. The need for greater cooperation between key stakeholders of tourism is essential to the development of urban environmental sustainability.

As with businesses, the public and private sectors have an important part to play with regard to environmental management. The responses show that they need to take a 
much more proactive role and administer what has been set down at the national level. Although there has been a lack of leadership and guidance, the public and private sectors have begun to recognise the importance in becoming an environmentally responsible leader. This is evidenced by the RTO in the Wellington Visitor Strategy 2015 (PWT, 2008) which is in line with tourism's national strategy and WCC's vision for the city to become sustainable. This again makes the connection back to changing role of the RTO from marketing to managing. As noted, Timur and Getz (2008) support this idea as the DMO is pivotal to sustainable urban tourism. In addition, recent government funding for the Sustainable Tourism Advisers in Regions (STAR) programme will see tourism operators being assisted one on one by an employed adviser who will work with businesses in minimising their impacts on the environment (Tourism New Zealand, 2008). The introduction of this programme represents a key contribution to one of the main outcomes in the New Zealand Tourism Strategy as outlined in Chapter One. This outcome underlines the need for the tourism sector to take a leading role in protecting and enhancing the environment. Furthermore, the STAR programme is aligned with Qualmark's environmental criteria and priority is given to those already signed up with Qualmark. This accreditation scheme recognises tourism businesses efforts in managing their environmental impacts. Furthermore, in New Zealand the Inbound Tour Operators Council (ITOC) has recently stated that all full members are to be Qualmarked by 31 March 2009 (ITOC, 2008).

At the global level, the UNWTO has called for tourism leaders to join the green economy. The Assistant Secretary General stressed that "tourism has only scratched the surface of our clean, green potential - now it's time to mainstream it." (Travel Mole, 2009). Even though Agenda 21 for the Travel and Tourism Industry was introduced in 1996, over a decade later, there has been another call to urgency for the tourism industry to do much more than it has in the past particularly during a time when the world is experiencing an economic downturn. This call to action is likely to filter down through to national government and the private sector reinforcing once again the importance of cooperation between multiple stakeholders in sustainable tourism. During the period of study (Feb 08 - Feb 09), a number of significant developments within the tourism industry occurring at the global-local level have pointed to the reality of this issue and thus its importance to the tourism industry as a 
whole. In investigating environmental sustainability further connections are made with economic and social considerations. While this study only concentrated on the environmental dimension or element, the overall goal is to achieve sustainable tourism. The aim for the future in tourism is likely to be focused on developing sustainable tourism destinations. Sustainable tourism provides a clear opportunity to combine environmental protection with socio-economic benefits in a profitable, future-proofed business.

\subsubsection{Recommendations for Industry}

The investigation into the environmental management approaches of tourism businesses in Wellington has contributed to the body of existing knowledge in this area of study as seen from the previous section. In formulating the overall research problem it was also hoped that this research might also assist in providing possible solutions to real problems by way of industry recommendations. These are described below with reference to both the individual tourism businesses, and the public and private sector.

In the context of this study, tourism businesses in Wellington are undertaking mainly informal approaches towards environmental management. A clear reason behind this finding is based on the number of barriers that may hinder businesses from adopting such practices. The biggest hurdle for these businesses whereby the majority of them are small-medium sized is to essentially overcome the barriers. While financial barriers in particular can cause a huge strain on businesses to becoming more environmentally responsible, the introduction of the STAR programme is likely to alleviate some of the burden. Tourism businesses that are serious about wanting to make a change need to embrace programmes such as this, as they represent a key step forward. The overall impression gained by the researcher from the majority of respondents is that they have good intentions but are uncertain as to how they can put these into practice. 
Furthermore, while tourism businesses have expressed they are undertaking informal methods of managing their impacts on the environment, many have simply not documented such actions and so in retrospect they are actually not aware of some of the environmental initiatives that they in fact do carry out. This notion reflects the informal nature and management of small businesses. However, as the environment has become a greater concern in today's society and within the tourism industry, individual operators need to work towards becoming more formal and strategic in their management of the business. A first step for smaller businesses would be to actually document their environmental initiatives so that they have a realistic idea of their efforts so far. By way of monitoring these, they then may be able to set realistic targets to achieve in areas such as water, energy and waste to begin with. As expressed by some respondents, when businesses get into good practices they often lead to greater performance which in turn, may result in an increase in efficiency. The changing nature of society and the importance placed on managing and protecting the environment suggests that smaller businesses may need to develop sound environmental management practices with a strategic outlook. Encouragement and assistance from public and private sector organisations is likely to be necessary.

As expressed, the need for greater cooperation between key stakeholders of tourism is essential to the development of urban environmental sustainability. The majority of the responses from those interviewed indicated that the public and private sector need to be taking on a more proactive role with regard to urban environmental management than they have in the past. The introduction of Qualmark Green and the STAR programme have seen the RTO embracing and facilitating these environmentally-focused programmes; indicating there is a move towards changing the RTO's role of marketing to putting a greater emphasis on management. This will be crucial in working towards the ultimate goal of sustainability in tourism with regard to the company's and WCC's overall vision for the future. Due to the importance of the environment at the national level, at the regional level in line with the city's vision, the tourism industry is perhaps likely to be seen as the lead sector in working towards this aim.

Public and private sector organisations in Wellington will need to take on a leadership role and guide the industry. As stated above, with the exception of 
providing information, respondents expressed that they need to engage more with them in terms of environmental issues, communicate and provide more encouragement. It is evident that there are some exceptional stories out there of businesses, regardless of size that are proactive in managing their impacts with the environment and so perhaps with the lead of these 'bigger' organisations, they could facilitate a networking system within the tourism industry. Business to business networking could be encouraged so that tourism operators could engage with other operators and learn from others' experiences. To add to this, such organisations will also need to take on the role of providing training for smaller businesses in particular, in developing more formal or strategic management skills that are related to environmental management.

Tourism businesses that are practising environmental management could also be featured in an environmentally sustainable tourism business section of the RTOs website. This notion was evident from the respondents who commented on the marketing advantages associated with becoming environmentally-friendly. Other advantages or benefits of practising environmental management also need to be communicated within the industry, particularly in relation to the financial implications of adopting environmental management practices. Businesses need to understand that they can realistically save money in the long-term. The provision of information and communication of these benefits may encourage businesses to takeup such practices. Actual case studies based on real scenarios or stories of where tourism businesses have actually saved money may serve as a further way in which to inform businesses of the long-term financial benefits.

Iconic tourist attractions and large chain hotels within the region could also play an important role in leading the tourism sector by example. Based on their public reputation they may have an influence on other tourism businesses to follow in their footsteps to becoming environmentally responsible. In addition, they may have the ability to enhance tourist's perceptions of Wellington as an environmentally sustainable tourism destination which leads to an overall positive image. Some tourism businesses in Wellington are responsible for the running of big events and because of the high degree of public exposure that such events bring; future events are likely to be focused on environmental sustainability. In achieving urban 
environmental sustainability in Wellington, greater provision of specific information regarding environmental sustainability, increased communication, engagement and encouragement among all key stakeholders in tourism is likely to be necessary.

\subsubsection{Recommendations for Future Research}

This study has examined the environmental management approaches by tourism businesses in Wellington. By doing this, it has provided a snapshot of where the tourism industry is at with regard to environmental management. While this study has concentrated on the main sectors of tourism: namely accommodation, attractions and activities, and transport, there is a need to explore other sectors related to tourism given the size and fragmented nature of the industry. Tourism incorporates a number of different sectors of the economy so future research may aim to explore different environmental management approaches regarding the events, retail, entertainment and food and beverage sector. In addition, future research may narrow the focus down to look at individual areas of environmental management such as supply chain, environmental awareness and training, and environmental interpretation particularly within an urban setting. The lack of environmental interpretation by Wellington tourism businesses points to the need to further investigate this area of enquiry as it is likely to become a more important aspect that businesses take more notice of in the future because of the increase in consumers seeking environmentally-friendly tourism products and experiences.

Similar research examining urban environmental management approaches may also be conducted within other New Zealand cities such as Auckland and Christchurch to identify whether or not there are any differences in the attitudes and environmental behaviours of tourism businesses other than in Wellington. Wellington is the capital of New Zealand so does being the capital city put more pressure on tourism businesses to follow the 'green path'? This type of research could also extend to other capital cities of the world as there may be lessons to be learnt from other cities. The presence and influence of a diverse range of organisations concerned with 
tourism and the environment may possibly impact on the extent to which tourism businesses are practising environmental management.

Due to the introduction of Qualmark's enhanced environmentally responsible criteria through Qualmark Green there remains a need to investigate the merits of this business tool as it is recognised as the world's first fully integrated quality and environmental system. International visitors are drawn to New Zealand for its perceived 'clean and green' image thus future research may continue to explore the environment as a value of quality within the tourism industry. Future research may also be aimed at utilising a similar framework and methodology to monitor progress and report any changes in the attitudes and behaviours of tourism businesses with regard to environmental management especially to assess the outcomes of such initiatives as Qualmark Green and the recently introduced STAR programme.

Given the relatively small sample of this study, it has provided a snapshot of urban environmental management approaches by tourism organisations in Wellington and indicated their current stage of adoption. While this study brings with it a number of inherent limitations and may not be representative of New Zealand, it has, nonetheless, brought to mind a number of ideas and further implications of environmental management at the national, regional and local level. For tourism, a global economic activity that relies heavily on the environment; it is undoubtedly clear that tourism businesses cannot simply ignore environmental issues.

Environmental management for tourism businesses will continue to become an even more important issue in the future as general public awareness and education of these issues increases at the global-local level. Coupled with this, advances in innovative technologies aimed at managing environmental impacts will assist businesses to continually improve. However, at present, the overwhelming evidence of impending climate change and rise in recent natural disasters only further emphasises the importance of taking the necessary steps in managing and protecting the environment. In addition, the increase in the size of urban populations coupled with the increase in visitor activity at urban destinations indicates the serious need to work towards sustainable tourism within urban settings. As the world's largest industry, it is evident that tourism will continue to be seen as a potential leader in effecting change in order to safeguard the environment for future generations. 


\section{REFERENCES}

Absolutely Positively Wellington (2007). Towards Carbon Neutrality: A Climate Change Vision for Wellington. Available:

http://www.wellington.govt.nz/services/environment/climate/climatechange.h $\underline{\text { tml }}$ [08 April 2008]

Air New Zealand (2008). About Us: Environment.

Available: http://www.airnewzealand.co.nz/aboutus/environment/default.htm

[06 Jan 2009]

Alavarez Gil, M.J., J. Jimenez Burgos and J.J. Cespedes Lorente (2001). An Analysis of Environmental Management, Organisational Context and Performance of Spanish Hotels. Omega, 29: 457-471.

An Inconvenient Truth (2006). The Science: What is Global Warming? Available: http://www.climatecrisis.net/thescience/ [March 22 2008]

Ateljevic, J. (2002). Survival of small tourism firms: Owners, environment and management practices in the Centre Stage Region. $\mathrm{PhD}$ Thesis, Victoria University of Wellington, New Zealand.

Ayuso, S. (2006). Adoption of Voluntary Environmental Tools for Sustainable Tourism: Analysing the Experience of Spanish Hotels. Corporate Social Responsibility and Environmental Management, 13: 207-220.

Bartone, C., J. Bernstein, J. Leitmann and J. Eigen (1994). Toward Environmental Strategies for Cities: Policy Considerations for Urban Environmental Management in Developing Countries. Washington, D.C.: The World Bank.

Bohdanowicz, P. (2006). Environmental Awareness and Initiatives in the Swedish and Polish Hotel Industries - Survey Results. International Journal of Hospitality Management, 25: 662-682.

Brundtland, G.H. (1987). Our Common Future: World Commission on Environment and Development. Oxford: Oxford University Press.

Buckley, R. (2002). Tourism EcoLabels. Annals of Tourism Research, 29 (1): 183208.

Buckley, R., and G.F. Araujo (1997). Environmental Management Performance in Tourism Accommodation. Annals of Tourism Research, 24 (2): 465-469.

Bulkeley, H., and M. Betsill (2005). Rethinking Sustainable Cities: Multilevel Governance and the 'Urban' Politics of Climate Change. Environmental Politics, 14 (1): 42-63. 
Camagni, R., R. Capello and P. Nijkamp (1998). Towards Sustainable City Policy: An Economy-Environment Technology Nexus. Ecological Economics, 24: 103-118.

Canadian Travel Press (2007). Sandals and Beaches Resorts: A Responsible Champion. November 22.

Carson, R. (1962) Silent Spring. New York: Houghton Mifflin.

Carter, R.W., D. Whiley and D. Knight (2004). Improving Environmental Performance in the Tourism Accommodation Sector. Journal of Ecotourism, 3 (1): 46-48.

Chan, E.S.W. (2008). Barriers to EMS in the Hotel Industry. International Journal of Hospitality Management, 27: 187-196.

Chan, E.S.W., and S.C.K Wong (2006). Motivations for ISO 14001 in the Hotel Industry. Tourism Management, 27: 481-492.

Chan, W.W., and K. Ho (2006). Hotels' Environmental Management Systems (ISO 14001): Creative Financing Strategy. International Journal of Contemporary Hospitality Management, 18 (4): 302-316.

Chiesura, A. (2004). The Role of Urban Parks for the Sustainable City. Landscape and Urban Planning, 68: 129-138.

Claver-Cortes, E., J.F. Molina-Azorin, J. Pereira-Moliner and M.D. Lopez-Gamero (2007). Environmental Strategies and Their Impact on Hotel Performance. Journal of Sustainable Tourism, 15 (6): 663-679.

Collier, A., and S. Harraway (2006). The New Zealand Tourism Industry. Auckland: Longman.

Collins, E., S. Lawrence, K. Pavlovich and C. Ryan (2007). Business Networks and the Uptake of Sustainability Practices: The Case of New Zealand. Journal of Cleaner Production, 15: 729-740.

D'Amore, L.J. (1993). A Code of Ethics and Guidelines for Socially and Environmentally Responsible Tourism. Journal of Travel Research, 31 (3): 64-66.

Dahlmann, F., S. Brammer and A. Millington (2008). Environmental Management in the United Kingdom: New Survey Evidence. Management Decision, 46 (2): 264-283.

Darnall, N., I. Henriques and P. Sadorsky (2008a). Do Environmental Management Systems Improve Business Performance in an International Setting? Journal of International Management, 14: 364-376. 
Darnall, N., G.J. Jolley and R. Handfield (2008b). Environmental Management Systems and Green Supply Chain Management: Complements for Sustainability. Business Strategy and the Environment, 17 (1): 30-45.

Davies, M.B. (2007). Doing a Successful Research Project: Using Qualitative or Quantitative Methods. New York: Palgrave MacMillan.

Department of Conservation (2008a). About DOC New Zealand Department of Conservation. Available: http://www.doc.govt.nz/about-doc/ [06 Jan 2009]

Department of Conservation (2008b). New Zealand Environmental Care Code. Available: http://www.doc.govt.nz/parks-and-recreation/plan-andprepare/care-codes/nz-environmental-care-code/ [08 June 2008]

Diamantini, C., and B. Zanon (2000). Planning the Urban Sustainable Development: The Case of the Plan for the Province of Trento, Italy. Environmental Impact Assessment Review, 20: 299-310.

DiCicco-Bloom, B., and B. F. Crabtree (2006). Making Sense of Qualitative Research. Medical Education, 40: 314-321.

Dymond, S.J. (1997). Indicators of Sustainable Tourism in New Zealand: A Local Government Perspective. Journal of Sustainable Tourism, 5 (4): 279-293.

Edgell, D. L. (2006). Managing Sustainable Tourism: A Legacy for the Future. Binghamton, New York: Haworth Hospitality Press.

Edmonds, J. (2006). Landscape: A Cultural Phenomena. Presented at the New Zealand Tourism and Hospitality Research Conference, University of Otago, New Zealand, December.

Erdogan, N., and E. Baris (2007). Environmental Protection Programs and Conservation Practices of Hotels in Ankara, Turkey. Tourism Management, 28: 604-614.

Flick, U. (2006). An Introduction to Qualitative Research. London: Sage.

Font, X. (2002). Environmental Certification in Hospitality: Progress, Process and Prospects. Tourism Management, 23: 197-205.

Font, X., and C. Harris (2004). Rethinking Standards from Green to Sustainable. Annals of Tourism Research, 31 (4): 986-1007.

Garrod, B., and P. Chadwick (1996). Environmental Management and Business Strategy: Towards a New Strategic Paradigm. Futures, 28 (1): 37-50.

Gindl, M., and F. Wukovitsch (2005). Partnerships Contributing to Sustainable Urban Tourism. In Spillovers and Innovations: Space, Environment and the Economy edited by G. Maier and S. Sedlacek. Vienna Austria: Springer, pp. 119-133. 
Glesne, C., and A. Peshkin (1992). Becoming Qualitative Researchers: an Introduction, New York, NY: Longman.

Gonzalez-Benito, J., and O Gonzalez-Benito (2005). Environmental Proactivity and Business Performance: An Empirical Analysis. Omega, 33: 1-15.

Gough, S., and W. Scott (1999). Education and Training for Sustainable Tourism: Problems, Possibilities and Cautious First Steps. Canadian Journal of Environmental Education, 4: 193-212.

Greater Wellington Regional Council (2007). Long-Term Council Community Plan (LTCCP). Wellington, New Zealand.

Greenhotelier (2008). About Us. Available:

http://www.greenhotelier.org/pages/about us.html [28 March 2008]

Green Globe (2007). What is the History of the Green Globe Programme? Available: http://www.ec3global.com/products-programs/green-globe/your-questionsanswered/history-of-green-globe/Default.aspx [26 March 2008]

Grubb T.R.J (2007). Exploring Environmental Management among Tourism operators in New Zealand's Nelson/Tasman Region. Masters Thesis, Victoria University of Wellington, New Zealand.

Ham, S.H. (1992). Environmental Interpretation: A Practical Guide for People with Big Ideas and Small Budgets. Golden, Colorado, USA: Fulcrum Publishing.

Hardy, A.L., and R.J.S. Beeton (2001). Sustainable Tourism or Maintainable Tourism: Managing Resources for More Than Average Outcomes. Journal of Sustainable Tourism, 9 (3): 168-192.

Haughton, G. (1999). Environmental Justice and the Sustainable City. Journal of Planning Education and Research, 18: 233-243.

Healey, M.J., and M.B. Rawlinson (1993). Interviewing Business Owners and Managers: A Review of Methods and Techniques. Geoforum, 24(3): 339-355.

Herremans, I.M. (2006). Introduction to Cases and Environmental Thought Leaders. In Cases in Sustainable Tourism: An Experiential Approach to Making Decisions edited by I.M. Herremans. New York: Haworth Hospitality Press, pp. 1-6.

Hillary, R. (2004). Environmental Management Systems and the Smaller Enterprise. Journal of Cleaner Production, 12: 561-569.

Hinch, T.D. (1996). Urban Tourism: Perspectives on Sustainability. Journal of Sustainable Tourism, 4 (2): 95-110. 
Hunter, C. (1997). Sustainable Tourism as an Adaptive Paradigm. Annals of Tourism Research, 24 (4): 850-867.

Hunter, C. (2002). Aspects of the Sustainable Tourism Debate from a Natural Resources Perspective. In Sustainable Tourism: A Global Perspective edited by R. Harris, T. Griffin and P. Williams. Boston: Butterworth-Heinemann, pp. $3-23$.

Inbound Tour Operators Council (2008). New ITOC Members. Available: http://www.itoc.org.nz/newsletters 1.asp?id=118 [28 Jan 2009]

International Council for Local Environmental Initiatives. (2007). Tales of Two Cities: Partnerships for Urban Sustainability. Available: http://www.unep.org/urban_environment/urbannewsletter/issuefeb/publicatio $\underline{\text { ns.asp }}$ [26 July 2008]

International Tourism Partnership (2008). ITP and the Environment. Available: http://www.tourismpartnership.org/Leadership/Environment.html [28 March 2008]

Irvine, H., and M. Gaffikin. (2006). Getting In, Getting On, and Getting Out: Reflections on a Qualitative Research Project. Accounting, Auditing, and Accountability Journal, 19 (1): 115-145.

Jayaraman, V., R. Klassen and J.D. Linton (2007). Supply Chain Management in a Sustainable Environment. Journal of Operations Management, 25 (6): 10711074.

Jennings, G. R. (2005). Interviewing: A Focus on Qualitative Techniques In Tourism Research Methods: Integrating Theory with Practice edited by B.W. Ritchie, P. Burns and C. Palmer. Wallingford, Oxfordshire, UK: CABI, pp. 99-117.

Jiang, R.J., and P. Bansal (2003). Seeing the Need for 14001. Journal of Management Studies, 40 (4): 1047-1067.

Kasim, A. (2007). Corporate Environmentalism in the Hotel Sector: Evidence of Drivers and Barriers in Penang, Malaysia. Journal of Sustainable Tourism, 15 (6): 680-699.

Kirk, D. (1995). Environmental Management in Hotels. International Journal of Contemporary Hospitality Management, 7 (6): 3-8.

Kirk, D. (1998). Attitudes to Environmental Management Held by a Group of Hotel Managers in Edinburgh. International Journal of Hospitality Management, 17: 33-47. 
Le, Y., S. Hollenhorst, C. Harris, W. McLaughlin and S. Shook (2006). Environmental Management: A Study of Vietnamese Hotels. Annals of Tourism Research, 33 (2): 545-567.

Lear. L. (2002). Introduction. In Silent Spring edited by R. Carson and E. O. Wilson. New York: Houghton Mifflin Harcourt, pp. x-xix.

Leslie, D. (2001). Serviced Accommodation, Environmental Performance and Benchmarks. Benchmarks and Hospitality in Tourism, 127-147.

Lynes, J.K., and D. Dredge (2006). Going Green: Motivations for Environmental Commitment in the Airline Industry. A Case of Scandinavian Airlines. Journal of Sustainable Tourism, 14 (2): 116-138.

McCool, S.F., R.N. Moisey and N.P. Nickerson (2001). What Should Tourism Sustain? The Disconnect with Industry Perceptions of Useful Indicators. Journal of Travel Research, 40: 124-131.

McKercher, B. (1993). The Unrecognised Threat to Tourism: Can Tourism Survive Sustainability? Tourism Management, 131-136.

McManus, P. (2005). Vortex Cities to Sustainable Cities: Australia's Urban Challenge. Sydney: UNSW Press.

McNamara, K.E., and C. Gibson (2008). Environmental Sustainability in Practice? A Macro-Scale Profile of Tourist Accommodation Facilities in Australia's Coastal Zone. Journal of Sustainable Tourism, 16 (1): 85-100.

Macbeth, J. (2005). Towards an Ethics Platform for Tourism. Annals of Tourism Research, 32 (4): 962-984.

Madin, E., and D.M. Fenton (2004). Environmental Interpretation in the Great Barrier Marine Park: An Assessment of Programme Effectiveness. Journal of Sustainable Tourism, 12 (2): 121-137.

Mahadevia, D. (2001). Sustainable Urban Development in India: An Inclusive Perspective. Development in Practice, 11 (2 \& 3): 242-259.

Meade, B., and A. del Monaco (2001). Introducing Environmental Management in the Hotel Industry: A Case Study of Jamaica. Tourism in South America, 129142 .

Meade, B. and J. Pringle (2001). Environmental Management Systems for Caribbean Hotels and Resorts: A Case Study of Five Properties in Jamaica. Benchmarks in Hospitality and Tourism, 149-159.

Melnyk, S.A., R.P. Sroufe and R. Calantone (2003). Assessing the Impact of Environmental Management Systems on Corporate and Environmental Performance. Journal of operations Management, 21: 329-351. 
Memon, P.A., and H.C. Perkins. (2000) Environmental Planning and Management: The Broad Context. In Environmental Planning and Management in New Zealand edited by P.A. Memon and H.C. Perkins. Palmerston North, NZ: Dunmore Press, pp. 11-23.

Mensah, I. (2006). Environmental Management Practices among Hotels in the Greater Accra Region. International Journal of Hospitality Management, 25: 414-431.

Mihalic, T. (2000). Environmental Management of a Tourist Destination: A Factor of Tourism Competitiveness. Tourism Management, 21: 65-78.

Milne, S., and I. Ateljevic (2001). Tourism, Economic Development and the GlobalLocal Nexus: Theory Embracing Complexity. Tourism Geographies, 3 (4): 369-393.

Milne, S. (1998). Tourism and Sustainable Development: Exploring the GlobalLocal Nexus. In Sustainable Tourism, edited by. C.M. Hall and A.A. Lew. London: Addison Wesley, pp. 35-48.

Ministry for the Environment (2008a). About the Environment Act 1986. Available: http://mfe.govt.nz/laws/environment.html [04 April 2008]

Ministry for the Environment (2008b). About the Ministry for the Environment. Available: http://mfe.govt.nz/about/ [04 April 2008]

Ministry for the Environment (2008c). Simply Sustainable: Tools and Resources Tourism. Available: http://www.mfe.govt.nz/issues/sustainableindustry/toolsservices/types.php?id=8 [04 April 2008]

Ministry for the Environment (2009). Laws and Treaties. Available: http://www.mfe.govt.nz/laws/index.html [05 Feb 2009]

Ministry of Tourism (2008). Sustainable Tourism Charter Project. Ministry of Tourism, Wellington, New Zealand.

Muhanna, E. (2006). Sustainable Tourism Development and Environmental Management for Developing Countries. Problems and Perspectives in Management, 4 (2): 14-30.

Mwangi, S.W. (2000). Partnerships in Urban Environmental Management: An Approach to Solving Environmental Problems in Nakuru, Kenya. Environment and Urbanisation, 12 (2): 77-92.

Natural Resources Defense Council (1997). The Story of Silent Spring. Available: http://www.nrdc.org/health/pesticides/hcarson.asp [26 March 2008]

New Zealand Tourism Strategy Group (2007). New Zealand Tourism Strategy 2015. Available: http://www.nztourismstrategy.com/download.htm [16 April 2008] 
Palmer, J.A. (1998). Environmental Education in the $21^{\text {st }}$ Century: Theory, Practice, Progress and Promise. London: Routledge.

Paskaleva-Shapira, K. (2001). Promoting Partnerships for Effective Governance of Sustainable Urban Tourism: The Case of Germany. Presented at the SUTGovernance Conference, Turin, Italy, February.

Patton, M.Q. (2002). Qualitative Research and Evaluation Methods $3^{\text {rd }}$ Edition. London: Sage Publications.

Positively Wellington Tourism (2007). Green Edition of Positively Informed. WellingtonNZ.com, Wellington, New Zealand.

Positively Wellington Tourism (2008). Wellington Visitor Strategy 2015. Available: http://www.wellingtonnz.com/about_us/wellington_visitor_strategy_2015 [16 Jan 2009]

Qualmark (2008a). Responsible Tourism. Available: http://www.responsibletourism.co.nz/ [26 Jan 2009]

Qualmark (2008b). New Zealand Leads the Way in Responsible Tourism. Available: http://www.responsibletourism.co.nz/news.php?type=news\&cat $=$ news\&id $=3$ 7 [26 Jan 2009]

Rubin, H.J., and I.S. Rubin (2005). Qualitative Interviewing: The Art of Hearing Data $2^{\text {nd }}$ Edition. Thousand Oaks, CA: Sage Publications.

Saarinen, J. (2006). Traditions of Sustainability in Tourism Studies. Annals of Tourism Research, 33 (4): 1121-1140.

Sandiford, P.J., and D. Seymour (2007). A Discussion of Qualitative Data Analysis in Hospitality Research with Examples from Ethnography of English Public Houses. Hospitality Management, 26: 724-742.

Sarkis, J. (2003). A Strategic Decision Framework for Green Supply Chain Management. Journal of Cleaner Production, 11 (4): 397-409.

Satterthwaite, D. (1997). Sustainable Cities or Cities that Contribute to Sustainable Development. Urban Studies, 34 (10): 1667-1691.

Sautter, E.T., and B. Leisen (1999). Managing Stakeholders: A Tourism Planning Model. Annals of Tourism Research, 26 (2): 312-328.

Scanlon, N.L. (2007). An Analysis and Assessment of Environmental Operating Practices in Hotel and Resort Properties. International Journal of Hospitality Management, 26: 711-723.

Seuring, S., J. Sarkis, M. Muller and P. Rao (2008). Sustainability and Supply Chain Management - An Introduction to the Special Issue. Journal of Cleaner Production, 16 (15): 1545-1551. 
Silverman, D. (2005). Doing Qualitative Research. London: Sage Publications.

Stabler, M.J., and B. Goodall (1997). Environmental Awareness, Action and Performance in the Guernsey Hospitality Sector. Tourism Management, 18 (1): 19-33.

Stanford, D. (2006). Responsible Tourism, Responsible Tourists: What Makes A Responsible Tourist in New Zealand? PhD Thesis, Victoria University of Wellington.

Swarbrooke, J. (1999). Sustainable Tourism Management. Oxford: CABI Publishing.

Tepelus, C.M., and R.C. Cordoba (2005). Recognition Schemes in Tourism - From Eco to Sustainability? Journal of Cleaner Production, 13: 135-140.

Timur, S., and D. Getz (2008). A Network Perspective on Managing Stakeholders for Sustainable Urban Tourism. International Journal of Contemporary Hospitality Management, 20 (4): 445-461.

Tourism New Zealand, (2004). New Zealand's Ideal Traveller. Available: http://www.tourismnewzealand.com/tourism info/latest-news/archivednews/new-zealands-ideal-traveller.cfm [26 Jan 2009]

Tourism New Zealand (2008). Guides Give Sustainability Tips to Tourism Businesses. Available: http://www.tourismnewzealand.com/tourism info/ latest-news/guides-give-sustainability-tips-to-tourism-businesses.cfm [04 June 2008]

TravelMole (2009). Lipman Calls Tourism Leaders to Join Green Economy. Available: http://www.travelmole.com/ [28 Jan 2009]

Tzschentke, N. A., D. Kirk and P.A. Lynch (2008). Going Green: Decisional Factors in Small Hospitality operations. International Journal of Hospitality Management, 27: 126-123.

United Nations Environment Programme (2008). What is Climate Change?

Available: http://www.unep.org/themes/climatechange/whatis/index.asp [25 March 2008]

United Nations World Tourism Organisation (1996). Agenda 21 for the Travel and Tourism Industry: Towards Environmentally Responsible Development. Available: http://www.world-tourism.org/sustainable/publications.htm [19 March 2008]

United Nations World Tourism Organisation (1999a). Tourism: 2020 Vision. Madrid: UNWTO. 
United Nations World Tourism Organisation (1999b). Global Code of Ethics for Tourism. Available: www.world-tourim.org/code ethics/eng/brochure.htm [23 March 2008]

Vernon, J., S. Essex, C. Pinder and K. Curry (2003). The 'Greening of Tourism Micro-Businesses: Outcomes of Focus Group Investigations in South East Cornwall. Business Strategy and the Environment, 12 (1): 354-365.

Weaver, D. (2006). Sustainable Tourism: Theory and Practice. Amsterdam; Boston: Elsevier Butterworth-Heinemann.

Wellington City Council (2006). Environmental Strategy: Protecting and Enhancing Our Natural Environment. Available:

http://www.wellington.govt.nz/plans/index.html [11 April 2008]

Wellington City Council (2007). Climate Change Action Plan: Creating a Carbon Neutral Council and Community. Available:

http://www.wellington.govt.nz/plans/policies/climatechange/index.html [07 April 2008]

Wellington City Council (2008). Council Controlled Organisations. Available: http://www.wellington.govt.nz/about/ctrlorgs/index.html [12 April 2008]

Williams, M. (2002). Creating our Future: Sustainable Development for New Zealand: Summary of Findings. Wellington, NZ: Office of the Parliamentary Commissioner for the Environment.

Yeung, H.W. (1995). Qualitative Personal Interviews in International Business Research: Some Lessons from a Study of Hong Kong Transnational Corporations. International Business Review, 4 (3): p313-339.

Zhu, Q., and J. Sarkis (2004). Relationships between Operational Practices and Performance among Early Adopters of Green Supply Chain Management. Journal of Operations Management, 22 (3): 265-289.

Zutshi, A., and A. Sohal (2004). Environmental Management System Adoption by Australian Organisations: Part 1: Reasons, Benefits and Impediments. Technovation, 24: 335-357. 


\section{APPENDICES}

\section{Appendix 1: Organisations Concerned for the Environment}

\begin{tabular}{|c|c|c|c|}
\hline $\begin{array}{c}\text { ORGANISATION } \\
\text { (GLOBAL) }\end{array}$ & $\begin{array}{c}\text { POLICY/DOCUMENT/ } \\
\text { PROGRAMME }\end{array}$ & PURPOSE & $\begin{array}{l}\text { ENVIRONMENTAL } \\
\text { POLICIES/ACTIONS }\end{array}$ \\
\hline UNWTO & $\begin{array}{l}\text { Global Code of Ethics for } \\
\text { Tourism }\end{array}$ & $\begin{array}{l}\text { Frame of reference: } \\
\text { responsible, sustainable } \\
\text { development of world } \\
\text { tourism }\end{array}$ & $\begin{array}{l}\text { Article III, Tourism: a } \\
\text { factor of sustainable } \\
\text { development, safeguard } \\
\text { natural environment; } \\
\text { save rare and precious } \\
\text { resources e.g. water, } \\
\text { energy; protect natural } \\
\text { heritage, ecosystems, } \\
\text { biodiversity }\end{array}$ \\
\hline UNWTO \& WTTC & $\begin{array}{l}\text { Agenda } 21 \text { : strategy and } \\
\text { implications for travel } \\
\text { and tourism }\end{array}$ & $\begin{array}{l}\text { Blueprint for securing } \\
\text { sustainable future of } \\
\text { the planet (UNCED), } \\
\text { programme of action }\end{array}$ & $\begin{array}{l}\text { I. Government, NTOs } \\
\text { and representative trade } \\
\text { organisations: } 9 \text { priority } \\
\text { areas of action i.e. } \\
\text { planning for sustainable } \\
\text { development, design of } \\
\text { new tourism products } \\
\text { with sustainability at } \\
\text { their core } \\
\text { II. Companies: } 10 \\
\text { priority areas including } \\
\text { transport, design for } \\
\text { sustainability, } \\
\text { partnerships }\end{array}$ \\
\hline Green Globe & $\begin{array}{l}\text { International } \\
\text { environmental awareness } \\
\text { and certification } \\
\text { programme for travel and } \\
\text { tourism companies }\end{array}$ & $\begin{array}{l}\text { Demonstrate } \\
\text { commitment to } \\
\text { environmental } \\
\text { performance through } \\
\text { environmentally } \\
\text { responsible behaviour }\end{array}$ & $\begin{array}{l}\text { Companies: key priority } \\
\text { areas (similar to Agenda } \\
21 \text { ) }\end{array}$ \\
\hline ITP & $\begin{array}{l}\text { Formally: IHEI - a } \\
\text { number of environmental } \\
\text { programmes }\end{array}$ & $\begin{array}{l}\text { Forum for members to } \\
\text { exchange ideas and } \\
\text { develop tools which } \\
\text { improve environmental } \\
\text { performance }\end{array}$ & $\begin{array}{l}\text { ITP environmental } \\
\text { programmes: } \\
\text { monitoring and } \\
\text { benchmarking waste, } \\
\text { water, and energy; } \\
\text { greening the supply } \\
\text { chain; providing } \\
\text { environmental } \\
\text { management systems } \\
\text { (EMS). } \\
\text { Environmental } \\
\text { Management Handbook; } \\
\text { Greenhotelier magazine }\end{array}$ \\
\hline
\end{tabular}




\begin{tabular}{|c|c|c|c|}
\hline $\begin{array}{l}\text { ORGANISATION } \\
\text { (NATIONAL) }\end{array}$ & $\begin{array}{c}\text { POLICY/DOCUMENT/ } \\
\text { PROGRAMME }\end{array}$ & PURPOSE & $\begin{array}{l}\text { ENVIRONMENTAL } \\
\text { POLICIES/ACTIONS }\end{array}$ \\
\hline \multirow[t]{2}{*}{$\begin{array}{l}\text { Ministry for the } \\
\text { Environment }\end{array}$} & Environment Act (1986) & $\begin{array}{l}\text { Promote the sustainable } \\
\text { management of natural } \\
\text { and physical resources }\end{array}$ & $\begin{array}{l}\text { Managing the effects of } \\
\text { activities on the } \\
\text { environment }\end{array}$ \\
\hline & $\begin{array}{l}\text { Resource Management } \\
\text { Act (1991) }\end{array}$ & $\begin{array}{l}\text { Main piece of } \\
\text { environmental } \\
\text { legislation based on } \\
\text { sustainable } \\
\text { management of our } \\
\text { resources; encourages } \\
\text { planning for the future }\end{array}$ & $\begin{array}{l}\text { Sustaining natural and } \\
\text { physical resources to } \\
\text { meet needs of future } \\
\text { generations; safeguard } \\
\text { life-supporting capacity } \\
\text { of air, water, soil, and } \\
\text { ecosystems; and } \\
\text { mitigate adverse effects } \\
\text { of activities on } \\
\text { environment }\end{array}$ \\
\hline $\begin{array}{l}\text { Ministry for the } \\
\text { Environment \& } \\
\text { Ministry of } \\
\text { Tourism }\end{array}$ & $\begin{array}{l}\text { Environmentally } \\
\text { Sustainable Tourism } \\
\text { Project: } 6 \text { RTOs }\end{array}$ & $\begin{array}{l}\text { Increase awareness of } \\
\text { businesses about } \\
\text { importance of } \\
\text { environmental } \\
\text { management, influence } \\
\text { sustainable business } \\
\text { practices }\end{array}$ & $\begin{array}{l}\text { "Bottom-up" approach - } \\
\text { businesses concentrate } \\
\text { on their specific issues } \\
\text { e.g. measuring and } \\
\text { managing energy } \\
\text { efficiency, supply chain } \\
\text { issues, pollution } \\
\text { prevention, community } \\
\text { involvement, waste } \\
\text { management }\end{array}$ \\
\hline $\begin{array}{l}\text { Tourism New } \\
\text { Zealand }\end{array}$ & $\begin{array}{l}\text { NZ Tourism Strategy } \\
2015\end{array}$ & $\begin{array}{l}\text { Provides the vision, } \\
\text { values and direction to } \\
\text { lead the tourism sector } \\
\text { into the future: } \\
\text { sustainable approach to } \\
\text { the tourism industry }\end{array}$ & $\begin{array}{l}\text { Outcome Three: The } \\
\text { tourism sector takes a } \\
\text { leading role in } \\
\text { protecting and } \\
\text { enhancing the } \\
\text { environment } \\
\text { Introduce initiatives that } \\
\text { will reduce carbon } \\
\text { emissions, increase } \\
\text { energy efficiency of } \\
\text { transport within and en } \\
\text { route to NZ. Improve } \\
\text { energy efficiency, } \\
\text { energy conservation, use } \\
\text { of renewable energy, } \\
\text { reduce and manage } \\
\text { waste }\end{array}$ \\
\hline
\end{tabular}




\begin{tabular}{|c|c|c|c|}
\hline $\begin{array}{l}\text { ORGANISATION } \\
\text { (REGIONAL/ } \\
\text { LOCAL) }\end{array}$ & $\begin{array}{c}\text { POLICY/DOCUMENT/ } \\
\text { PROGRAMME }\end{array}$ & PURPOSE & $\begin{array}{l}\text { ENVIRONMENTAL } \\
\text { POLICIES/ACTIONS }\end{array}$ \\
\hline $\begin{array}{l}\text { Greater Wellington } \\
\text { Regional Council }\end{array}$ & $\begin{array}{l}\text { Long-Term Council } \\
\text { Community Plan } \\
\text { (LTCCP) }\end{array}$ & $\begin{array}{l}\text { Statutory } \\
\text { responsibility } \\
\text { (Resource Policy } \\
\text { Statement)- bring } \\
\text { social, economic, } \\
\text { cultural and } \\
\text { environmental } \\
\text { benefits to the region, } \\
\text { reach community } \\
\text { outcomes }\end{array}$ & $\begin{array}{l}\text { Manage the regions key } \\
\text { natural resources - } \\
\text { water, soil, air and the } \\
\text { coast, regulatory role: } \\
\text { ensure compliance with } \\
\text { Resource Management } \\
\text { Act, environmental } \\
\text { monitoring: report on } \\
\text { state of region's } \\
\text { environment, working } \\
\text { with the community - } \\
\text { environment education, } \\
\text { encourage use of public } \\
\text { transport, water - } \\
\text { treatment and } \\
\text { management of demand }\end{array}$ \\
\hline $\begin{array}{l}\text { Wellington City } \\
\text { Council (WCC) }\end{array}$ & $\begin{array}{l}\text { Environmental Strategy: } \\
\text { Protecting and Enhancing } \\
\text { our Natural Environment } \\
\\
\text { Absolutely Positively } \\
\text { Wellington: Towards } \\
\text { Carbon Neutrality - A } \\
\text { Climate Change Vision } \\
\text { for Wellington }\end{array}$ & $\begin{array}{l}\text { Provides high-level } \\
\text { statement of long- } \\
\text { term environmental } \\
\text { intentions for } \\
\text { Wellington and } \\
\text { shorter-term priority } \\
\text { areas of action (based } \\
\text { on sustainable } \\
\text { development) } \\
\text { Propose vision for } \\
\text { Council in response to } \\
\text { climate change - } \\
\text { carbon neutrality. }\end{array}$ & $\begin{array}{l}\text { Protecting sensitive } \\
\text { natural areas and } \\
\text { resources, reducing } \\
\text { resource use and relying } \\
\text { on renewable energy } \\
\text { sources, effective } \\
\text { disposal of waste } \\
\text { products, minimising } \\
\text { impact of resource use } \\
\text { Revised carbon } \\
\text { emission reduction } \\
\text { targets, development for } \\
\text { an expanded, integrated } \\
\text { work programme across } \\
\text { a range of areas and } \\
\text { activities e.g. energy, } \\
\text { transport, urban } \\
\text { development, water and } \\
\text { waste management }\end{array}$ \\
\hline $\begin{array}{l}\text { Positively } \\
\text { Wellington Tourism } \\
\text { (PWT) }\end{array}$ & $\begin{array}{l}\text { Green Edition - } \\
\text { Positively Informed }\end{array}$ & $\begin{array}{l}\text { Promote awareness } \\
\text { and acknowledge } \\
\text { sustainability as an } \\
\text { issue pertinent to } \\
\text { tourism - local } \\
\text { industry }\end{array}$ & $\begin{array}{l}\text { Aim: to become carbon } \\
\text { neutral under proposed } \\
\text { vision of Wellington } \\
\text { City Council., increase } \\
\text { awareness of } \\
\text { sustainability to visitors } \\
\text { and businesses }\end{array}$ \\
\hline
\end{tabular}


Appendix 2:

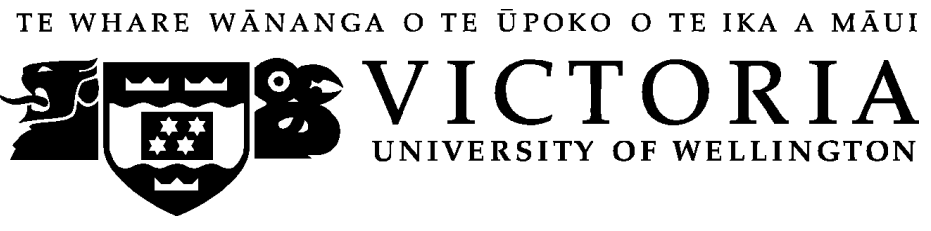

\section{Urban Environmental Management Approaches by Tourism Organisations in Wellington}

\section{Interview Schedule}

Raymond Mullan

Contents

\section{$\underline{\text { I - Individual Businesses }}$}

1. Business Profile

2. Environmental Management Issues

3. Environmental Management Approaches

4. Factors and Barriers Influencing Adoption

\section{$\underline{\text { II - Public and Private Sector Agencies }}$}

1. Organisation Profile

2. Role Regarding Environmental Management

3. Relationship with Tourism Businesses

4. Environmental Management Approaches 
TE WHARE WĀNANGA O TE ŪPOKO O TE IKA A MĀUI

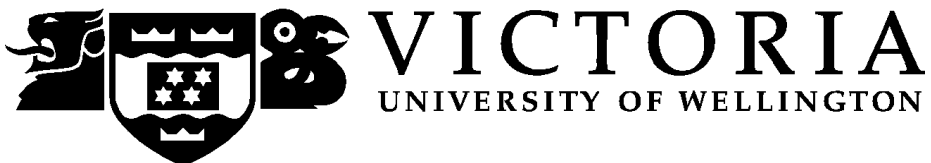

\section{TOUR 591 - Masters of Tourism Management (Thesis) \\ Urban Environmental Management Approaches by Tourism \\ Organisations in Wellington}

\section{Interview Schedule I - Individual Businesses}

Good morning/afternoon. My name is Raymond Mullan, and I am conducting research as part of my Masters of Tourism Management (MTM) at Victoria University. The study aims to better understand and explore the nature of environmental management approaches of tourism organisations in Wellington. It also aims to identify the role and relationship of the Regional Tourism Organisation (RTO) and other public and private sector agencies, and attempts to explore factors influencing the adoption of environmental management approaches and the barriers which may hinder the adoption of such practices. The information that is recorded will be kept confidential, and displayed in a form whereby, neither you nor your business is identifiable.

Date:

Time:

Opening Question: Role or position of participant in their business (i.e. who is responsible for environmental management)?

\section{SECTION I - BUSINESS PROFILE}

1.1. Which tourism sector? E.g. attraction/activity operator/accommodation/transport

(a) Type of product/service?

1.2. How many years has your firm been operating for?

1.3. How many people are employed by the business? 
(a) - Full Time Equivalent:

(b) - Part Time Equivalent:

(c) - Seasonal/Contract:

SECTION II - ENVIRONMENTAL MANAGEMENT ISSUES

2.1. How would you define environmental management?

2.2. What types of global environmental issues are you or your business aware of?

2.3. In what way(s) do you think your business may have an impact on the environment?

2.4. How has this awareness/knowledge of these types of environmental issues and their impacts of the business made your firm consider managing them? 


\section{SECTION III - ENVIRONMENTAL MANAGEMENT APPROACHES}

3.1. Does your firm currently carry out any kind of environmental management approaches? (i.e. formal or informal practices in relation to energy reduction, water and waste minimisation \& management, air emissions, land/building planning \& development)

Yes/No (Please Describe)

(a) Why or why not?

3.2. Please outline the nature of each environmental practice, where applicable:

(a) formal/written environmental strategy/policy 
(b) informal/unwritten level of environmental management

(c) assessment of environmental impacts of business/resource use

(d) awareness/communication \& training among staff

(e) awareness/education and interpretation to visitors

(f) supply chain management/purchasing of products \& transportation 
3.3. What type of outside involvement (if any) does your business have in working with the RTO or other public and private sector agencies regarding environmental management? E.g. Green Globe, Ministry for the Environment, TIANZ, DOC etc.

3.4. More specifically, what do you believe the role of the RTO or other public and private sector agencies should be regarding environmental management? (i.e. information, infrastructural)

3.5. How important do you think is managing the environmental impacts of your business now, and into the future?

SECTION IV - FACTORS INFLUENCING ADOPTION AND BARRIERS HINDERING ADOPTION OF ENVIRONMENTAL PRACTICES

Please answer where applicable:

4.1. What factors do you believe have influenced your business in adopting environmentally friendly practices? 
4.2. What barriers do you think may have hindered the adoption of environmentally friendly practices to your business?

4.3. For tourism businesses practising environmental management; what do you believe are the benefits? Or advantages of this?

4.4. Are there any disadvantages of environmental management that you would like to mention? Describe

5. Other comments

Thank you very much, for your time and participation 
TE WHARE WĀNANGA O TE ŪPOKO O TE IKA A MĀUI

TOUR 591 - Masters of Tourism Management (Thesis)

Urban Environmental Management Approaches by Tourism

Organisations in Wellington

\section{$\underline{\text { Interview Schedule II - Public and Private Sector Agencies }}$}

Good morning/afternoon. My name is Raymond Mullan, and I am conducting research as part of my Masters of Tourism Management (MTM) at Victoria University. The study aims to better understand and explore the nature of environmental management approaches among tourism organisations in Wellington. In particular, it aims to identify the role and relationship of the Regional Tourism Organisation (RTO) and other public and private sector agencies regarding environmental management. The information that is recorded will be kept confidential, and displayed in a form whereby, neither you nor your organisation is identifiable.

Date:

Time:

Opening Question: Role or position of participant in their business (i.e. who is responsible for environmental management)?

\section{SECTION I - ORGANISATION PROFILE}

1.1. What is the current size and range of membership of your business?

1.2. How many years has your firm been operating for? 
1.3. Number of employees?

(a) - Full Time Equivalent:

(b) - Part Time Equivalent:

(c) - Seasonal/Contract:

\section{SECTION II - ROLE REGARDING ENVIRONMENTAL MANAGEMENT}

2.1. What is your organisation's role regarding environmental management to tourism businesses? (I.e. information, infrastructural)

Please Describe

2.2. What sort(s) of information or advice do you provide to tourism businesses in regards to managing their firm's impacts on the environment?

2.3. What environmental initiatives/activities (if any) are currently in place by your organisation for tourism businesses wishing to adopt such practices? 


\section{SECTION III - RELATIONSHIP WITH TOURISM BUSINESSES}

3.1. Have you ever been approached by tourism businesses regarding environmental management?

Yes/No

What has been your typical response to this type of enquiry?

3.2. Please describe your typical relationship with a business in regards to environmental management

\section{SECTION IV- ENVIRONMENTAL MANAGEMENT APPROACHES}

NB: relates back to the relevant section from the 'business' interview schedule in that if these organisations are giving advice, providing information etc then realistically they should be practicing their own environmentally friendly practices in their organisation.

3.1. Does your firm currently carry out any kind of environmental management approaches? (i.e. formal or informal practices in relation to energy reduction, water and waste minimisation \& management, air emissions, land/building planning \& development)

Yes/No (Please Describe) 
(a) Why or why not?

3.2. Please outline the nature of each environmental practice, where applicable:

(a) formal/written environmental strategy/policy

(b) informal/unwritten level of environmental management

(c) assessment of environmental impacts of business/resource use

(d) awareness/communication \& training among staff 
(e) awareness/education and interpretation to visitors

(f) supply chain management/purchasing of products \& transportation

4. Other comments

Thank you very much, for your time and participation 


\section{Appendix 3:}

\section{Information Sheet - Urban Environmental Management Approaches by Tourism Organisations in Wellington}

Researcher: Raymond John Mullan

School: Victoria School of Management (VMS), Victoria University of Wellington.

I am currently studying a Masters of Tourism Management (MTM) degree at Victoria University of Wellington. As part of this degree I am required to complete a thesis research project. I have chosen to research the environmental management approaches of tourism organisations in Wellington in order to better understand what their environmental strategies are; identify the factors influencing adoption of environmental management approaches and the barriers which may hinder adoption of such approaches.

As well as this, to identify the role and relationship of the Regional Tourism Organisation (RTO) and other public and private sector agencies regarding environmental management. The research has obtained Human Ethics Committee approval from the university. I am also a proud recipient of the Ministry of Tourism Research Scholarship 2008.

I am seeking to invite tourism organisations in Wellington to participate in in-depth, semi-structured interviews. I will ask questions related to better understanding your businesses' approaches towards environmental management.

For better recollection of the data, the answers will be tape-recorded and you will be given the option of having the interview notes written if you do not wish to be taperecorded. The interviews are likely to take 30-40 minutes to complete. The responses will form the basis of my thesis research project. 
Responses will be treated confidentially and reported only in an aggregate format so neither you nor your business will be able to be identified. All data that is collected will be kept confidential and no one other than my supervisor Bob Garnham and I will see the interviews or have access to the recorded material.

If you wish to withdraw from the research project, then you may do so without any question at any time before the data is analysed (end of October 2008). You also have the right to review or check interview notes.

At the completion of the thesis research project, all the data included will be destroyed within one year. If participants would like feedback they are welcome to enquire about it. It will be provided in an identical form to the written report submitted for marking, as soon as possible. To make it easier to request feedback, please tick the box on the consent form.

If you have any questions regarding this research project or would like to receive further information about it, please feel free to contact me, by e-mail at mullanraym@student.vuw.ac.nz or alternatively my supervisor, Dr. Bob Garnham, at the Victoria Management School, Victoria University, PO Box 600, Wellington. Or by e-mail at Bob.Garnham@vuw.ac.nz

Raymond Mullan 


\section{Urban Environmental Management Approaches by Tourism Organisations in Wellington}

I have been provided with adequate information relating to the nature and objectives of this research project. I understand that information, and have been given the opportunity to seek further clarification or explanation.

I understand that any information I provide will be kept confidential. Only the researcher and the supervisor will have access to the information provided.

I understand the published results will not be used in a way that identifies me personally or my business and no opinions will be attributed to me in any way that will identify me.

I give permission for the interview to be tape-recorded.

I understand that the tape recording of interviews will be electronically wiped one year after the research project completion or be returned to me if requested. All opinions and data obtained will be destroyed by the researcher.

I would like to check the interview notes.

I understand that I may withdraw from this study at any time before the final analysis (end of October 2008) of the data without question. Therefore, any data that I have provided will not be used for any other purpose, nor released to others without my written consent. It will be destroyed.

I would like to receive feedback - a summary copy of the findings of the research.

I agree to participate in this thesis research project.

Signed:

Date:

Name/Organisation: 